NBSIR 75-916

\title{
The Role of Passive Film Growth Kinetics and Properties in Stress Corrosion and Crevice Corrosion Susceptibility
}

J. Kruger, J. R. Ambrose, and T. Kodama

Corrosion and Electrodeposition Section Metallurgy Division Institute for Materials Research National Bureau of Standards

October 1975

Technical Summary Report Number 6

Prepared for

Office of Naval Research Department of the Navy Arlington, Va. 22217 

THE ROLE OF PASSIVE FILM GROWTH

KINETICS AND PROPERTIES IN

STRESS CORROSION AND CREVICE

CORROSION SUSCEPTIBILITY

J. Kruger, J. R. Ambrose, and T. Kodama

Corrosion and Electrodeposition Section

Metallurgy Division

Institute for Materials Research

National Bureau of Standards

October 1975

Technical Summary Report Number 6

DISTRIBUTION OF THIS DOCUMENT IS UNLIMITED

Prepared for

Office of Naval Research

Department of the Navy

Arlington, Va. 22217

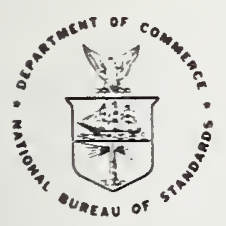

U.S. DEPARTMENT OF COMMERCE, Rogers C.B. Morton, Secretary James A. Baker, III, Under Secretary Dr. Betsy Ancker-Johnson, Assistant Secretary for Science arid Technology

NATIONAL BUREAU OF STANDARDS, Ernest Ambler, Acting Director 

(To be submitted to J. Electrochemical Society)

Effect of llolybdate Ion on the Repassivation Kinetics

of Iron in Solutions containing Chloride Ions

\author{
T. Kodama* and J. R. Ambrose \\ Institute for :laterials Research \\ National Bureau of Standards \\ Washington, D. C. 20234
}

It has been well established that molybdenum additions improve the resistance of stainless steels to localized corrosion (especially pitting) in chloride environments (1-7). Several investigations, however, have given seemingly contradictory results concerning the role of molybdenum on this enhanced corrosion resistance.

Rhodin, using microchemical analysis, found that molybdenum content was increased in the passive $f i 1 \mathrm{~m}$ on 316 stainless steel immersed in a $5 \% \mathrm{HNO}_{3}-$ $0.5 \% \mathrm{~K}_{2} \mathrm{Cr}_{2} \mathrm{O}_{7}$ solution (8).

An Auger electron spectroscopic (AES) study by Barnes et al showed surface segregation of molybdenum in 316 and 304 stainless steels (9). They used mill-finished materials without passivation pretreatment.

Another AES study by Lumsden et al showed that molybdenum was depleted in the passive film of 316 stainless steel exposed potentiostatically to a pH! 7 solution at $442 \mathrm{mV}$ iNhE (10). They found relative chromium enrichment in the passive film of the molybdenum-bearing steels. The depletion in molybdenum seems to be reasonable when we compare Lumsden's anodization conditions with the polarization data of pure molybdenum (11-14); molybdenum is readily soluble in its hexavalent ion state at the potential and $\mathrm{pH}$ that they used for the anodization.

In all likelinood, then, the presence of molybdenum oxide in the passive film should not be a prerequisite for the enhanced resistance to pitting. In fact, it may be that the beneficial effect of alloyed molybdenum on localized. corrosion resistance may be related to the fact that soluble and insoluble molybdates are known to act as corrosion inhibitors for steels (15-19).

The work described here is aimed at examining whether molybdenum exerts its beneficial effect on diminishing susceptibility to localized corrosion via its dissolved, hexavalent state ( $\left.h_{00}{ }_{4}{ }^{-}\right)$. Moreover, since recent work from this laboratory found that molybdenum in ferrous alloys enhanced the rate of repassivation (20) and rate of repassivation has been proposed as having an important bearing on localized corrosion, we have studied the effect of dissolved molybdate ion on repassivation kinetics of iron. Anodic current changes following oxide removal by abrasion were measured using a device developed for tribo-ellipsometry.

*Guest worker at NBS INov. 1974 to 0ct. 1975 from Wational Research Institute for hetals, Tokyo, Japan. 


\section{EXPERIMENTAL}

To measure the anodic current transient following oxide film removal by abrasion, a device which was extensively applied in tribo-ellipsometric measurement was used. The surface of a potentiostatically controlled iron specimen was abraded with SiC paper mounted on a rotating wheel. An abrupt current increase caused by the retraction of the abrasion wheel from the metal surface triggered an oscilloscope. Details of the device have been described in previous papers (21-22). Anodic currents during longer time intervals $(>500$ iils) were measured with a strip chart recorder.

Specimens used were prepared from a Ferrovac iron rod and mounted in lucite. Specimens were mechanically polished with SiC papers, followed by rotary polishing. with $6 \mu$ diamond paste.

A borate buffer solution ( $\mathrm{ph}$ 8.4) was used as a supporting electrolyte. The solution containing $14.30 \mathrm{~g} \mathrm{Na}_{2} \mathrm{~B}_{4} \mathrm{O}_{7} \cdot 10 \mathrm{H}_{2} \mathrm{O}$ and $9.26 \mathrm{~g} \mathrm{H}_{3} \mathrm{BO}_{3}$ per liter was prepared from ACS grade chemicals and distłlled water ( $7 \times 30-7$ ohm- $^{-1}$ $\mathrm{cm}^{-1}$ ).

For measuring the effect of chloride or molybdate ion, small amounts of $\mathrm{NaCl}$ or $\mathrm{Na}_{2} \mathrm{MOO}_{4}$ were added to the supporting electrolyte. No attempt at deaeration was $^{4}$ made in these experiments.

\section{RESULTS AND DISCUSSION}

Anodic current transients, recorded by oscilloscope and strip chart recorder were plotted on a log-log scale, and are shown in Figs. 1, 3, and 4. Although in an experiment the oscilloscope was triggered by the abrupt current increase accompanied by the retraction of the abrasion wheel, there was an uncertainty of time interval between the trigger pulse and the starting of film growth. Conventionally, we used the time of the current maximum appearing in the oscilloscope picture as the start of film-growth initiation $(t=0)$. The current maximum was not reproducible since it was dependent on the effective metal surface abraded and the roughness of an abrasive paper. Attention was, therefore, placed only on the relative change of anodic current.

a) Repassivation in the absence of chloride

Fig. 1 shows the anodic current transients of iron in a plain borate buffer solution (curve A) and in a borate buffer solution with $0.01 \mathrm{M} \mathrm{Na}_{2} \mathrm{HoO}_{A}$ added (curve B), both at $442 \mathrm{mV}$ NHE. Since the buffer solution was used as a supporting electrolyte, the $\mathrm{pH}$ shift resulting from $\mathrm{Na}_{2} \mathrm{HOO}_{4}$ addition was very slight; $\mathrm{pH}$ for borate buffer - $0.01 \mathrm{H} \mathrm{Na}_{2} \mathrm{MOO}_{4}$ solution ${ }^{2}$ as 8.43 , while the borate solution alone showed pH 8.40 .

Both curves $A$ and $B$ represent typical current decays accompanying virtually complete or "perfect" passivation. Assuming the anodic current efficiency for film formation alone to be unity, we obtain the following relationship between the film-growth rate law and the slope on the $\log i-\log t$ plot (m): 
for logarithmic rate law

for cubic rate law

for parabollic rate law

$$
\begin{aligned}
& m=-1 \\
& m=-2 / 3 \\
& m=-1 / 2
\end{aligned}
$$

The derivation of these relations is given in Appendix 1 . Slopes corresponding to $\mathrm{m}=-1,-2 / 3$, and $-1 / 2$ are also depicted in Fig. 1 . It should be pointed out that all the above rate laws are based upon a uniform film-growth model.

It can be seen in Fig. I that the passive film grows approximately in accordance with a logarithmic rate law after the lapse of $300 \mathrm{~ms}$. A logarithmic growth of a passive film on iron has been found from the current decay that is observed when the metal surface is brought to a potential in the passive region $(23,24)$. The initial stage of current decay $(t<250 \mathrm{~ms})$ cannot be represented on a log-log plot by a straight line, since the gradient is continuously changing from $-1 / 3$ to -1 . This part was re-plotted in semi-logarithmic scale and is shown in Fig. 2. The plots of log $i$ vs. $t$ are represented by straight lines with a discrete break in the shape of the decay curve at $t=80 \mathrm{~ms}$; current decay can be expressed to obey the following equation:

$$
i=i_{1} \exp \left(-k_{1} t\right)+i_{2} \exp \left(-k_{2} t\right)
$$

A simple exponential current decay,

$$
i=i_{1} \exp \left(-k_{1} t\right)
$$

can be derived if we assume the first layer of an oxide film develops in a similar manner to that found for monolayer adsorption: after the passive film nucleates randomly on the bare surface, uniform film thickening occurs. By this model, we further assumed that oxide-covered sites are inert enough to prevent active dissolution or film growth, while uncovered sites are subjected to active dissolutior. This model can be regarded as an extreme case of the generalized nucleation-and-growth theory. In this case, nucleation rate > two-dimensional film growth (25). The equation thus derived is expressed as:

$$
i=\left(i_{d}^{\circ}+q_{f}^{\circ} k\right) \exp (-k t) \text {, }
$$

where $i_{d}^{\circ}$ and $q^{\circ}$ respectively, denote the active dissolution current density at uncovered sites and the amount of charge required to form the monolayer-type oxide film per unit surface area. Details of the derivation of equation (3) are given in Appendix 2. Equation (1) could be obtained in the same way as that for equation (3), except that there are two different film-nucleation probabilities depending upon, e.g., grain orientation or lattice defects of the bare metal surface.

Perfect passivation kinetics of iron can be represented by the following two steps: the first layer of an oxide film develops two-dimensionally, where oxide nucleation is rate-determining; followed by film thickening which obeys a logarithmic rate law. 
Another point to be mentioned in Fig. 1 and 2 is a good parallelism between curves $A$ and $B$. Apparently, dissolved molybdate ion does not affect the growth law for a perfect passive film on iron.

\section{b) Repassivation in the presence of chloride}

Shown in Fig. 3 are anodic-current transients of iron in a borate-buffered $0.01 \mathrm{M} \mathrm{NaCl}$ solution at different potentials. These curves demonstrate the onset of pitting corrosion. The growth of pits is indicated by the current rise following initial passive film formation. During the stage of passive film formation, neither any noticeable potential dependence of the current decay slope nor the effect of chloride addition could be observed.

Even with the technique of abrasion, we cannot determine when pit initiation occurs. However, this technique does eliminate the so-called induction period which otherwise is very dependent upon surface pre-treatment and history; thus it allows a clearer definition of the pitting potential.

Anodic current transients in a buffer solution containing $0.01 \mathrm{M} \mathrm{NaCl}$ and $0.01 \mathrm{M} \mathrm{Na}_{2} \mathrm{MOO}_{4}$ are shown in Fig. 4.

Although initial, non-logarithmic current-decay slopes are somewhat steeper than those in Fig. 1 and 2, the major effect of molybdate shows up in a slow return of the anodic current to pre-abrasion levels following a fairly nigh, constant current level. On this current plateau, small current oscillations were also measured, possibly indicating repetitive film rupture and recovery (Fig. 5 ). As seen in Fig. 4, the plateau current was lower with decreasing anodic potential, and at $242 \mathrm{mV}$ NHE current decay was similar to that for perfect passivation. This current level was also decreased with increasing molybdate concentration. Fig. $\dot{6}$ shows anodic current transients in borate buffer $-0.01 \mathrm{M} \mathrm{NaCl}$ - $\mathrm{xM} \mathrm{NaMoO}$ solutions $(0 \leq x \leq 0.03)$ at a constant potential of $200 \mathrm{mV}$.

The current transient curves in Figs. 4 and 6 can be regarded as the intermediate case between perfect passivity (Fig. 1) and pitting corrosion (Fig. 3). Apparently, pit initiation preceded the current plateau; this was confirmed by inicroscopic examination.

Optical photomicrographs, shown in Figs. $7 a$ and b indicate active pits formed in a $0.01 \mathrm{M} \mathrm{NaCl}$ solution at $442 \mathrm{mV}$ NHE and inactive pits in a 0.01 闸 $\mathrm{NaCl}-0.01 \mathrm{~W} \mathrm{Na} \mathrm{Na}_{2} \mathrm{MOO}_{4}$ solution at $442 \mathrm{mV}$ INHE respectively. Iron pits induced by chloride ( $\mathrm{Fig}$. $7 \mathrm{a}$ ) are of crystallographic nature, which indicate active dissolution of iron in the form of $\mathrm{Fe}^{2+}$ at the pit wall. The corroded surface in the solution containing both chloride and molybdate also exhibited localized attack (Fig. 7b). However, no crystallographic characteristics were observed in the dissolution morphology. In other words, molybdate seems to inhibit three-dimensional propagation.

From these results, it is concluded that molybdate is effective in retarding the propagation stage of pitting corrosion. 
c) Hechanism of the molybdate effect on retardation of pitting

The chemistry of pit propagation has been fairly well established in comparison to the initiation process. It is characterized by reduced $\mathrm{pH}$ and potential and chloride ion accumulation within the pit. These factors favor the active dissolution of iron at the pit wall.

A possible mechanism by which molybdate effectively inhibits pit propagation might be similar to those which have been proposed for chromate or nitrite. Molybdate might oxidize ferrous ion resulting in a coprecipitation of less soluble ferric oxide and molybdenum suboxide. However, by superimposing Pourbaix diagrams (6), it can be seen that molybdate is not an oxidizer of ferrous ion (Fig. 8). Experimentally, this has been proved by the classic works of Robertson (15) and Pryor (16). The coprecipitation mechanism thus can be excluded.

Molybdate shows a tendency to form insoluble compounds with cations other than alkali metals and magnesium. From the $\Delta \mathrm{G}^{\circ}$ value of $\mathrm{FelloO}_{4}, \mathrm{Fe}^{2+}$ and $\mathrm{MoO}_{4}{ }^{2+}$ listed in the NBS selected values of thermochemical data (27), we can calculate the solubility pgoduct of FelloO; the solubility product thus obtained is $\mathrm{K}_{\mathrm{sO}}=\left[\mathrm{Fe}^{2 \mathrm{~T}}\right]\left[\mathrm{MoO}_{4}{ }^{-}\right]=10^{-10.5}$ at $298^{\circ} \mathrm{K}$. The $5^{\text {estimated valued }}$ by $0^{\prime}$ Hare et al was somewhat larger than this value $\left(10^{-9.15}\right)(28)$.

Using the $K_{\text {so }}$ value, and assuming that molybdate ion is electrochemically inert with respect to dissolved iron species, we can construct an $\mathrm{E}-\mathrm{pH}$ diagram for $\mathrm{Ee}$ in a $\mathrm{MOO}_{4}{ }^{2-}$ solution. Fig. 9 represents an E-pH diagram for $\mathrm{Fe}$ in a $\left[\mathrm{MOO}_{4}{ }^{2-}\right]=10^{-2}$ lin solution. Iron hydroxides, $\mathrm{Fe}(\mathrm{OH})_{2}$ and $\mathrm{Fe}(\mathrm{OH})_{3}$, were accepted as the solid iron compounds, since hydroxides were ${ }^{2}$ thought more likely to exist during pit propagation than were anhydrous oxides.

Another E-pll diagram, in which the redox reaction of molybdenum is involved, can be drawn by superimposing Fig. 9 and Pourbaix's diagraln for lio (26) and is shown in Fig. $4^{0}$. In Fig. 10, total dissolved molybdenum and iron species are $10^{-2}$ in and $10^{-4}$ in, respectively.

These diagrams are not fully consistent, particularly with regard to the selection of $\Delta G^{\circ}$ values for $100{ }^{2-}$. Pourbaix et al in constructing the diagram referred to Latimer's data (29) $\left(\Delta G^{\circ}\left(\mathrm{HOO}_{4}^{2-}\right)=-205.42 \mathrm{kcal} / \mathrm{mole}\right)$, while our calculations of $K_{\text {so }}$ was based on the NBS selected values $\left(\Delta G^{\circ}\left(W_{0 O}{ }^{2-}\right)=-199.9 \mathrm{kcal} / \mathrm{mole}^{-}\right)$. Horeover, the $\Delta G^{\circ}$ for $\mathrm{FeMOC}_{4}$ employed here is that for the thermally synthesized, well crystallized compound (30). It is not quite certain whether this value would still be valid in aqueous systems, where molybdate shows a tendency to form colloidal, amorphous precipitates.

Despite the above uncertaingjes, we can derive some useful qualitative insights from these diagrams: $\mathrm{Fe}^{2+}$ ion reacts with HoO ${ }^{2-}$ forming solid Feilo ${ }_{4}$ at neutral to slightly acid $\mathrm{pH}$ regions and at a potential where active dissolution of metallic iron occurs. The region at which $\mathrm{FellOO}_{4}$ occurs corresponds well to those regions of potential and $\mathrm{pH}$ as measured inside a pit. 
Spectrophotometric studies of solutions containing $\mathrm{Fe}^{+2}, \mathrm{Fe}^{+3}$ and $\mathrm{HOO}_{4}^{-}$ ions have shown a solution complex to be formed which is related to the initiation process (32).

The formation of $\mathrm{FellOO}_{4}$ at the pit wall exlains the anodic current transients shown in Fig. 3. Since molybdate is inert to $\mathrm{Fe}^{3+}$ ion, it affects less the formation and breakdown of the passive film. On the contrary, molybdate reacts with ferrous ion dissolving from the pit wall to form a solid compound which contributes to retardation of propagation. This stage is thought to correspond to the current plateau in Fig. 4.

In order to verify this inypothesis, an electron probe microanalysis (EPIIA) of materials within pits was carried out. Figs. 11 and 12 show EPHA images of pits formed at $442 \mathrm{mV}$ NHE in a $0.01 \mathrm{M} \mathrm{NaCl-borate} \mathrm{solution} \mathrm{and} \mathrm{in} \mathrm{a}$ $0.07 \mathrm{ll} \mathrm{NaCl}-0.07$ il $\mathrm{Na}_{2} \mathrm{FoO}_{4}$ solution, respectively. In both solutions, $\mathrm{Cl}$ accumulation was obsefved inside pits, but was significantly less in the molybdate-containing solution. Secondly, Mo accumulation in the pit is quite noticeable in the molybdate-containing solution. Na was not detected in either solution. EPViA results strongly suggest that molybdate ions displace chloride ions within the pit. These results are also in agreement with that inhibition mechanism in which formation of $\mathrm{FellO}_{4}$ contributes to repassivation of pits.

It should be'emphasized that FelloO, would occur only at occluded sites wirere both potential and $\mathrm{pH}$ are lower than those of the bulk solution, i.e., under those very conditions expected to be characteristic in active pit growth. The bulk potential and $\mathrm{pH}$ used in those experiments described by Figs. 6, 7, 11, and 12 (442 $\mathrm{mV}$ NHE and $\mathrm{pH} 8.4$ ) are in a region, however, where $\mathrm{Fe}(\mathrm{OH})_{3}$ or $\mathrm{Fe}_{2} \mathrm{O}_{3}$ is stable. It is thus quite reasonable that Mo could not be found By EPMA in areas outside pits. For the same reason, Mo could not be detected in studies by Lumsden and Staehle (10). In this work, the analytical technique of Auger Electron Spectroscopy would not be expected to detect concentrations of elements across small areas such as pits.

Studies by Okada at el have shown that 1.10 is present in the film when $\mathrm{Cl}^{-}$ ions are present in the solution using a similar AES technique (33).

However, if analytical techniques capable of looking at specific areas of surface covered by pits were used, then high concentrations of molybdenum would be expected to be present. Studies by Yahalom et al (37) did in fact show the presence of molybdenum in films covering pits on molytdenum bearing stainless steels.

A variety of molybdenum chlorides and oxychlorides could contribute to the pitting inhibition. Among those found in literature, even the most probable one, $\mathrm{HO}_{2} \mathrm{Cl}_{2}$, is soluble in aqueous solution. A reaction, for instance, $\mathrm{MOO}_{4}{ }^{-}+2 \mathrm{Cl}^{-}+4 \mathrm{H}^{+} \longrightarrow \mathrm{MOO}_{2} \mathrm{Cl}_{2}(\mathrm{aq})+2 \mathrm{H}_{2} \mathrm{O}$ would favor pit inhibition since it decreases the activitfes of both chforide and hydrogen ions. However, it fails to explain the corrosion inhibition of iron under a system of limited $1.100_{4}^{2-}$ and unlimited $\mathrm{Cl}^{-}$supply. No further discussion will be made regarding the formation of the molybdenum oxychlorides since no suitable thermochemical data were available. 
The results of this investigation clearly demonstrated that dissolved molybdate ion is effective in repassivating iron undergoing pitting corrosion. The mechanism proposed in the present work can hopefully be extended to elucidate the mechanism for enhanced corrosion resistance of Mo-bearing stainless steels in neutral chloride media. However, it should be noted that the present mechanism gives only one aspect of the complex chemistry of alloyed 10. As has been reported in our previous study (20), the repassivation rate for times less than $100 \mathrm{~ms}$ following initiation of repassivation is increased with increasing Mo content in steels, while the present study has shown that dissolved molybdate does not affect the repassivation rate of iron. Also lio-bearing stainless steels are reported to exhibit excellent corrosion resistance in acid environments (1-7) where $\mathrm{FellO}_{4}$ is not stable. As is expected from Figs. 8 to 10 , molybcienum trioxide, $\mathrm{MoO}_{3}$, becomes less soluble with increasing acidity, suggesting direct involvement of Wo in the passivation or Mo enrichment in the film to occur: this is in agreement with the microanalytical ivork of Rhodin (8), who used an acid solution for passivation treatment. The chemistry of tio is, however, far more complex especially in acid regions than is shown in Pourbaix's diagram because of the variety of polymolybdates and valence states. Further work using various environments is needed to elucidate the role of Mo on the increased corrosion resistance of Mo-bearing alloys.

\section{ACKNOWLEDGEMEINT}

We are grateful to $\mathrm{Dr}$. J. Kruger for discussions and encouragement concerning this work, to the Office of Naval Research who supported this work under Contract No. NAONR 18-69, NR 036-082, and to the Japanese Science and Technology Agency who sponsored one of the authors' (T. Kodama) visit to the National Bureau of Standards. 
In electrochemical oxidation, the amount of charge for oxide film formation $\left(Q_{f}\right)$ is proportional to the weight gain $\left(\Delta w_{j}\right)$ if the anodic current efficiency for film formation is unity.

$$
\Delta W \propto U_{f}
$$

Parabolic, cubic, and logarithmic rate laws for film formation are respectively expressed as follows as a function of time:

$$
\begin{aligned}
\Delta W \propto Q_{f} & =A t l / 2 \\
Q_{f} & =A t l / 3 \\
Q_{f} & =A 1 n t+B
\end{aligned}
$$

where $A$ and $B$ are constants.

Since the derivative of $Q_{f}$ gives anodic current, eqs. (4) to (u) give eqs.

(7) to (9), respectively.

$$
\begin{aligned}
& i_{f}=\frac{d Q_{f}}{d_{t}}=\frac{1}{2} A t^{-1 / 2} \\
& i_{f}=\frac{d Q_{f}}{d_{t}}=\frac{1}{3} A t^{-2 / 3} \\
& i_{f}=\frac{d Q_{f}}{d_{t}}=A t^{-1}
\end{aligned}
$$

The exponent of $t$ gives the slope $(m)$ in the $\log i-\log t$ plot. Thus one can obtain the following results:

$$
\begin{array}{ll}
\text { for parabolic } & m=-1 / 2 \\
\text { for cubic } & m=-2 / 3 \\
\text { for logarithmic } & m=-1
\end{array}
$$


Current transient for monolayer-type oxide film

Assuming a monolayer film to nucleate randomly without subsequent twodimensional or thickness growth, the rate of $f i l m$ coverage is proportional to the area of uncovered sites (first-order rate).

$$
\frac{d \theta}{d t}=k(1-\theta)
$$

Integration of eq. (10) yields:

$$
\theta=1-\exp (-k t)
$$

Anodic current consists of that for active dissolution at uncovered sites, $i_{d}$, and that for film formation, $i_{f}$. The following relations exist for $i_{d}$ and $i_{f}$ :

$$
\begin{aligned}
& i_{d}=i_{d}^{\circ}(1-\theta) \\
& i_{f}=q_{f}^{\circ} \frac{d \theta}{d t}=q_{f}^{\circ} k(1-\theta)
\end{aligned}
$$

From (10) to (1), the exponential decay of total anodic current can be obtained:

$$
\begin{aligned}
i & =i_{d}+i_{f} \\
& =\left(i_{d}^{\circ}+q_{f}^{\circ} k\right)(1-\theta) \\
& =\left(i_{d}^{\circ}+q_{f} k\right) \exp (-k t)
\end{aligned}
$$

Notation

i: total anouic current

$i_{d}$ : active dissolution current at uncovered sites

$i_{d}^{\circ}$ : active dissolution current per unit area

$i_{f}$ : anodic current for film formation

k: rate constant (dimension: $\sec ^{-1}$ )

$q_{f}$ : amount of charge required for oxide film formation per unit area

$\theta$ : fraction of $\mathrm{film}$ covered area to total area 
1) 11. Prazak and V. Cihal, Corr. Sci., 2, 71 (1962).

2) E. A. Lizlov, Corrosion, 22, 297 (1966).

3) E. A. Lizlov and A. P. Bond, J. Electrochem Soc., 118, 22 (1971).

4) E. A. Lizlov and A. P. Eond, J. Electrochem Soc., 122, 719 (1975).

5) R. J. Brigharn, Corrosion, 28, 177 (1972).

6) K. J. Brigham and E. W. Tozer, Corrosion, 29, 33 (1973).

7) H. B. Rockel, Corrosion, 29, 393 (1973).

8) T. W. Rinodin, Corrosion, 12, 123t and 465t (1956).

9) G. J. Barnes, A. W. Aldey and R. C. Jerner, J. Electrochem. Soc., 119, $684(1972)$.

10) J. B. Lumsden and R. W. Staehle, Scr. Met., E, 1205 (1972).

11 ) J. Besson and G. Drautzburg,, Electrochim. Acta, $\underline{3}, 158$ (1960).

12) A. A. Pozdeeva, E. I. Antonovskaya and A. M. Sukhotin, Corr. Sci., $\underline{6}, 149$ (1966).

13) L. L. Wikstrom and K. Nobe, J. Electrochem. Soc., 116, 525 (1969).

14) J. W. Johnson, C. H. Chi, C. K. Chen and W. J. James, Corrosion, 26, $238(1970)$.

15) W. D. Robertson, J.Electrochem. Soc., 98, 94 (1951).

16) M. J. Pryor and M. Cohen, J. Electrochem. Soc., 100, 203 (1953).

17) G. H. Cartledge and R. F. Sympson, J. Phys. Chem., 61, 973 (1957).

18) E. A. Lizloves, J. Electrochem. Soc., 114, 1015 (1967).

19) A. Weisstuch and C. E. Sche11, Corrosion, 28, 299 (1972).

20) J. Kruger and J. R. Ambrose, National Bureau of Standards Report No. NBSIR 74-583, Technical Summary Report No. 5, Contract NAONR 18-69, INR 036-082, 1974.

21) J. K. Ambrose and J. Kruger, Corrosion, 28, 30 (1972).

22) J. R. Ambrose and J. Kruger, J. Electrocinem. Soc., 121, 599 (1974). 
23) H. Nagayama and M. Cohen, J. Electrochem. Soc., 109, 781 (1962).

24) N. Sato and M. Cohen, J. Electrochem. Soc., 111, 512 (1964).

25) M. Fleischmann and H. R. Thirsk, Advances in Electrochemistry and Electrochemical Engineering, Vol. 3, ed., P. Delahay, p. 123, Interscience, New York.

26) M. Pourbaix, Atlas of Electrochemical Equilibria at $25^{\circ} \mathrm{C}, \mathrm{pp}, 275$ and 313 , 1966, Pergamon Press.

27) D. D. Wagman et al., National Bureau of Standards Technical Note, 270-4 (1969).

28) P.A.G. O'Hare, K. J. Jensen and H. R. Hoekstra, J. Chem. Thermodynamics $\underline{6}, 681(1974)$.

29) W. M. Latimer, Oxidation Potential, 2nd ed., Prentice Hall, New York, 1952.

30) W. W. Weller, U. S. Bur. Mines Rep. Invest., No. 6787 (1966).

31) J. Yahalom, L. K. Ives, and J. Kruger, J. Electrochem. Soc., 120, 384 (1973).

32) G. H. Cartledge, Corrosion, 24, 223 (1968).

33) H. Okada, H. Ogana, I. Hoh, and H. Omata, Auger Electron Spectroscopic Analysis of the Passive Film of Stainless Steels, presented at the Joint Japan-USA Seminar on Passivity, Honolulu, 1975. 


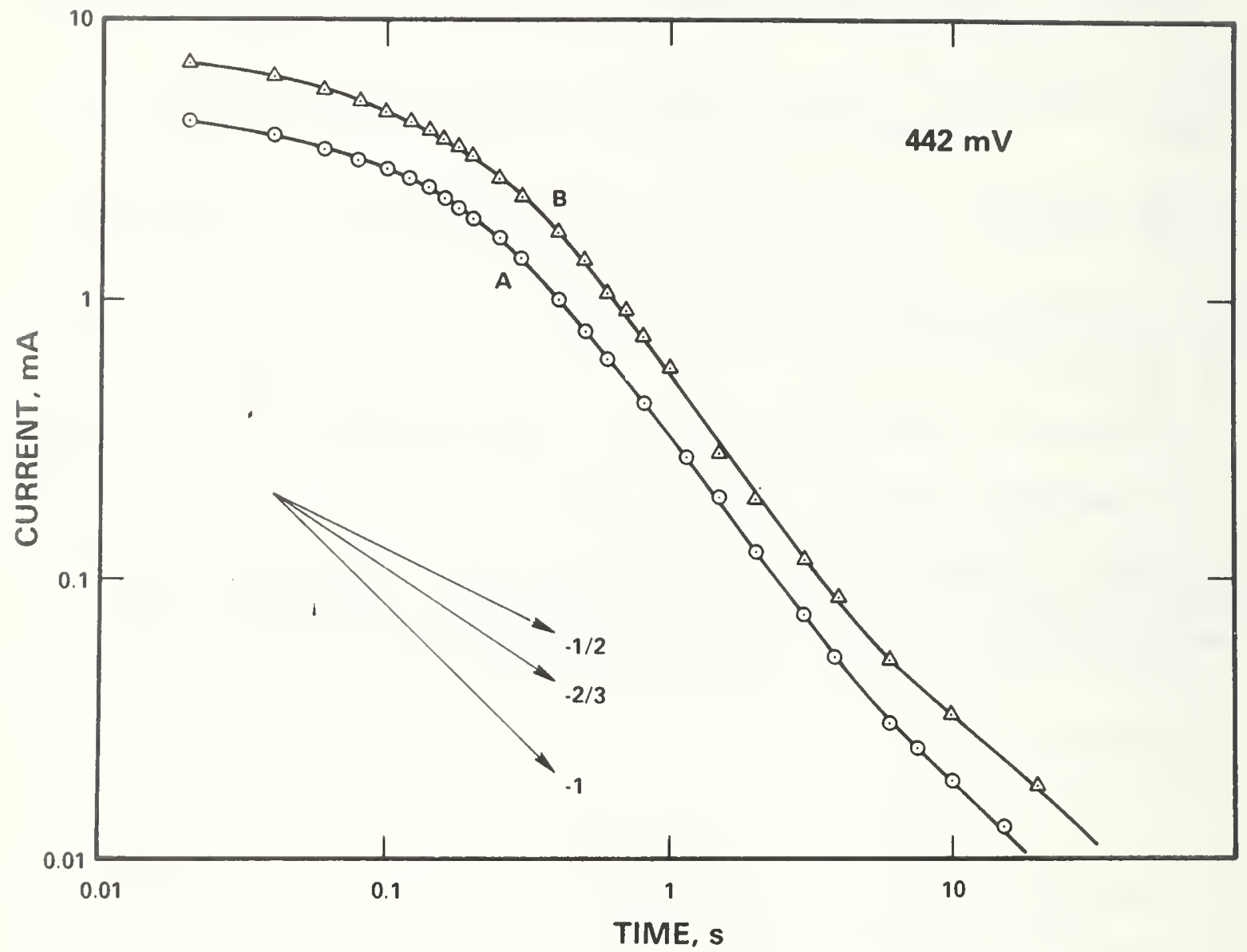

Fig. 1 Anodic current transients following abrasion at $442 \mathrm{nV}$ iNHE (A) in a borate buffer solution (pHi 3.4) and (B) in a $0.01 \mathrm{M} \mathrm{Na}_{2} \mathrm{MoO}_{4}$ - borate solution. Slopes $m=-1 / 2,-2 / 3$, and -1 on a $\log -\log$ scale indicate parabolic, cubic, and logarithmic rate laws for film growth, respectively. 


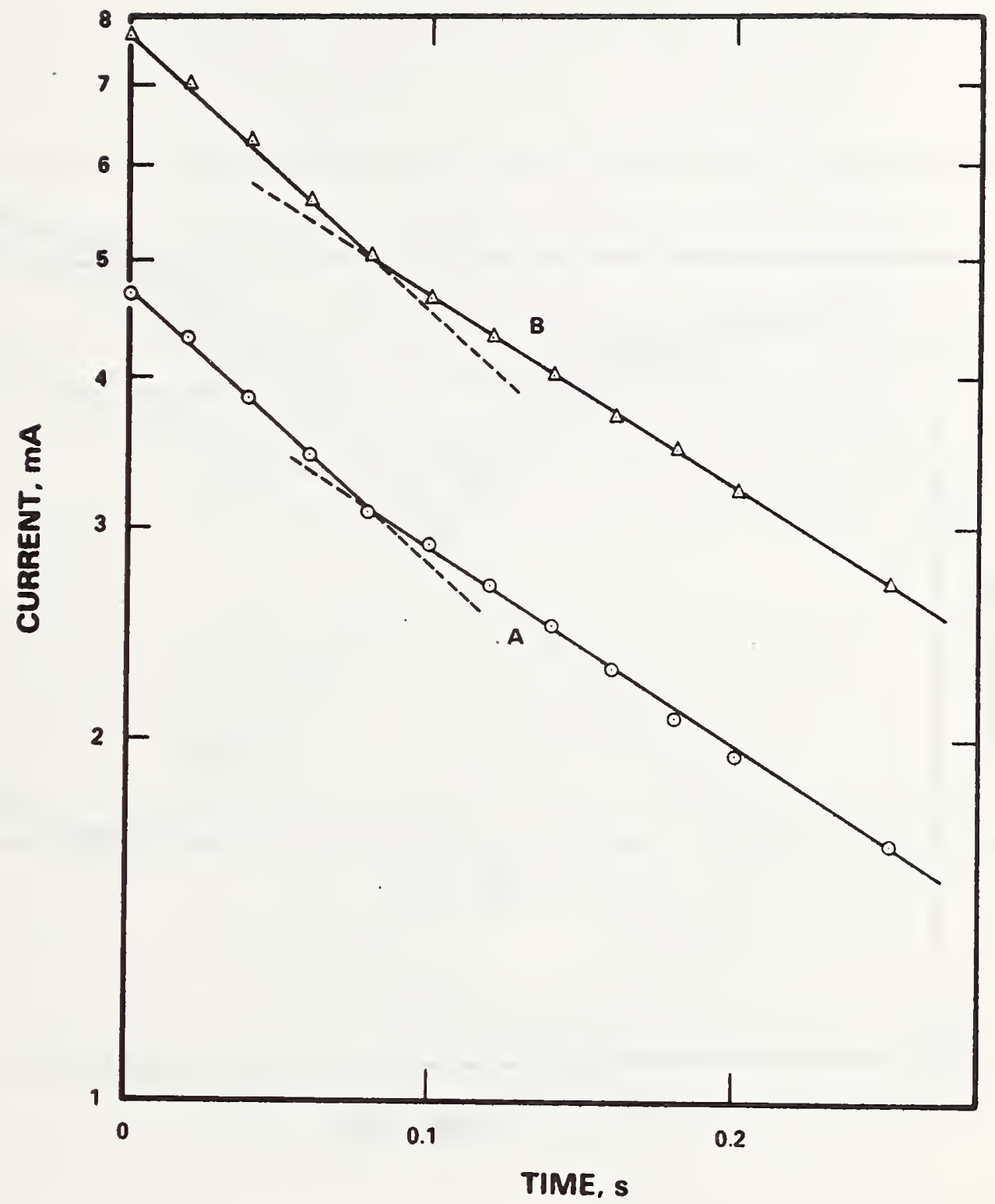

Fig. 2 Semilogarithmic plots of anodic transients for times less than $250 \mathrm{~ms}$ following abrasion at $442 \mathrm{mV}$ ilHt $(A)$ in a borate buffer solution (pH 8.4), and (B) in a $0.01 \mathrm{M} \mathrm{Na}_{2} \mathrm{MoO}_{4}$ - borate solution. 


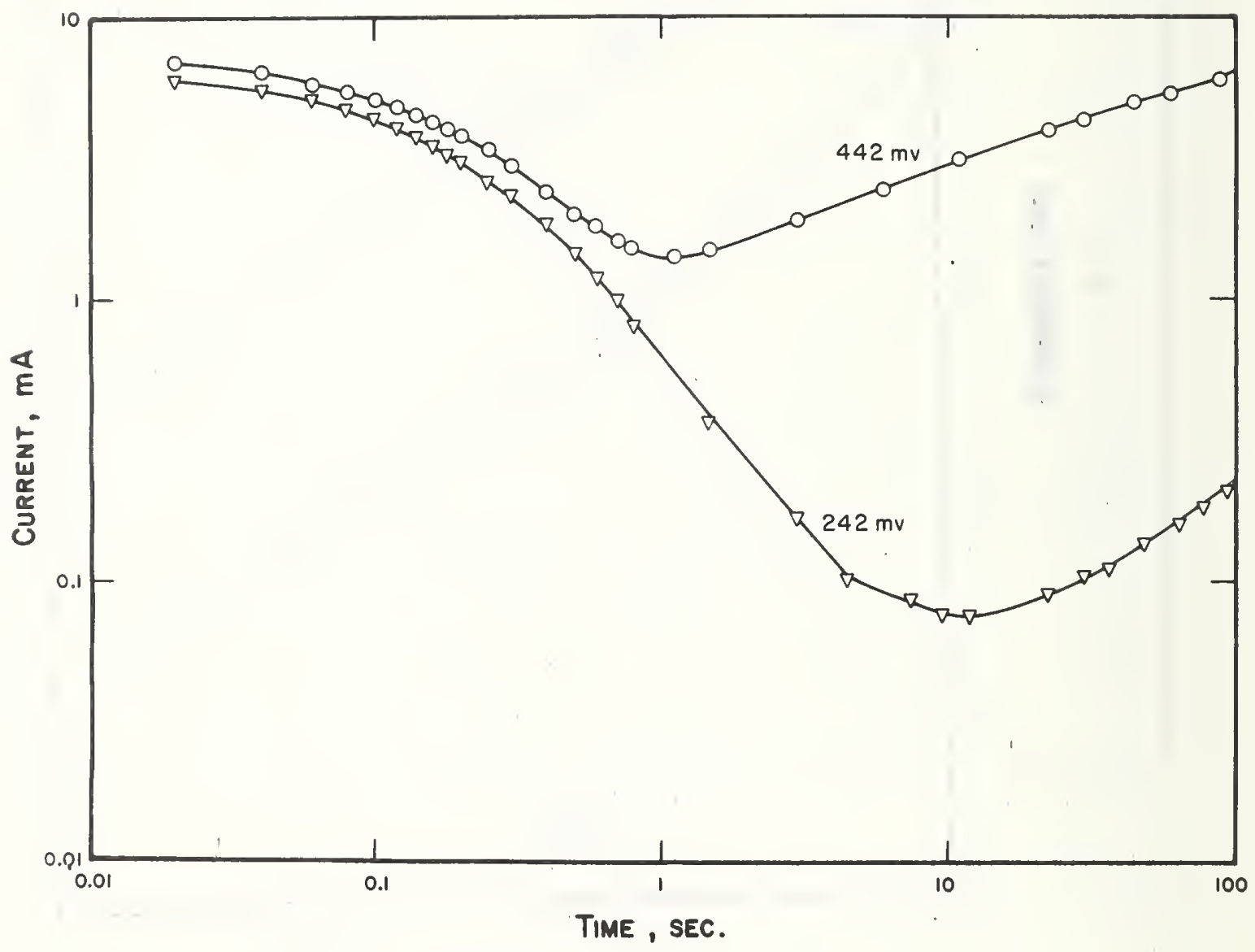

Fig. 3 Anodic current transients following abrasion in a $0.01 \mathrm{M} \mathrm{NaCl}$ - borate solution at different potentials. 


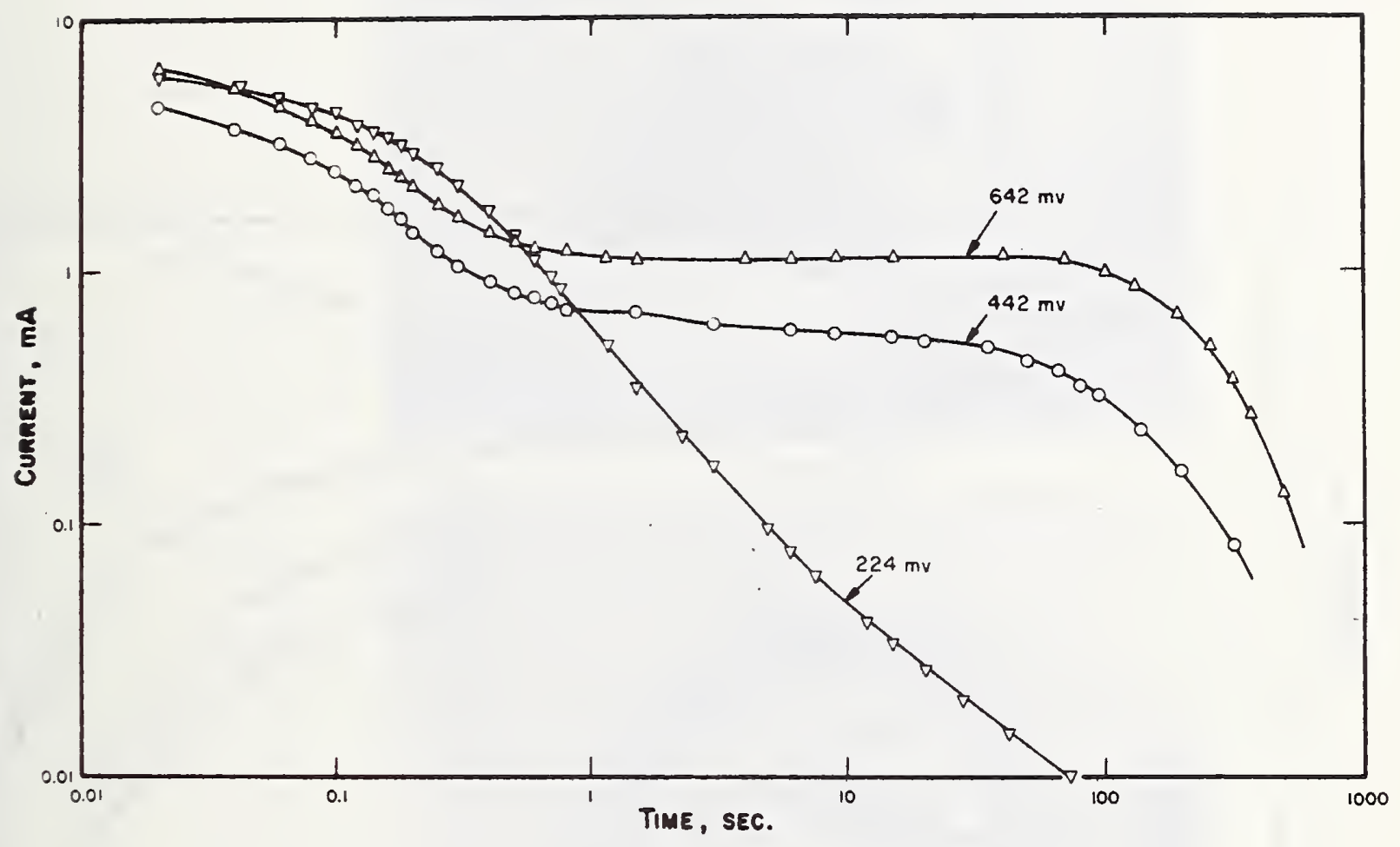

Fig. 4 Anodic current transients following abrasion in a $0.01 \mathrm{M} \mathrm{NaCl}-$ $0.01 \mathrm{M} \mathrm{Na}_{2} \mathrm{MoO}_{4}$ - borate solution at different potentials. 


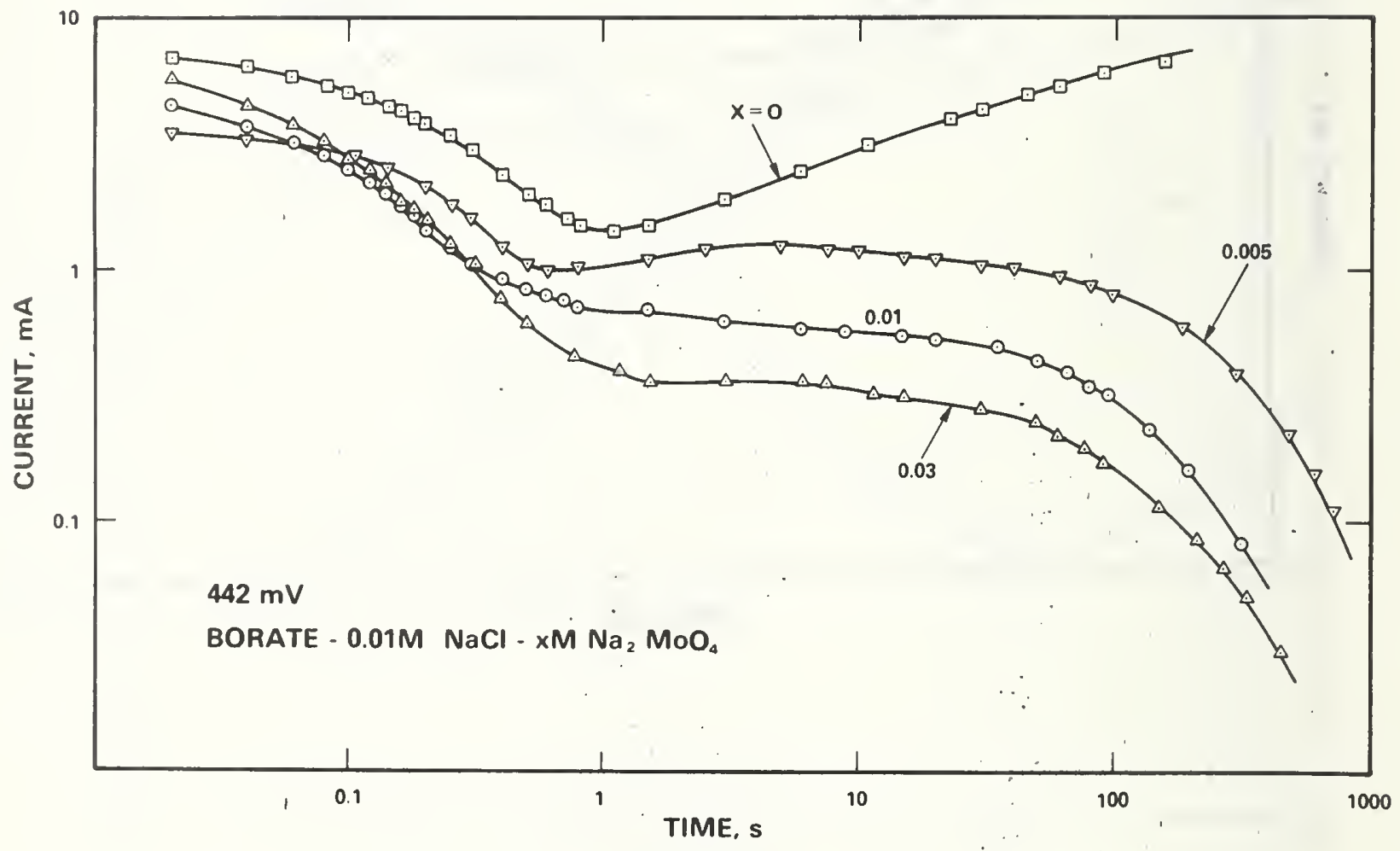

Fig. 5 Effect of ila $\mathrm{MOO}_{4}$ addition to a $0.01 \mathrm{M} \mathrm{NaCl} \mathrm{-} \mathrm{borate} \mathrm{solution} \mathrm{on} \mathrm{the}$ anodic current transients at $442 \mathrm{mV}$ NHË. 

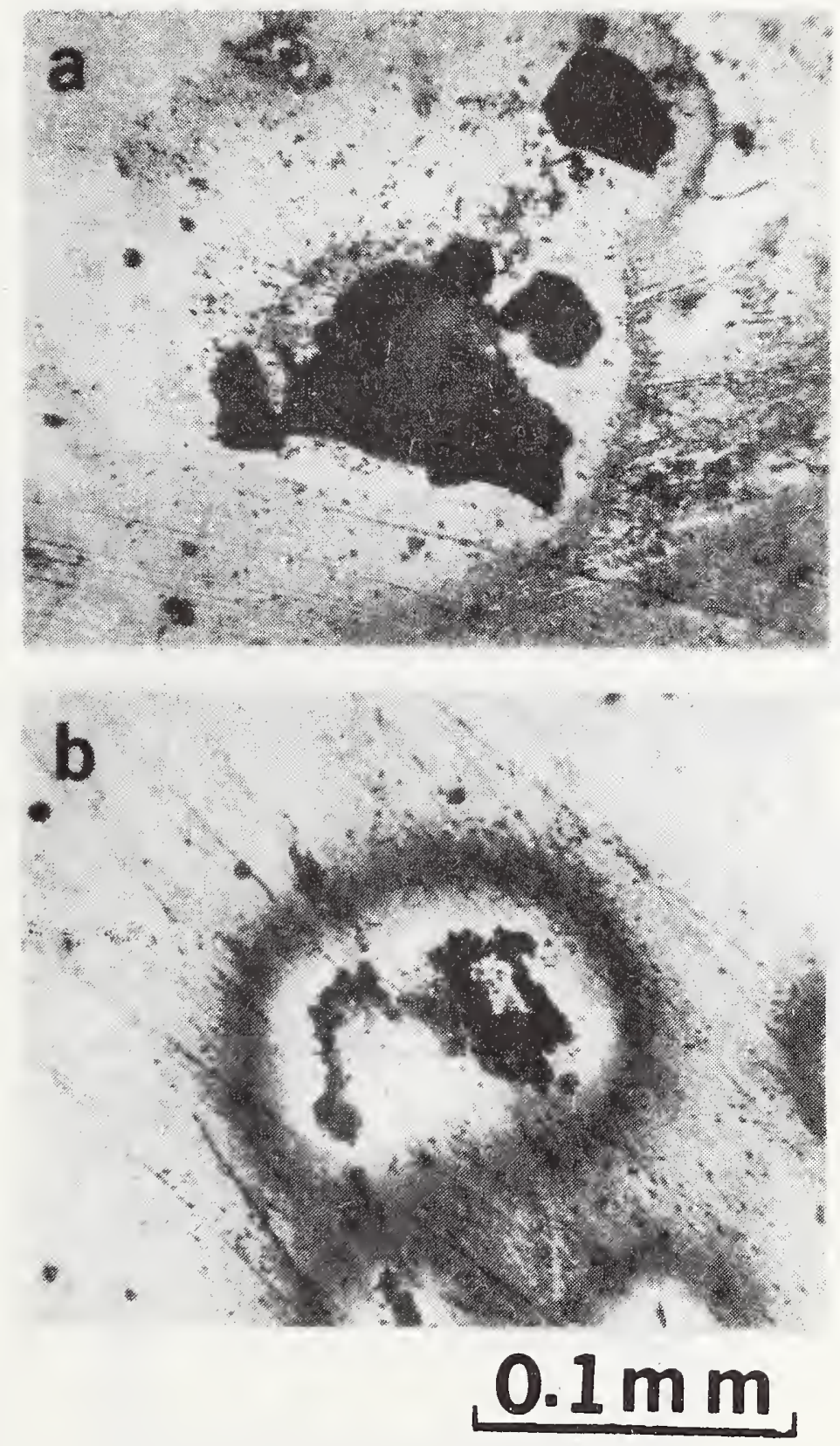

Fig. 6 Optical photomicrographs of (a) active pits in a $0.01 \mathrm{M} \mathrm{NaCl}$ - borate solution and (b) inactivated pits in a $0.01 \mathrm{M} \mathrm{NaCl}-0.01 \mathrm{M} \mathrm{Na}_{2} \mathrm{MoO}_{4}$ solution. Both (a) and (b) are formed at $442 \mathrm{mV}$. 


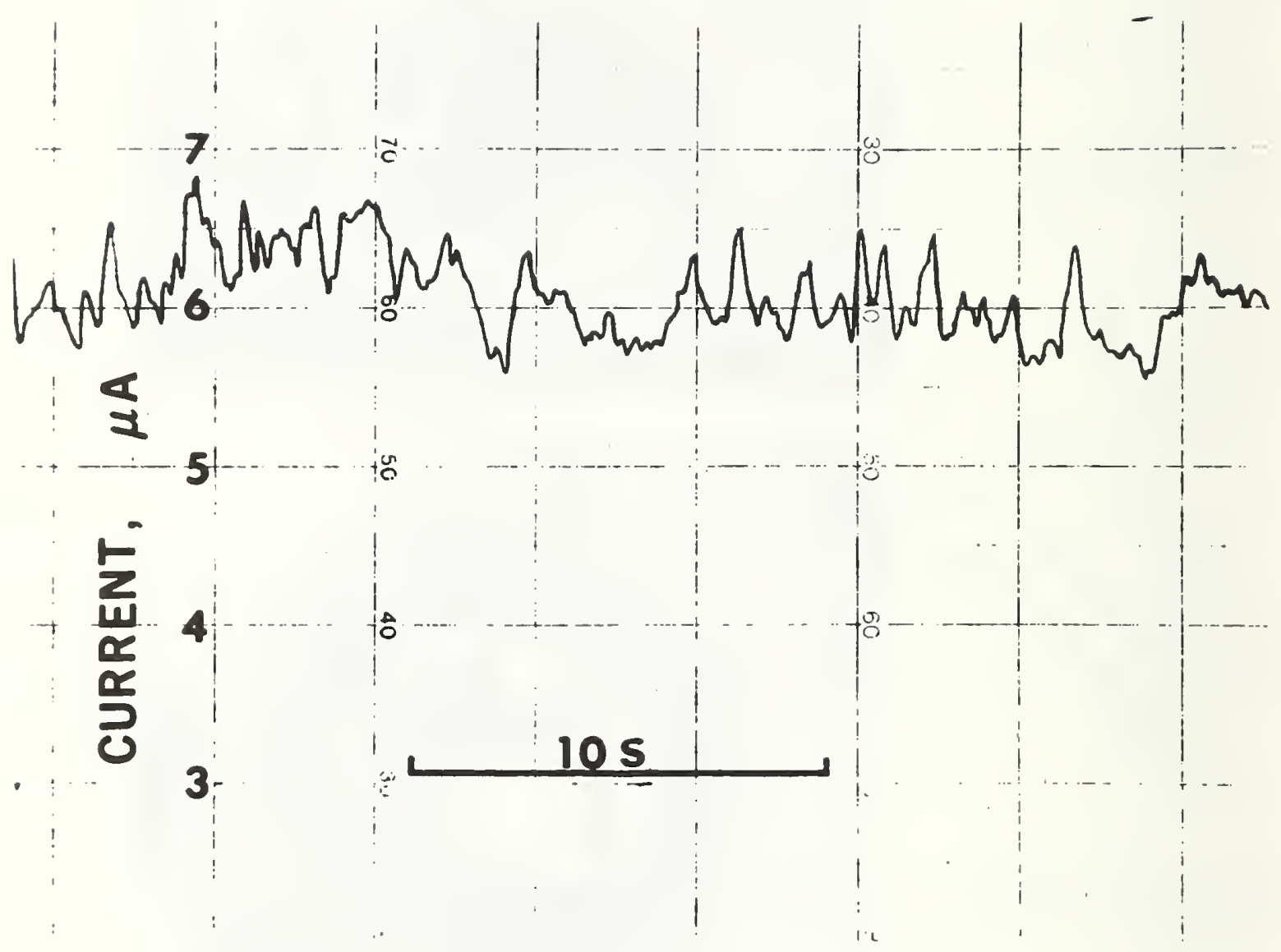

Fig. 7 Anodic current fluctuations observed in the repassivation stage at $422 \mathrm{mV}$ liHE in a $0.01 \mathrm{M} \mathrm{NaCl} \mathrm{-} 0.01 \mathrm{M} \mathrm{Ha}_{2} \mathrm{MoO}_{4}$ - borate solution. 

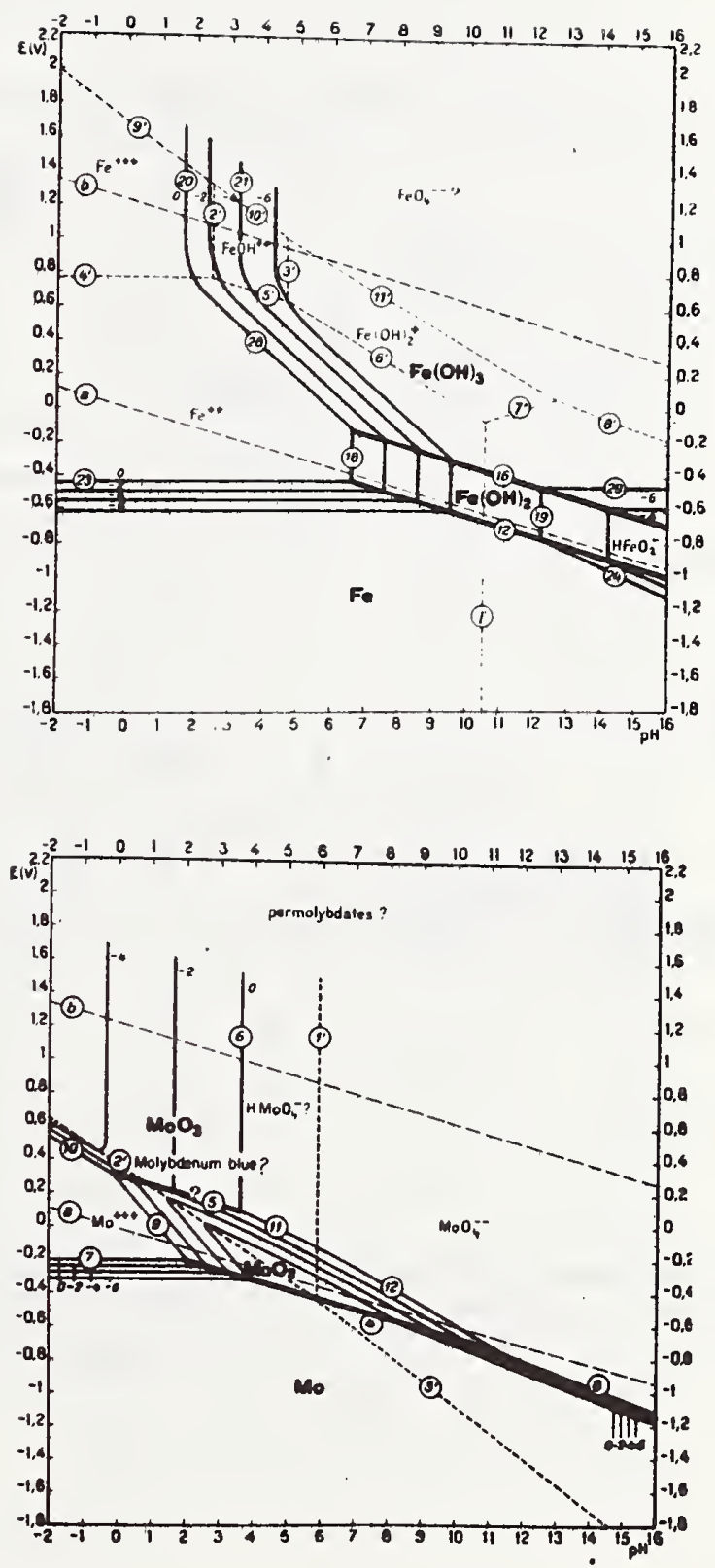

Fig. 8 Potential-pH diagrams for Fe and Mo. (From Ref. 26). 


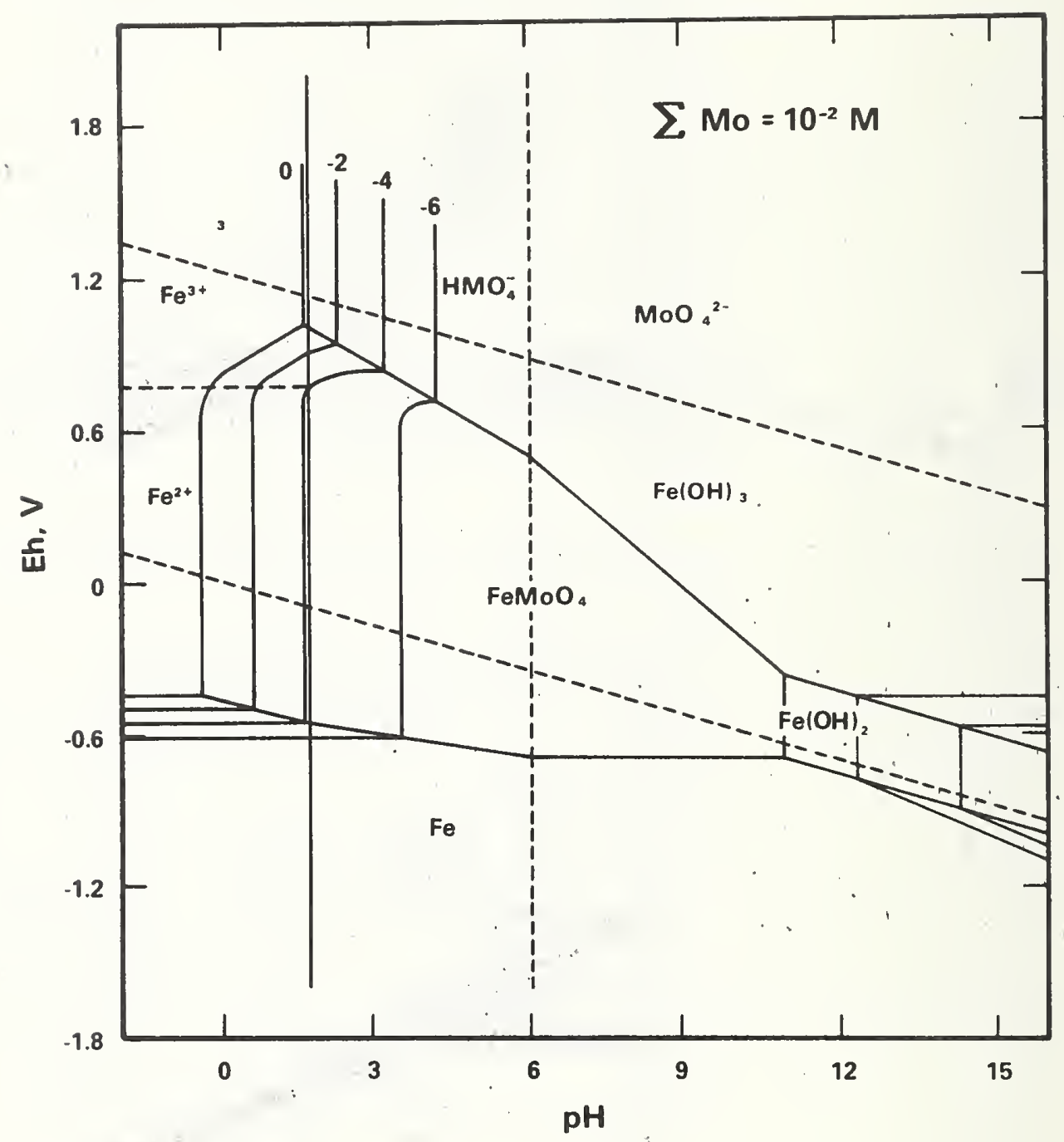

Fig. 9 Potential-pH diagram for $\mathrm{Fe}$ in molybdate solutions. (Total molybdate concentration $=10^{-2} \mathrm{M}$ ) at $298 \mathrm{~K}$. Molybdate ion is assumed to be electrochemically inert. 


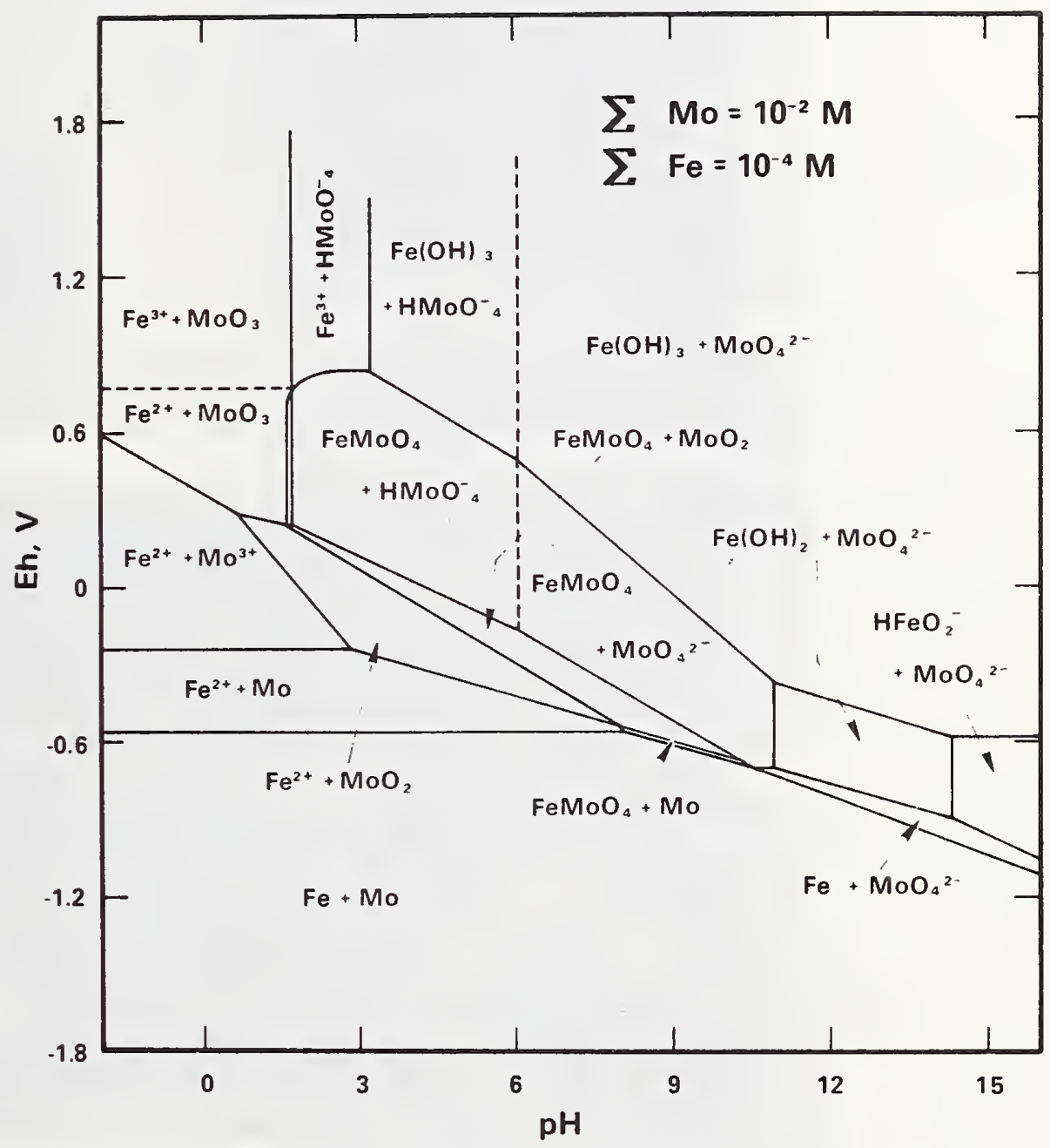

Fig. 10 Potential-pH diagrams for a mixed Fe and Mo system. (Total Ho concentration $=10^{-2} \mathrm{M}$ and total Fe concentration $=10^{-4} \mathrm{M}$ ) at 298 K. 

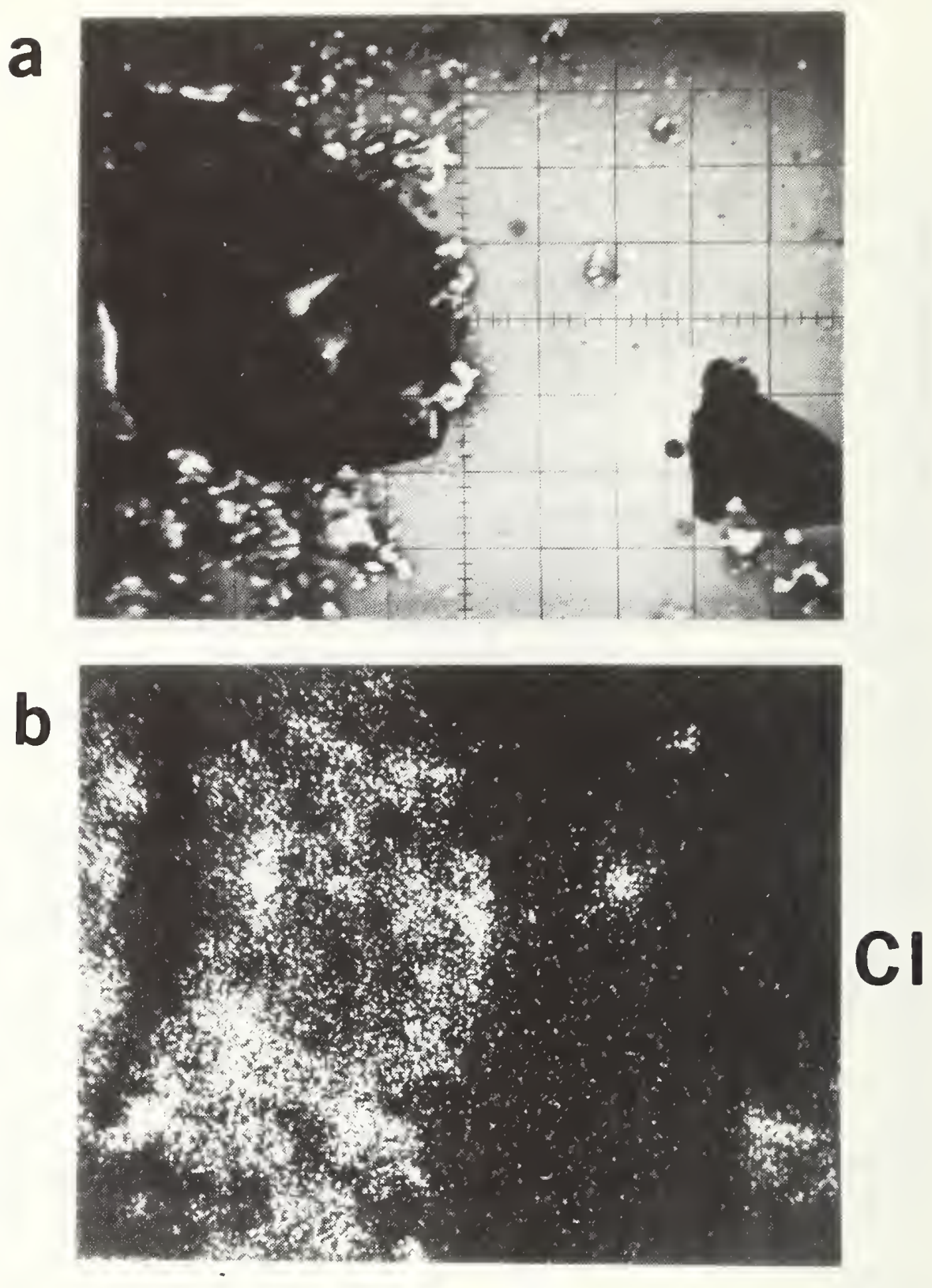

\section{$0.1 \mathrm{~mm}$}

Fig. 11 EPMA images of pits formed in a $0.01 \mathrm{M} \mathrm{NaCl}$ - borate solution at $442 \mathrm{mV}$ NHE. a) secondary electron image, b) area scan for C1. 

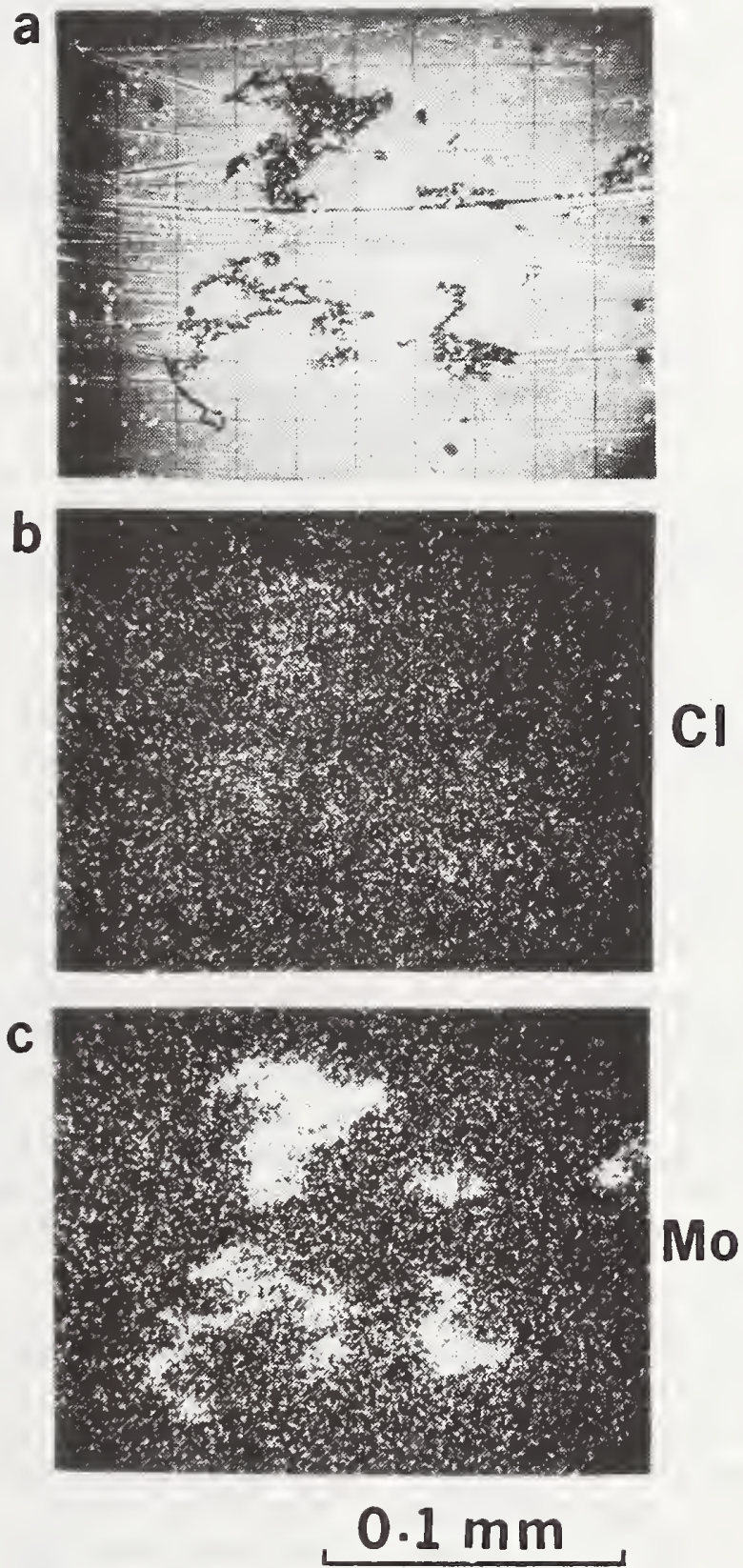

Fig. 12 EPMA images of pits formed in a $0.01 \mathrm{M} \mathrm{NaCl}-0.01 \mathrm{M} \mathrm{Na}_{2} \mathrm{MoO}_{4}$ borate solution at $442 \mathrm{mV}$ NHE. a) secondary electron image, b) area scan for $\mathrm{Cl}, \mathrm{c}$ ) area scan for Mo. 
(To be submitted to the Journal of the Electrochemical Society)

\author{
The Effect of a Crevice on \\ Passive Film Growth Kinetics for Iron \\ John R. Ambrose \\ Corrosion and Electrodeposition Section \\ National Bureau of Standards \\ Washington, D. C. 20234
}

There is usually agreement that the underlying cause of crevice corrosion is related to the fact that within the restricted geometry of a crevice there is contained a solution in which mass transport of certain critical species is sufficiently limited so as to inhibit continuation of the passive state normally displayed by a metal (1-3). This agreement continues when these critical species are enumerated, al though their ranking has been open to some discussion. They are, in arbitrary order (4):

(1) metal cations

(2) bulk solution anions (e.g., chloride ion)

(3) hydrogen ions

(4) dissolved oxygen

Finally, considerable agreement prevails when discussion expands to include the specific effect that would be manifest when mass transport of these species is restricted. Without the reaction products from oxygen reduction within the crevice available to neutralize hydrogen ions produced by hydrolysis of metal ions, the crevice solution eventually deteriorates to a point where it is difficult to maintain the passive state. Since it is generally regarded that this passive state results from the presence of a protective surface film, then the properties of this film - its ability to sustain, repair or even regenerate itself in those environments considered aggressive - are critical with respect to evaluating susceptibility to crevice corrosion attack.

Techniques which provide measurements of overall corrosion rates during crevice attack using electrochemical test methods alone cannot be expected to allow measurement of $f i l m$ properties. There are too many diffusion limited steps in the process which contribute to overall reaction kinetics to permit a focus on the most important area - the film, itself - unless measures are taken to look at the $f i 1 \mathrm{~m}$ alone. The work described here is based on results obtained by observing the film that exists on a metal surface exposed to a crevice. Pure iron exposed to a borate buffer solution to which sodium chloride could be added was selected since film growth processes within and wi thout a crevice could be compared.

Recently a technique was developed in this laboratory that utilized ellipsometry to measure variations in optical properties inside a crevice while a specimen was potentiostated at a fixed corrosion potential. This approach was shown 
to be useful in measuring relative susceptibility toward crevice corrosion of a series of ferritic stainless steels as a function of molybdenum content (5). This earlier developed technique is of value in predicting susceptiblity to crevice attack, but it is difficult to use as a tool for making studies concerned with developing an understanding of the mechanism of crevice corrosion because it is difficult to interpret the changes in the

ellipsometric parameters observed during the onset of attack. The work described here is based on results obtained from a modification of that technique. Whereas the former procedure involved measurement of ellipsometer changes which occurred following exposure of a film covered metal surface to a crevice, in this procedure, a bare metal surface was produced

electrochemically on iron before ellipsometer measurements were begun. From this study, it was hoped that some idea of exactly how the restricted geometry of a crevice affects film growth could be obtained by ellipsometrically measuring film growth and reduction during potentiometric and galvanostatic cycles.

\section{EXPERIMENTAL}

Material used in this study was ferrovac iron, which was mounted in Tucite, then drilled and tapped for electrode assembly. The crevice assembly shown in Fig. 1 was the same as that used in previous studies (5). However, for this work, the assembly was positioned as shown in Fig. 2, allowing solution to be drawn into the crevice by capillary action. Within this particular configuration, ellipsometric measurement was facilliated due to easier optical allignment of the specimen assembly. Experiments performed utilizing the crevice assembly were compared to experiments performed under identical conditions without the presence of a crevice. The distance between the quartz plate and the metal surface (the crevice thickness) was $0.25 \mathrm{~mm}$ in each experiment. This thickness was assured for each experiment using a teflon shim.

A11 experiments were performed using solutions prepared from reagent grade chemicals and distilled water $\left(7 \times 10^{-7} \mathrm{ohm}^{-7} \mathrm{~cm}^{-1}\right)$. A tuffer solution containing $9.3 \mathrm{~g} \mathrm{H}_{3} \mathrm{BO}_{3}$ and $14.6 \mathrm{~g} \mathrm{Na} \mathrm{B}_{4} \mathrm{O}_{7}$. $10 \mathrm{H}_{2} \mathrm{O}$ per liter ( $\mathrm{pH} \cdot 8.4$ ) was used as a stock solution. In order to evaluate contributions from the presence of chloride ion, an aliquot of $1.0 \mathrm{n} \mathrm{VaCl}$ solution was added to the stock solution to make an overall chloride ion concentration of $10^{-2} \mathrm{H}$.

Specimens were polished using SiC metallographic papers, then rotary polished with 1 m diamond paste. Following polishing, specimens were ultrasonically cleaned with ethyl alcohol, rinsed with spectro grade methanol, dried in air, then mounted for exposure.

Two experimental techniques were used in this study:

a) Potentiodynamic Scan Technique

Following positioning of the specimen, the specimen potential was fixed at $-758 \mathrm{mV}$ SHE until initial ellipsometric measurements were completed. $A$ ramp function was then applied so that the potential was varied at a fixed rate of from 400 to $2000 \mathrm{mV} / \mathrm{minute}$ to $1242 \mathrm{mV}$ SHE; at this point the potential was returned to $-758 \mathrm{mV}$ SHE. Measurements of cell current were recorded. Simultaneous measurement of decrease in ellipsometer light intensity (proportional to film thickness) was made using the off-null technique (6). 
b) Galvanostatic Scan Technique

Following positioning of the specimen, a constant current of $-100 \mu \mathrm{A}$ was passed until initial ellipsometer measurements were completed. Current was then switched to a constant anodic value of from +100 to $+500 \mu \mathrm{A}$ and continued until the measured potential reached either $1242 \mathrm{mV} \mathrm{SCE}$, or, in the cases where chloride ion had been added, the potential remained constant or dropped off. At this point, current was reversed and reduction was allowed to occur at either -100 (crevice) or $-200 \mu \mathrm{A}$ (non-crevice) until a constant potential was maintained. Ellipsometer intensity measurements and electrode potential were simultaneously recorded.

After each experiment, the specimen was removed, repolished, and the solution changed before a new experiment was initiated. Results reported here are based on the average of three separate experimental determinations.

\section{RESULTS}

Potentiodynamic 0xidation Without Chloride Ion

The results of a typical potentiodyanmic scan for iron exposed to the borate stock solution inside and without a crevice are shown in Fig. 4 and 3 , respectively. A comparison of the results from these two experiments show two important results: 1) when not exposed to a crevice, iron goes through an active to passive transition at a potential of about $358 \mathrm{mV}$ SHE (Fig. 3). Film growth begins almost instantly upon initiation of the potential ramp function; 2) when exposed to a crevice iron does not passivate as it did in the previous case. As seen in Fig. 4, the current rise changes slope as film begins to form, but does not drop off as in Fig. 3. Note also, that the initiation of film growth in measureably retarded within the crevice.

Since the ellipsometer light beam is usually positioned roughly in the center of the specimen, it was thought that this result might be due to an edge effect, where the current being passed by the counter electrode is consumed at the edge of the specimen within the crevice; however, reallignment to look at the specimen edge gave identical results.

Although these results were dramatic, it was felt that evaluation of the film growth and decay measurements would be more meaningful if the overall oxidation and reduction rates of the system were fixed. For this reason, galvanostatic oxidation and reduction experiments were begun. Log film thickness vs. log time plots were used to display the data from these experiments.

Galvanostatic Oxidation Without Chloride Ion

In Fig. 5 are compared film growth at $+100 \mu \mathrm{A}$ in the borate buffer solution for iron within and without a crevice. It is clear from this figure that film growth is relatively constant over the time span of the galvanostatic oxidation when a crevice is not present. With the crevice, however, film growth is initially non-detectable for the first 10-15 seconds, after which film growth occurs rapidly, almost seeming to "catch up" with the film thickness which would occur outside a crevice. After about 50 seconds, growth rates for the two systems appear identical. Log film growth within the 
crevice versus log time is plotted in Fig. 6 for a galvanostatic oxidation at $+200 \mu \mathrm{A}$. On the same plot is included results from Fig. 5 for crevice growth at $+100 \mu \mathrm{A}$. It can be seen that although the point in time at which growth begins is much earlier (at about $6 \mathrm{sec}$. following start of the scan) the rate of $\mathrm{fi} 7 \mathrm{~m}$ growth is nearly the same as in the $+100 \mu \mathrm{A}$ oxidation.

Ga]vanostatic Oxidation With Chloride Ion

In Fig. 7 are compared film growth at $+100 \mu \mathrm{A}$ in the borate buffer $-10-2 \mathrm{~N}$ $\mathrm{NaCl}$ solution for crevice and non-crevice iron. The same phenomonology is observed as when chloride was absent, but it is clear that the presence of chloride ion for crevice iron does result in a slight decrease in the rate of film growth during $+100 \mu \mathrm{A}$ galvanostatic oxidation.

However, in each case, once the potential exceeds about $400 \mathrm{mV}$ SHE, pits initiate on each specimen. The potential remains fairly constant for the noncrevice iron, but drops off to about $300 \mathrm{mV}$ SHE for crevice iron.

\section{DISCUSSION}

The borate buffer solution was selected for use in this study for several reasons:

1) Sufficient expertise has been assembled for film growth kinetics on iron in this solution $(7,8)$ to evaluate ellipsometer measurements made through a quartz disc.

2) The virtial $100 \%$ efficiency for electrochemical reduction of films on iron reported in this solution (9) prevents formation of $\mathrm{H}_{2}$ bubbles in the crevice which interfere with ellipsometer measurements.

3) Since pH has been thought to be an important parameter in the crevice solution composition (4), the use of a buffered solution allows some control over the hydrogen ion variable.

The comparison between film growth rates for iron initially exposed to the same solution but, in one case, under the kinetic restrictions imposed by a crevice shows that film growth is significantly retarded within a crevice, whether chloride ion is present or not. Why is this so? Since the solution is buffered, $\mathrm{OH}^{-}$concentration is fixed; at the start of a galvanostatic oxidation, initial $\mathrm{Fe}^{+2}$ flux should be the same for an iron surface whether it is exposed to a crevice or not. Since each experiment was initiated by passing a constant cathodic current to reduce surface oxide and allow time to make ellipsometric measurements, it is likely that this pre-treatment effectively removed all $\mathrm{O}_{2}$ from the crevice. Thus, when current is reversed, oxidizing at a constant rate of $30 \mu \mathrm{A} / \mathrm{cm}^{2}$, and with no other oxidizing agent present, a film will not begin to grow until the solubility product of $\mathrm{Fe}(\mathrm{OH})_{2}$ is exceeded. At that point, the film will grow rapidly as precipitation occurs. Since precipitation initially occurs from a super saturated solution, the rate at which this growth initially occurs would be expected to be independent of anodic current density. However, the time at which growth begins to occur should be quite dependent upon current density since that alone controls the $\mathrm{Fe}^{+2}$ flux passing into the crevice solution. If chloride ions are assumed to be involved in complexing $\mathrm{Fe}^{+2}$ ion as has been suggested by Foley (18), then a precipitated film growth model is further indicated since film growth within a crevice is reduced in the presence of chloride ions (Fig. 7). 
One other possibility is that because of the crevice, a portion of the applied current is consumed by the establishment of a significant iR drop in the solution and that film will not grow until the actual electrode potential Eappl.--iR) exceeds some critical value. Specimens are being redesigned to allow measurement of potential within a crevice. Whichever explanation is the correct one, the net result is the same, following creation of a bare metal site within a crevice, film growth during the repassivation process is retarded during galvanostatic oxidation.

Once some critical potential is exceeded, however, film growth kinetics are virtually identical whether growth on the iron occurs within the confines of a crevice or not. This potential (about $200 \mathrm{mV}$ SHE) happens to coincide quite well with several other so-called "critical potentials" described in the literature:

a) $E_{a}^{2}$, the potential reported by Nagayama and Cohen (9) for iron exposed to a buffered borate solution $(\mathrm{pH}=8.4)$ above which no $\mathrm{Fe}^{+2}$ ion was detectable in solution. It is about $200 \mathrm{mV}$ SHE.

b) $E_{C}$, the critical potential for pitting of iron in a borate buffer solution containing $10^{-2} \mathrm{~N}$ chloride ion (8) and is about $200 \mathrm{mV}$ SHE.

c) Formation potential of $\gamma \mathrm{FeOOH}$, expected to be formed by hydrolysis and precipitation of $\mathrm{Fe}(\mathrm{OH})_{2}^{+}$, at a potential of about $200 \mathrm{mV}$ SHE at a $\mathrm{pH}$ of 8 (10).

d) A potential shown by Ambrose and Kruger to be about $200 \mathrm{mV}$ SHE where below this potential film growth on iron in a borate solution containing chloride ion was the same as if chloride was not present (8). Above this potential, however, chloride markedly affected film growth.

Of course, the fact that these potentials are remarkably similar can be attributed to coincidence, but there are many good reasons to suppose that this should not be so. One very important condition should be pointed out these galvanostatic oxidations were performed in a buffered solution. In non-buffered solutions, crevice pH change would be expected to be proportional to the total anodic current density less that partial current density being consumed in film growth. All things being equal, for an anodic current transfer at $100 \mu A$ into a crevice volume of $10^{-1} \mathrm{~cm}^{3}$, and assuming double hydrolysis of ferrous ion according to:

$$
\mathrm{Fe}\left(\mathrm{H}_{2} \mathrm{O}\right)_{6}^{+2} \underset{\mathrm{k}_{-1}}{\stackrel{\mathrm{k}_{1}}{t}} \mathrm{Fe}\left(\mathrm{H}_{2} \mathrm{O}\right)_{5}(\mathrm{OH})^{+1} \underset{\substack{\mathrm{k}_{-2} \\ \mathrm{k}_{-2}}}{\mathrm{k}_{3}} \mathrm{Fe}\left(\mathrm{H}_{2} \mathrm{O}\right)_{4}(\mathrm{OH})_{2},
$$

the rate of build-up of hydrogen ions should be approximately 1 pH unit per second. By the time film growth could be expected to begin according to solubility product data, the crevice $\mathrm{pH}$ would be about 2 , the value measured for steady state crevice corrosion of iron by Bogar and Fujii (11). The lowering of $\mathrm{pH}$ would be expected to retard growth of a precipitated $\mathrm{Fe}(\mathrm{OH})_{2}$ film. In fact, studies by Kruger and Calvert (7) for iron in borate solutions show this effect (Fig. 8). 
If we now assume that above about $200 \mathrm{mV}$ SHE the film that is formed is an $\mathrm{Fe}$ (III) oxide, and that to be protective it must likely be $\gamma-\mathrm{Fe}_{2} \mathrm{O}_{3}$, as has been suggested by many researchers (12), then all that remains between bare metal and exposure to the solution within the crevice is a thin layer of $\mathrm{Fe}(\mathrm{OH})_{2}$, thinner because of retarded growth in $1 \mathrm{ow} \mathrm{pH}$ solution. This is quite important, because in the presence of chloride ion, protective $\mathrm{Fe}_{2} \mathrm{O}_{3}$ does not appear to be formed, rather a non-protective $\gamma$ - $\mathrm{FeOOH}$ compound, probably as a result of hydrolysis of $\mathrm{Fe}(\mathrm{OH})_{2}^{t}$ and precipitation of $\mathrm{FeOOH}$ from solution (12).

The results thus far obtained point to the fact that in a crevice where $\mathrm{O}_{2}$ has been depleted, film growth is retarded whether chloride ion is present or not. It is during this interval of time that processes occur which, in all probability, set the stage for propagation of crevice attack. If the rate of formation of film during this period could be accelerated, perhaps by additions of certain substances known to act as inhibitors, then the expected consequence of low film growth rates might be averted. For instance, studies by Kodama and Ambrose (13) have suggested that the beneficial effect of $\mathrm{MOO}_{4}=$ additions is related to the formation of an insoluble Fello $\mathrm{O}_{4}$ compound. Perhaps impraed resistance to localized corrosion is related to the rate of formation of such salt films. Such a possibility has been suggested by Beck in his studies of pitting on titanium (14). Studies into the effect of alloying Mo and additions of $\mathrm{NaMiO}_{4}$ to the solution are now being performed using the technique employed in this work.

A11 of the considerations just discussed that affect both the onset time and the rate of $f i 1 \mathrm{~m}$ formation are of importance if there exists spontaneous film rupture and repair in a crevice as was suggested in a previous report (5). The experiments performed here show that if film rupture does occur, then the sequence of events as described here will occur once $\mathrm{O}_{2}$ has been depleted within the crevice. Of course, $\mathrm{O}_{2}$ will be consumed by electrochemical reduction at a freely corroding surface as a part of the overall corrosion reaction. Within a crevice, however, mass transport restriction limit its replacement. Studies by Shiobara and Horioka (15) and Iverson (16) point to frequent current oscillations during "incubation" periods prior to actual progation of pitting and crevice attack. Videm showed similar breakdown and repair transients for aluminum (17). It is likely then, that chloride ion does promote spontaneous rupture of the protective film on iron, and, that repassivation phenomona will be controlled by the state of the solution when such rupture does occur. However, the important stage is the first one, for if $f i l m$ does not form, then the high metal ion concentration and low pH conditions created here will invariably affect repassivation behavior in any future spontaneous rupture event. It is towards elucidating still further the factors which influence early growth during galvanostatic oxidation that our efforts will be directed.

\section{ACKNOWLEDGEMENT}

I am grateful to the Office of Naval Research who supported this work under Contract No. NAONR 18-69, NR 036-082. 
References

1) I.L. Rosenfeld and I.K. Marshakov, Corrosion, 20, 115t (1964).

2) B.F. Brown, Corrosion, 26, 249 (1970).

3) E. HcCafferty, J. Ëlectrochem. Soc., 121, 1007 (1974).

4) W.D. France, Jr., Crevice Corrosion of Metals, GMC Research publ. GMR-1105 (1971).

15) J. Kruger and J.R. Ambrose, liational Bureau of Standards Report ilo. NBSIR 74-583, Techinical Summary Report Number 5, Contract MAOliR 18-69, NR 036-083 (1974).

6) V. Brusic, M.A. Genshaw, and B.D. Cahan, Appl. Optics, 9, 1634 (1970).

7) J. Kruger and J.P. Calvert, J. Electrochem. Soc., 114, 43 (1967).

8) J.R. Ambrose and J. Kruger, Proc. Fourth Intl. Cong. on Met. Corr., N.E. Hamner, Ed., Ams terdam, 1969 (WACE, Houston, 1972), p. 698.

9) M. Nagayama and M. Cohen, J. Electrochem. Soc., 109, 781 (1962).

10) M. Pourbajx, Atlas of Electrochemical Equilibria in Aqueous Solutions, CEBBELCOR (Pergamon, London, 1966), p. 312.

11) F.U. Bogar and C.T. Fujii, Waval Research Laboratory Report Ho. 7690, RR 022-08-44-5513, 1974.

12) C.L. Foley, J. Kruger, and C.J. Bechtoldt, J. Electrochem. Soc. 114, $994(1967)$.

13) T. Kodama and J.R. Ambrose, liational Bureau of Standards Report in print, Technical Summary Report Ho. 6, 1975.

14) T.R. Beck, "The Occurrence of Salt Films during Initial Stages of Titanium Corrosion", presented at Electrocherrical Society liational Heeting, Dallas, October, 1975.

15) K. Shiobara and S. Morioka, J. Jap. Inst. Met., 36, 3055 (1972).

16). W.P. Iverson, J. Electrochem. Soc., 115, 017 (1968).

17) K. Videm, The Electrochemistry of Uniform Corrosion and Pitting of Aluminum, Icjeller Report 1974.

18) R.T. Foley, "The Role of Chloride Ion in Corrosion - Part II", final report, OilB, Contract N00014-66-C-0025, The American University, Washington, U.C. (1969). 


\section{Crevice Electrode Schematic}
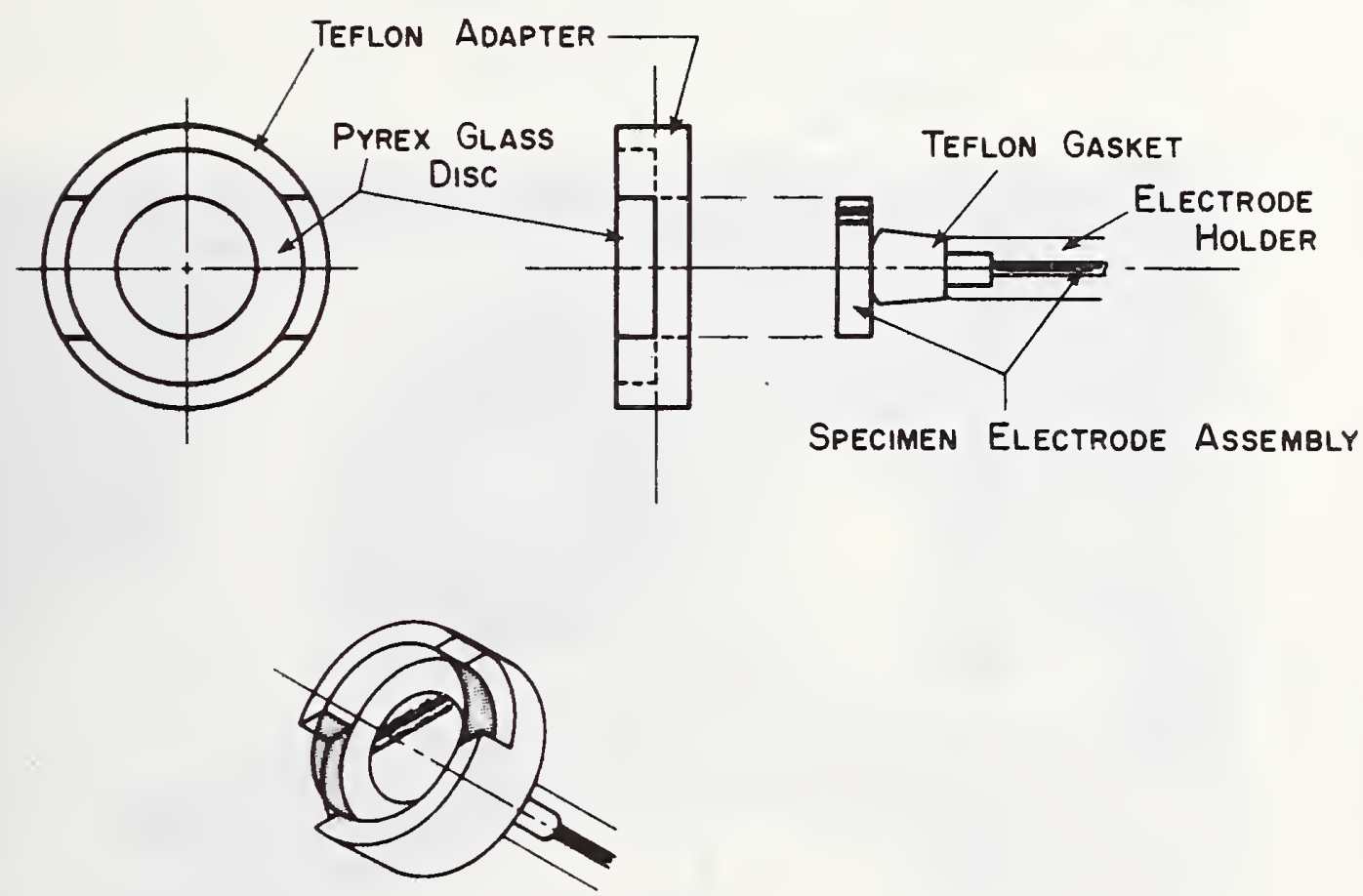

Fig. I Schematic of crevice electrode assembly used in crevice repassivation kinetic studies [from (5)]. 


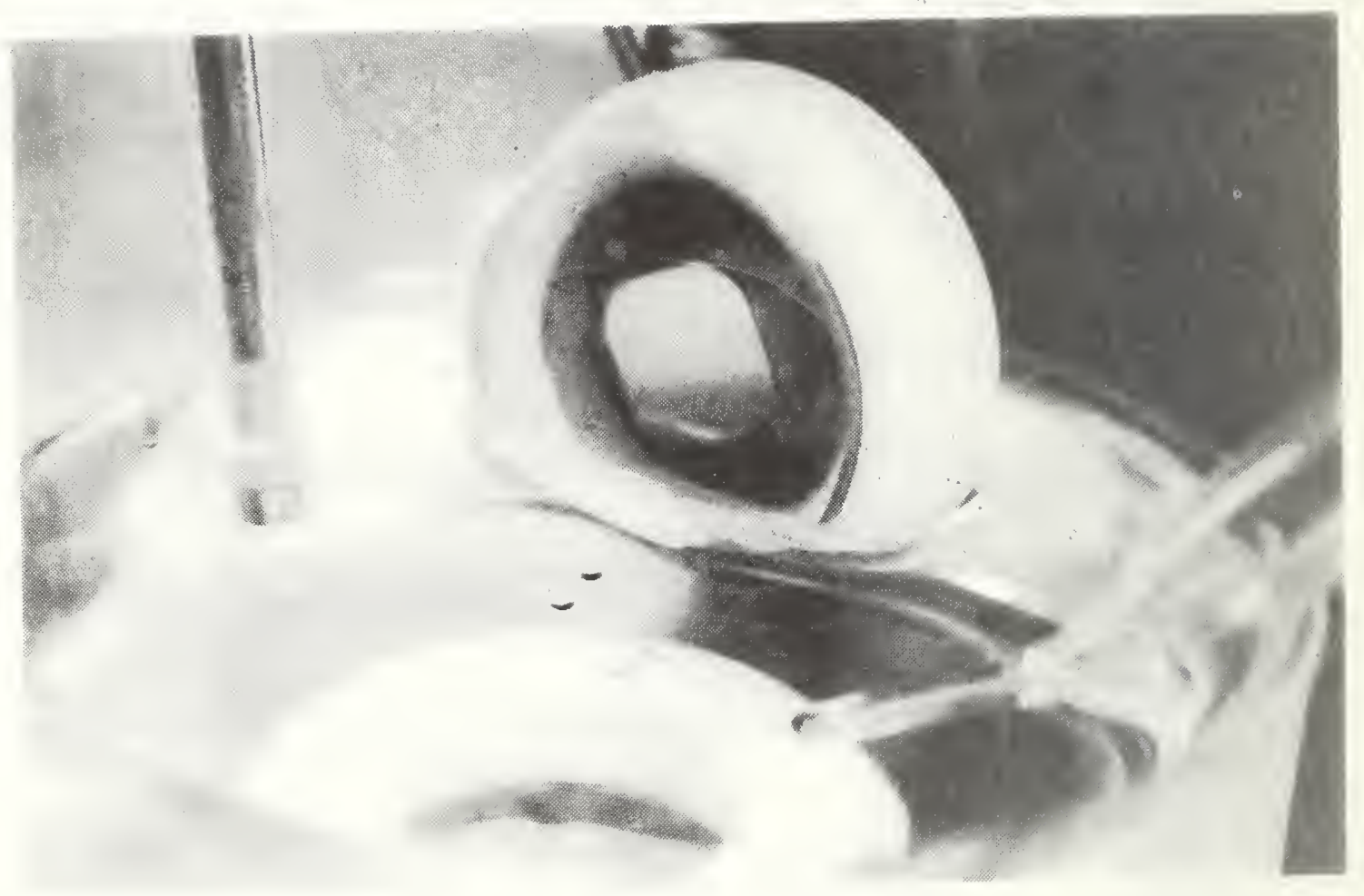

Fig. 2 Photograph of crevice electrode assembly positioned for repassivation measurements. 


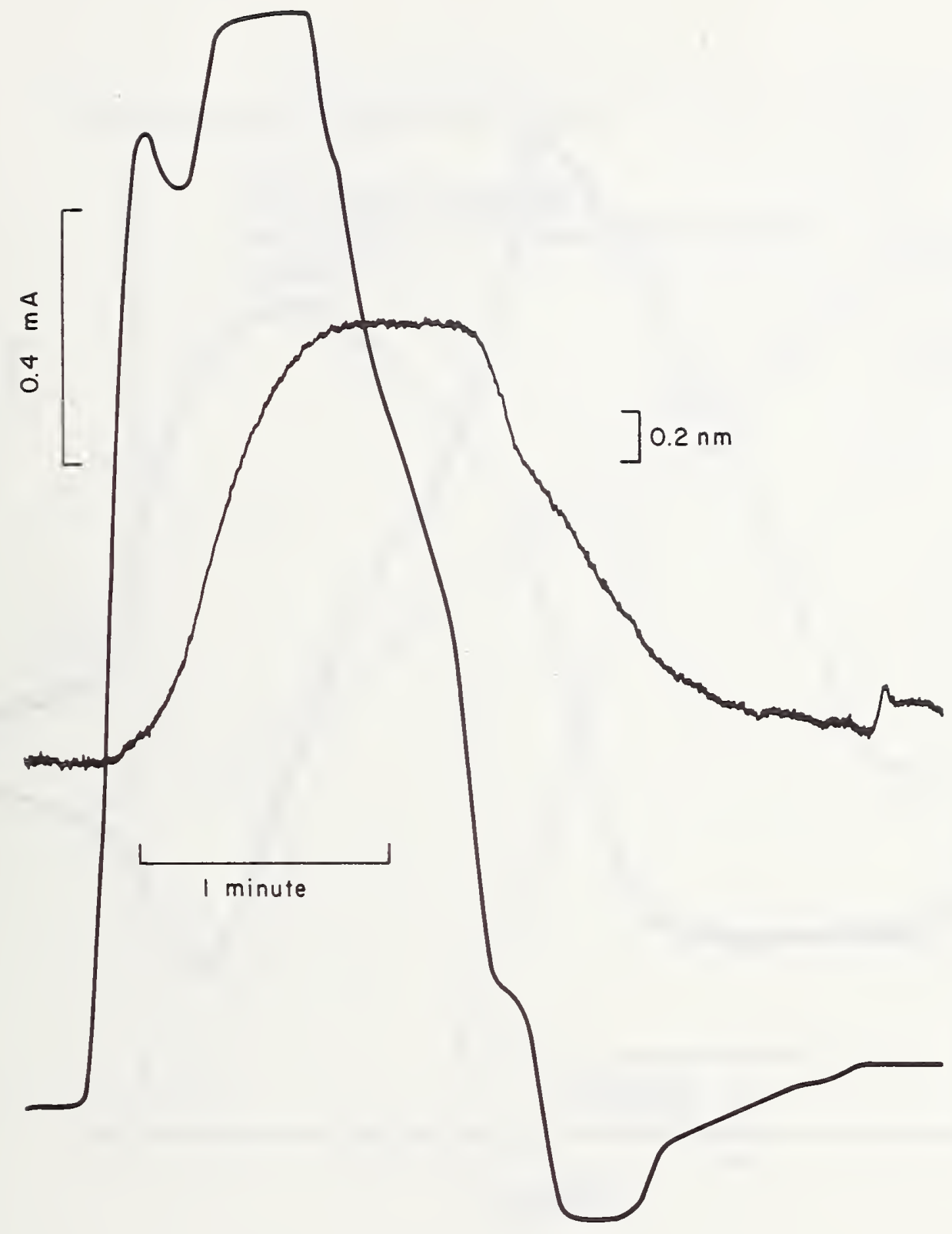

Fig. 3 Film growth and anodic current as measured during a potentiodynamic scan. The experiment was performed using iron exposed to borate buffer solution without a crevice and the potential was driven from $-750 \mathrm{mV}$ SHE to $1242 \mathrm{mV}$ SHE at a scan rate of $1000 \mathrm{mV} / \mathrm{min}$. 


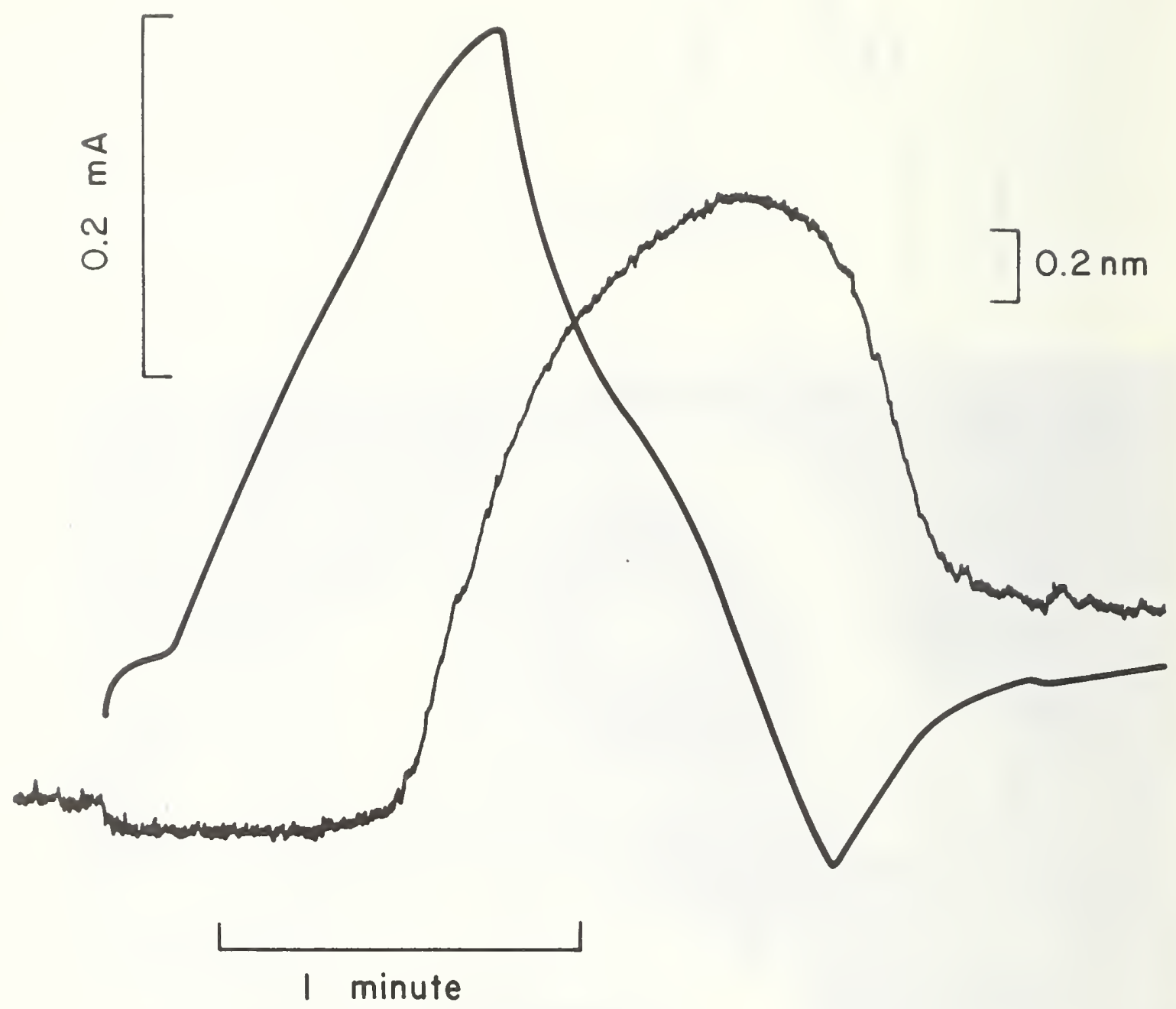

Fig. 4 Film growth and anodic current as measured during a potentiodynamic scan. The experiment was performed using iron exposed to borate buffer solution inside a crevice and the potential was driven from $-758 \mathrm{mV}$ SHit to $1242 \mathrm{mV}$ SHE at a scan rate of $1000 \mathrm{mV} / \mathrm{min}$. 


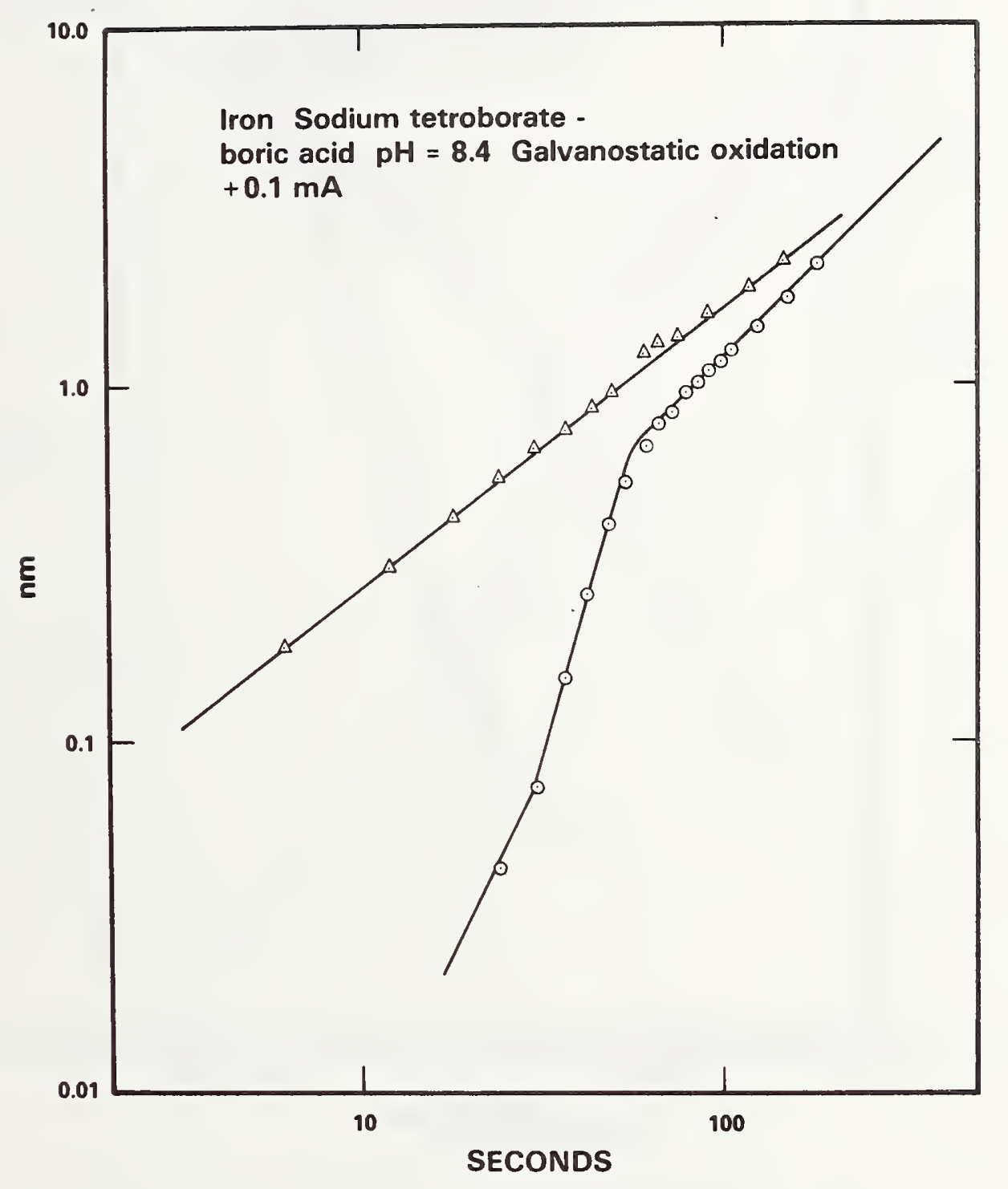

Fig. 5. Galvanostatic oxidation of iron at $100 \mu \mathrm{A}\left(33 \mu \mathrm{A} / \mathrm{cm}^{2}\right)$ from $-758 \mathrm{mV}$ to $+1242 \mathrm{mV}$ SHE both within (circles) and without (triangles) a crevice. Log film growth in $\mathrm{nm}$ is plotted vs. log time in seconds. The solution is the borate buffer $(\mathrm{pH}=8.4)$. 


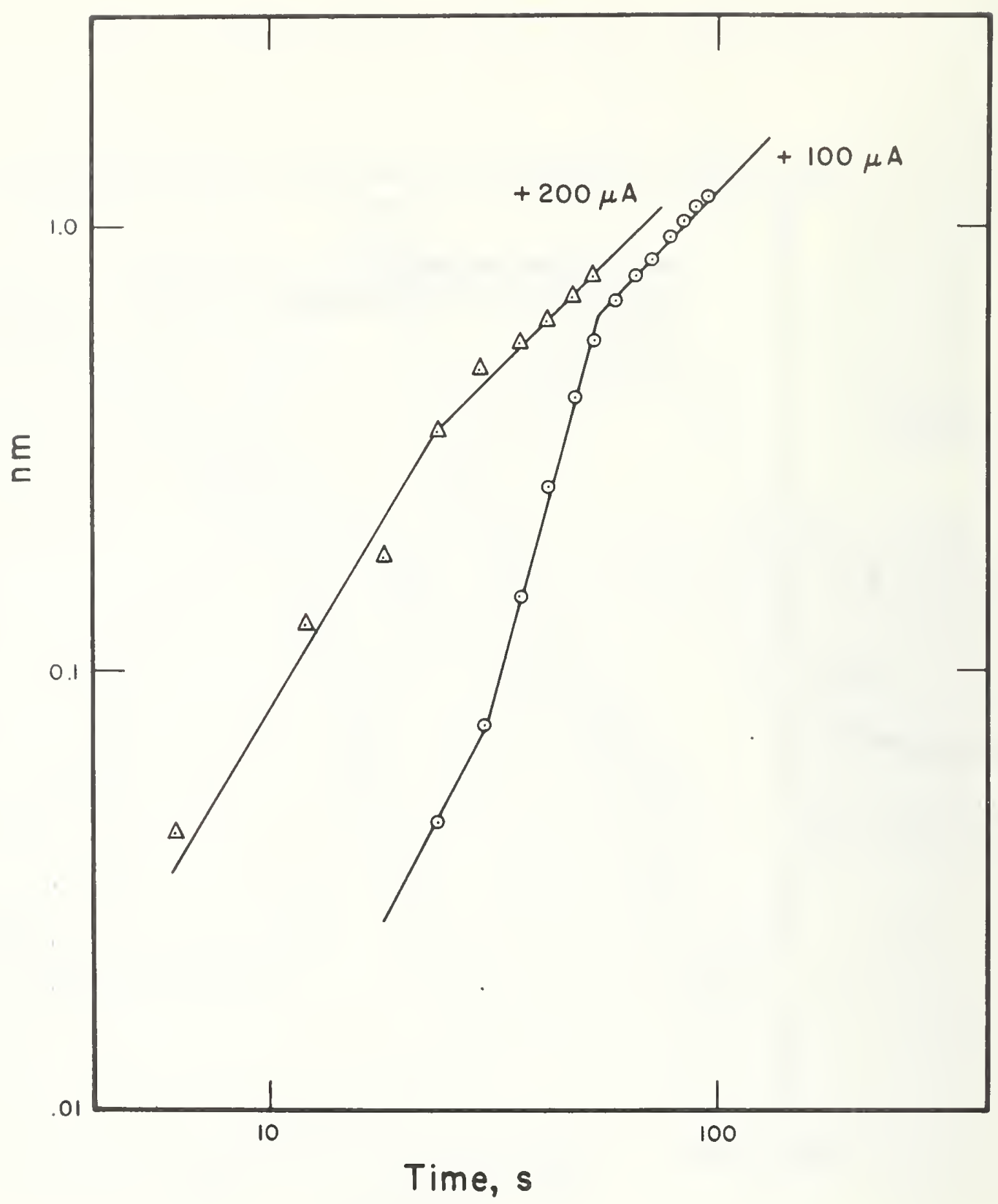

Fig. 6. Galvanostatic oxidation of iron at $100 \mu \mathrm{A}$ and $200 \mu \mathrm{A}\left(33\right.$ and $\left.67 \mu \mathrm{A} / \mathrm{cm}^{2}\right)$ from $-758 \mathrm{mV}$ to $+1242 \mathrm{mV}$ SHE within a crevice. Log film growth in $\mathrm{nm}$ is plotted vs. log time in seconds. The solution is the borate buffer ( $\mathrm{pH}=8.4)$. 


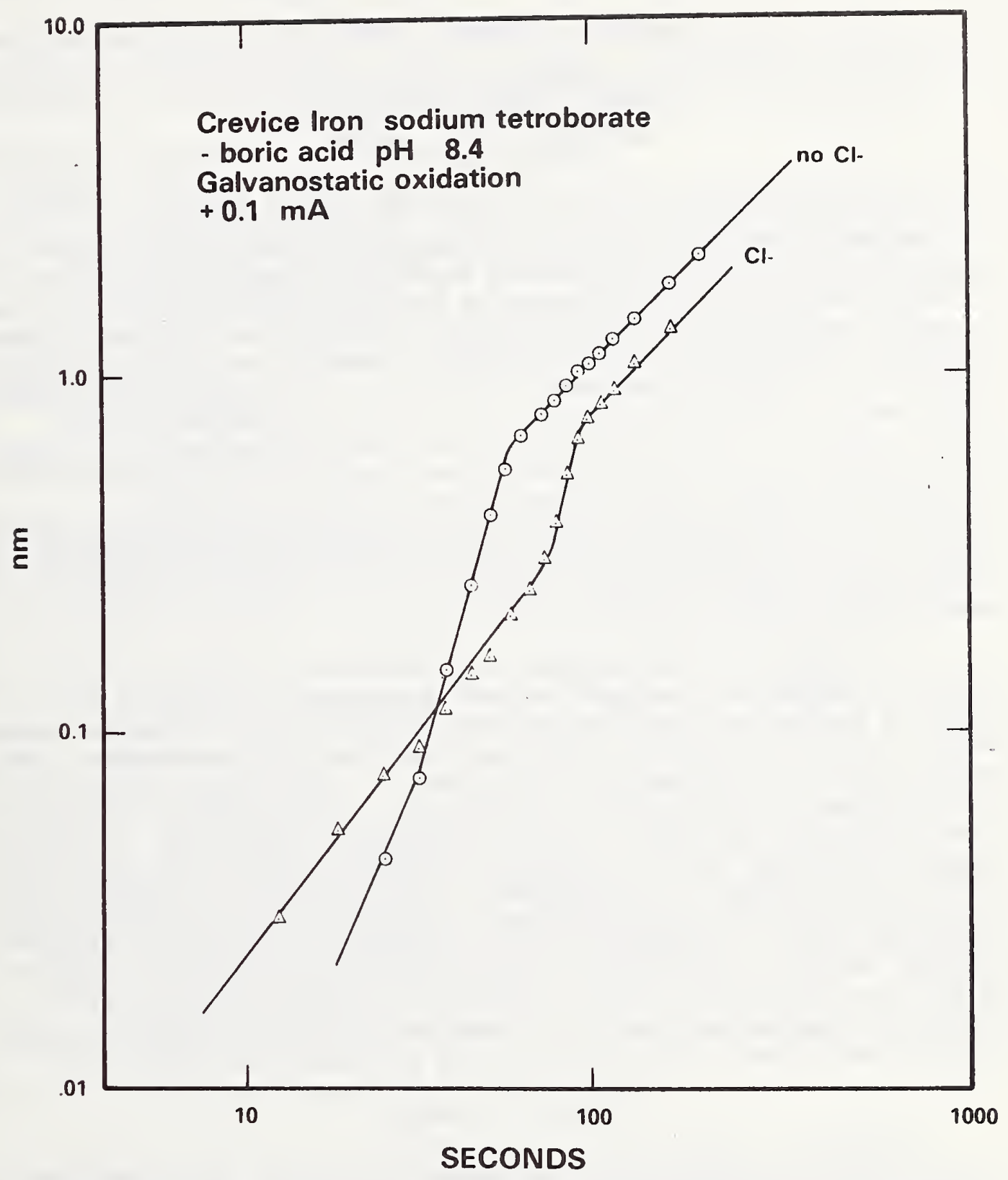

Fig. 7. Galvanostatic oxidation of iron at $100 \mu \mathrm{A}\left(33 \mu \mathrm{A} / \mathrm{cm}^{2}\right)$ from $-758 \mathrm{mV}$ to $+642 \mathrm{mV}$ in a borate buffer $(\mathrm{pH}=8.4)-0.01 \mathrm{~N} \mathrm{NaCl}$ solution with a crevice as compared to galvanostatic oxidation of iron with a crevice but no chloride ions present (Fig. 5.) 
(To appear in the proceedings of the Japanese-American Symposium on

"Passivity and its Breakdown on Iron and Iron Base Alloys" which will be published by N.A.C.E. in January 1976).

\title{
Chemical Breakdown of Passivity
}

\author{
Jerome Kruger \\ National Bureau of Standards \\ Washington, D.C. 20234
}

"By gnawing through a dyke even a rat may drown a nation"-E. Burke

Chemical ureakdown of passivity leads to the various forms of

localized corrosion--pitting, crevice corrosion, intergranular attack. It is, therefore, of crucial importance to be able to understand the processes that produce these most damaging forms of corrosion and thereby develop ways to control them. This brief, personal, and hence opinionated examination of chemical breakdown of passivity will concentrate attention on the passive film and what happens to it so that breakciown results. once breakdown has occurred and localized attack is proceeding, the scope of this discussion will be exceeded. Therefore, the problems associated with crevice attack or those of an actively growing pit such as propagation rates, morphology, potential, and composition distributions in pits will not be considered. There are a number of useful discussions (1-5) of these topics of crucial importance once chemical breakdown of the passive film has occurred.

To further limit the scope of this discussion, a clear definition of chemical breakdown must be spelled out. For the sake of brevity and to focus the discussion, I will define chemical breakdown as those processes brought about by chemical alteration of the film or the environment that produce changes in the passive film so that it can no longer effectively prevent damaging anodic currents from flowing. One way to destroy the effectiveness of the passive film is by mechanical disruption. When this is done by chemical means, as subsequent discussion will consider, it will fall within the scope of the discussion. When mechanical breakdown occurs by the introduction of externally applied stresses, it will be considered purely mechanical breakdown and will be described elsewhere (6). Also, excluded from this discussion are those activation processes that occur when a passivated metal surface potential is brought into the transpassive region or into the active region (below the Flade potential). A discussion of these modes of activation is given by Hoar (7).

\section{THEORETICAL MODELS}

A number of models have been proposed to describe the events leading to passive film breakdown and the subsequent pitting or crevice attack.

Most of these are listed by Hoar $(7,8)$. In order to be successful a model must, of course, explain the phenomenology of breakdown. While perhaps not al1 inclusive and in some cases controversial, the following phenomena are usually considered to be necessary requirements for chemical breakdown to occur:

1) A certain critical potential $E_{c}$ must be exceeded, called by some the critical potential for pitting $(9-10)$.*

*The situation is more complex. Pourbaix (11) has pointed out that there exists a potential $E_{p}$, which he calls the protection potential. This potential more active than $E_{C}$ is the potential below which breakdown once initiated can be stopped. Work by Pessel and Liu (12) indicates that when $E_{C}$ is determined in a way that eliminates the time for breakdown to occur, $E_{c}=E_{p}$. 
2) Damaging species ( $\mathrm{Cl}^{-}$or the higher atomic weight halides) are needed to initiate and propagate breakdown.

3) There exists an induction time separating the initiation of the breakdown processes by the introduction of conditions conducive to breakdown and the completion of the process when pitting or crevice attack commences.

\section{4) Breakdown occurs at highly localized sites.}

The models for breakdown that must satisfy the above requirements can be divided into three groups: 1) adsorbed ion displacement, 2) ion migration or penetration, and 3) chemico-mechanical. As Hoar (8) has pointed out there are common elements in all of the models, and if a true model for breakdown is ever achieved, it probably will contain elements of all three groups. The individual groups will be discussed in terms of how well they satisfy the phenomenological requirements.

\section{1) Adsorbed ion displacement models}

Two mechanisms have been suggested under this general model. First, there is the mechanism suggested by Kolotyrkin (13) and Uhlig $(14,15)$. This model considers the passive film to be an adsorbed film (probably a monolayer) of oxygen. Breakdown occurs when a more strongly adsorbing damaging anion (I will use the chloricie ion which is highly polarizable and hence capable of adsorption) displaces the oxygen forming the passive film. Once the $\mathrm{Cl}^{-}$ion is adsorbed at the surface, breakdown commences. When other anions are present they can compete with the $\mathrm{Cl}^{-}$for sites and inhibit breakdown $(14,15)$. Direct evidence that this occurs has been provided by Rozenfeld and ilaksimchuck (18) using radioactive $\mathrm{Cl}^{-}$. The model explains the critical pitting potential as that potential above which $\mathrm{Cl}^{-}$adsorbs on the surface under consideration. The effectiveness of ions such as $\mathrm{Cl}^{-}$in promoting breakdown is explained by their being more readily adsorbed than oxygen in the competition for surface sites. The effect of damaging ion concentration on induction times can perhaps be explained by this mechanism, but such important influences on induction time as thickness of the passive film (16) and heat treatment of the passive film $(16,17)$ can not be readily accounted for by this model. Finally, this mechanism is consistent with localized attack since adsorbed ion displacement will probably occur at discrete sites, defects, inclusions, etc., where displacement may be more likely.

The second model that can be considered as falling under the general heading of an adsorbed ion displacement model is that described by Hoar and Jacob (8). It has, however, elements in common with the ion migration models also. In this model a small number ( 3 or 4 ) of halide ions jointly adsorb on the surface of the passive film around a lattice cation. The probability of formation of such a high energy complex is small and thus requires a high activation energy for formation. Once formed, however, the halide ions will readily remove the cation from the passive film lattice (this model assumes a three dimensional passive $f i l \mathrm{~m})$. The $f i 1 \mathrm{~m}$ is thus made thinner at the site where the complex first formed and the stronger anodic field at the thinned site will rapidly pull another cation through, where it will meet more halide ions, complex with them and thereby enter the solution. Thus, once started, the passive film is locally thinned and breakdown proceeds, using Hoar's word "explosively". 
This model like the Uhlig one requires a critical potential where adsorption takes place. It also requires strongly adsorbing anions. Because of the difficulty of forming the transitional complex, an induction time is required, and in fact it was developed to explain the dependence of the induction time on $\mathrm{Cl}^{-}$concentration, temperature, and potential. Also, it is consistent with the localized nature of breakdown. This model does not appear to be applicable to all systems because Ambrose and Kruger (17) have shown that incorporation of $\mathrm{Cl}^{-}$in the passive film lattice rather than the formation of a complex on the outside of the film accelerates breakdown for passivated ion. Hoar (19) has also found that the proper functional dependence of induction time with temperature found for stainless steel, which was the basis for his model, does not hold for iron where he proposes a penetration model.

\section{2) Ion migration or penetration models}

The theoretical models that can be grouped under this heading all require the penetration of damaging anions through the passive film, the breakdown process being complete when the anion reaches the metal-film interface. Most of these models consider the passive film to be three dimensional. The models differ widely, however, in the mode of penetration.

At one extreme is a model that is quite old and was suggested by Evans (20) and co-workers. More recently, Richardson and Wood $(21,22)$ have revised the pore mechanism and conclude that breakdown of the passive film does not occur at all because there always exist pores or defects in the film that allow instantaneous penetration and hence instant localized corrosion. One consequence of this is that there is no induction time for the breakdown processes to take place because there are no breakdown processes. Richardson and Wood account for incubation by asserting that during the beginning stages of pitting the currents are so low at the small bare metal sites that it appears the pitting has not been initiated, although it actually has been going on from the instant that the surface was exposed to damaging anions. In this way it satisfies the phenomenological requirement for the existence of an induction period. The other phenomena this model must contain are also satisfied. Thus, since the pores, bare or "weak spots", are discrete sites, attack will be localized. The critical potential is the potential for adsorption at the bare metal at the base of the pores, and the role of the damaging anion is the same, and as mysterious, as it is for the other models.

At the other extreme of the types of penetration models are those models involving migration of the damaging arion through a lattice, via defects, or via some sort of ion exchange process. The processes which involve ion migration in a lattice can occur in a variety of ways. Hoar et al (23) suggest anion entry without exchange to produce "contaminated" passive films. Tre site where this occurs becomes a path of high conductivity where high cation currents and hence the initiation of pitting are possible. Pryor and co-workers $(24,25)$ also propose the production of an anion contaminated film but suggest that cation vacancies are created which lower ionic conductivity and promote breakdown. Another ion migration scheme can involve exchange of $\mathrm{O}^{=}$or $\mathrm{OH}^{-}$with the damaging anion (16). Eq. 1 shows that such a process can 
also create anion vacancies that will further enhance the migration of damaging anions to the film metal interface.

$$
\mathrm{Cl}_{\text {solution }}^{-}+\mathrm{Q}_{0}=+2 \mathrm{OH}^{-} \text {lattice }=\mathrm{Cl}^{-} \text {lattice }+2 \mathrm{O}_{\mathrm{OH}^{-}}+2 \mathrm{OH}^{-} \text {solution }
$$

The anion lattice migration models have no difficulty in satisfying the phenomenology of breakdown. The critical potential is, as with all the models, the potential required for adsorption, although in this case it is on the outer interface of the passive film. The induction time is the time required for the migration of the damaging anion through the passive film, and since this migration may be via discrete defects the localized nature of breakdown would be expected. The special role of certain damaging anions is not accounted for any better than it is by the other models thus far considered.

3) Chemico-mechanical models

This group of theoretical models which involves chemically induced mechanical disruption of the passive film is perhaps the newest. One version was briefly described by Hoar (7). He postulated that the adsorption of a damaging anion on the surface of the passive film lowers the interfacial surface tension (surface free energy) at the solution interface until "peptization" occurs. This "peptization" results from the mutual repulsion of the adsorbed anions. When the repulsive forces are sufficient, the passive film cracks and damaging anions can attack the metal exposed.

Sato (26) has extended this concept of chemical-mechanical breakdown by providing a more detailed examination of the model. He has suggested that high fields could lead to mechanical rupture of thin films by electrostriction pressures exceeding the compressive fracture strengths of the film. The so-called film pressure this generates is given by:

$$
\begin{aligned}
& p-p_{0}=\frac{\varepsilon(\varepsilon-1) E^{2}}{8 \pi}-\frac{\gamma}{L} \\
& \begin{aligned}
\text { where } p & =\text { film pressure } \\
p_{0} & =\text { atmospheric pressure } \\
\varepsilon & =\text { film dielectric constant } \\
E & =\text { electric field } \\
\gamma & =\text { surface tension } \\
L & =\text { film thickness }
\end{aligned}
\end{aligned}
$$

It is possible that those ions considered to be "aggressive" in promoting localized corrosion attack increase film pressure by decreasing the surface tension term in equation [2] through adsorption. Unlike the other theories we have considered, this theory does not consider the critical potential for breakdown to be related primarily to adsorption but instead to be the "critical potential above which the film pressure exceeds the critical compressive stress of film breakdown." (26) Also, this model differs from the other models described in that, although as with the others the special role 
of aggressive anions such as chloride is not clear, this model goes further and would appear to rule out any special role at all. This is so because zero charge potentials are similar on mercury and probably are likewise similar on oxides as well (27). The existence of an induction period is also difficult to explain using the mechanical breakdown model. Finally, the localized nature of attack is consistent with the model if one mode of breakdown involves rupture at discrete sites as Sato does suggest.

Sato points out in his description of his mechanical breakdown theory that whether a pit nucleates or dies depends not only on breakdown but also on film reformation. This concept, the interplay between breakdown and repair, underlies the last model of the chemico-mechanical group to be discussed. Videm (28) has recently proposed that it is the interplay between the breakdown (although he does not specifically say so, this could be mechanical as Sato has suggested) and repassivation that determines whether a passive film will suffer permanent breakdown that leads to pitting. Videm proposes that the critical pitting potential is determined by the relative rates of breakdown and repassivation. Another very recent variation of dynamic breakdown-repair and theory is that of Ambrose and Kruger (29). It differs from $V$ idem in that it supplies more details about the breakdown process. It proposes that breakdown results from penetration by the aggressive anion to the metal-film interface where localized film rupture could be affected by promoting formation there of pockets of non-protective low density material similar to that produced as a corrosion product during active pit growth. As the pockets expand upon continuing formation at the metal-oxide interface, further stress is placed on the film directly atop the pockets, eventually resulting in fracture of the film. In iron, for instance, this low density material was identified as $\gamma-\mathrm{FeOOH}$ (30). The special role of the aggressive anions is that they influence the rate of repassivation. Recent direct measurements of repassivation $(31,32)$ have verified this. The critical potential can influence a number of factors, adsorption of the aggressive anion as in other mechanisms, the rate of repassivation, and the mechanical properties of the film. The mechanism supports the existence of an induction period because penetration of anions, a time dependent step, is involved. Finally, because penetration is part of the model, the attack would be expected to occur at discrete sites.

\section{INITIATION PROCESSES}

It is evident from the discussion of the various theoretical models that even some of the widely different models have elements in common. For example, virtually all of them require the existence of an adsorption step. There is, however, a high probability that no one model is applicable to all systems. Thus, it will be very difficult to match experimental results to models in an orderly way. Instead, my approach will be to select only a few results described in the literature to emphasize contrasting points of view. It is anticipated that by doing so a clearer definition of the problems will be achieved and experimental work will be stimulated to provide new insights.

In conformity with the scope described earlier the discussion of the kinetics of the initiation process will confine itself to the induction period that leads to breakdown and active pitting. The role of potential will then be considered. Finally, a brief discussion of the influence of alloy 
composition, structure and environmental factors as they affect the initiation process will be given.

\section{Kinetics of Initiation--The Induction Period}

The only kinetics that need to be considered in chemical breakdown, as defined earlier, are the kinetics of the processes occurring during the induction or incubation period that takes place prior to the significant increase in current that marks the onset of pitting or crevice attack. A number of conflicting ideas, experiments, and explanations of these experiments exist to explain this induction period. Three representative groups will be described. A representative from the group of experiments such as those of Uhlig $(14,15)$ and Rozenfeld (18) which use the competitive adsorption model for interpretation is not included because no induction periods were reported.

a) Mechano-Chemical Breakdown - A very extensive study of the breakdown on pure $A \overline{1}$ has been made by Videm (28). His main conclusions were as follows:

1) He found, as Bogar and Foley (33) had also shown for an Al alloy,

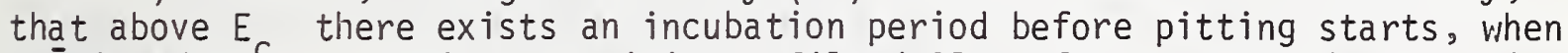
$\mathrm{Cl}^{-}$is added ${ }^{C}$ to solution containing a filmed $\mathrm{Al}$ surface. The induction time decreased exponentially with potential and a ten-fold increase in chloride concentration reduced the time to initiate a pit by a similar factor.

2) Because he could not detect $\mathrm{Cl}^{-}$by autoradiography, except at sites where pitting attack had taken place, and because he could not detect impedance changes after $\mathrm{Cl}^{-}$soaking, he concluded that theories for initiation of pitting of $A]$ requiring contamination of oxide films [see (25)] by gradual chloride pick-up and subsequent change in conductivity are not valid.

3) He was able to measure regular current pulses during anodic polarization which he ascribed to the development of local defects (see Fig. 1). The pulses were found both with and without the presence of $\mathrm{Cl}^{-}$in the experimental solution, but the nature of the pulses changed markedly and abruptly when pitting was initiated at the end of the induction period. This result led Videm to conclude that the Richardson and Woods (21) suggestion that there is no pit initiation step because pitting starts immediately at small flaws in the passive film is invalid.

4) The role of the chloride is not promoting breakdown per se, but in preventing repair during a dynamic breakdown-repair type of mechanism. Similar conclusions were reached for Al by Zahavi and Metzger (34).

These results of Videm's thus point to a non-penetration dynamic breakdown and repair theory. It does not explain, however, how a system predisposed to pit reaches the stage where there is sufficient chloride available at the initiation sites to stop repassivation effectively. For crevice attack where the crevice helps concentrate $\mathrm{C}^{-}$, his results would be understandable.* In the absence of a crevice, however, it is difficult to see

*Wilde's (4) admonition that the kinetics of pitting corrosion and crevice corrosion are different and that one must disentagle the two to assess susceptibility to localized attack is pertinent to this point. 
Why at some definite time prior to pitting the $\mathrm{Cl}^{-}$ions should suddenly start to prevent repassivation unless they concentrate in the film or somehow locally in the environment.

b) Transitional complex formation - An experimental representative of this group is that of Hoar and Jacob (8). Their model has been described earlier. Their experimental data for austenitic stainless steel showed that $1 / \tau$, where $\tau$ is the induction period, was an approximate measure of the rate of breakdown. A plot of $\log \tau$ vs. $\log \mathrm{C}_{\mathrm{Cl}}$ - showed that the breakdown rate is proportional to the $n$-th power of $\mathrm{C}_{1}$ - with $n$ having values between 2.5 and 4.5. They found an activation energy of $60 \mathrm{k} / \mathrm{mole}$ and $\tau$ to be dependent on potential. Their interpretation of the values found for $n$ was that 2.5 to 4.5 halide ions form a "transitional complex" which once formed (because of the high activation energy, a difficult and seldom event) will proceed to break down the film in the way described in the section on models. Because of the high activation energy and the requirement for 2.5 to 4.5 halide ions to form a complex, Hoar and Jacob rule out an ion migration model for stainless steel. However, for other systems their model may not be valid. For example, Engell and Stolica (36) found a value of 1 for $n$ for mild steel, and the induction time potential independent. This could mean a penetration model where individual aggressive anions were penetrating independently of each other. Foster and Hoar (19) and also Ambrose and Kruger (17) propose a penetration model for the passive film on iron. Other values of $n$ have, however, been found. For Al Bogar and Foley (33) found values of $n$ between 4 and 11 while Videm found a value of 2. Obviously, one must be careful in using a simple interpretation such as Hoar's and Jacob's to explain the meaning of $n$.

c) Penetration - All of the penetration models explain in a very direct way the existence of an induction period. This period is the time required for the damaging anion to travel through the passive film. An experiment directed at providing a test of this idea was given by licBee and Kruger (16) who measured the time to breakdown as a function of passive film thickness. As Fig. 2 shows the thicker the passive film, the longer the time to breakdown. Unfortunately as Fig. 2 also silows they were not able to establish a functional relation between thickness and breakdown time, since three functional relationships fitted the data equally well. To further show that penetration is involved in the breakdown of the passive film on iron, Ambrose and Kruger (17) showed that by removing part of the passive film by cathodic reduction and then regrowing the $\mathrm{film}$ in the presence of $\mathrm{Cl}^{-}$one could repassivate, but the time for breakdown was shortened. They interpreted this as evidence for the penetration model because the regrowth step incorporated $\mathrm{Cl}^{-}$ions. These ions therefore had a shorter distance to penetrate, and the time for breakdown was shortened. Finally, Ambrose and Kruger showed that annealing the passive $f i l m$ on iron at $65^{\circ} \mathrm{C}$ for one hour and then bringing the system back to room temperature increased the induction time over 100-fold. Therefore, they reasoned the defects in the film whereby penetration proceeds were removed by the annealing. Similar results for Ta were found by Vermilyea (37), but opposite results were found for stainless steels by okamoto (38)* (annealing shortened the induction time). These

*If the films on stainless steel are amorphous [see (39)], the annealing could have caused crystallization producing more diffusion paths. On the other hand, if the films are crystalline, annealing could destroy diffusion paths by grain growth and destruction of lattice vacancies. 
results plus others $(17,38)$ which show that longer passive film growth times lengthen the induction period, do not rule out the transitional complex model because the production or reduction of defects in the film can also be effected on the film surfaces and thereby affect the adsorption of damaging anions at that surface.

Two main experimental problems exist for the perietration model. First, micro breakdown events $($ see 28,40 ) as indicated by small current or potential pulses (Fig. 1) may continuously exist throughout the inauction period. If so why is penetration needed? There exists contradictory evidence of $\mathrm{Cl}^{-}$entry into the film lattice. Ellipsometric spectroscopy (16), inipedance measurements $(24,41)$, and autoradiography (42) have indicated gradual $\mathrm{Cl}^{-}$entry. Other work, however, using autoradiography (28) and impedance measurements $(28,43)$ show no $\mathrm{Cl}^{-}$up-take by the $f i 1 \mathrm{~m}$.

\section{Critical Potential for Breakdown}

There are vast numbers of experiments and discussions in the literature on the factors or underlying causes of the existence of a critical potential for breakdown, $E$. I will avoid a discussion of its practical significance (see $25,35,11$ ) methods of measurement (see 44,12 ) and I will detail briefly only those ideas or findings that relate to its role in initiation of breakdown. An incomplete listing of different explanations of the origin of $E_{C}$ follows:

a) $E_{c}$ determined by potential of zero charge - Almost all of the models require as their first step the adsorption of damaging anions. Roughly, the potential above which such adsorption takes place is the potential of zero charge ( $p z c)$. Thus, since the adsorbed ion displacement models require the damaging anion to adsorb and thereby displace the ions forming the passive film, such an explanation of $E$ would be reasonable, and the effect of such variables as the nature of the metal, concentration of anions, and temperature all affect $E$ and pzc (see 45,46). The transition complex model also could use the relation of pzC to $E$, not for a bare metal but for the passive film-solution interface. Likewise, for the penetration models, Ambrose and Kruger (17) have suggested the relationship of pZC to $E_{\text {. Because it is }}$ difficult to measure the pzc for solid electrodes (45) especially when adsorption may coincide with the initiation of breakdown processes, there have been no good experiniental verifications that $E_{c}$ is related to the pzc. Galvele (47) has pointed out that $E_{\text {and }}$ pzc may be related if $E_{C}$ is the potential to initiate pitting, but they are not related if $E_{C}$ is $C$ the potential to maintain pitting.

A major problem with relating pzc to $E$ is that the pzc for many anions, both aggressive and non-aggressive alike, are similar on mercury and probably are similar on oxides as well (27).

b) Ec determined by film pressure to fracture film - Sato (26) has identified $E$ with the critical potential above which the film pressure exceeds the Eritical compressive stress of film mechanical breakdown. The film pressure, $p$, resulting from both electrostriction and interfacial effects 
is given in Eq. [2]. Using the above assumption Sato has been at le to derive the relationship between the $E_{C}$ and the concentration of anions in solution as follows:

$$
\frac{\mathrm{dE}_{\mathrm{C}}}{\mathrm{d} \ln \mathrm{a}_{\text {HA }}}=\frac{8 \pi \mathrm{kT \Gamma} \Gamma_{\mathrm{A}^{-}}}{\varepsilon(\varepsilon+7) \mathrm{E}}
$$

where $a_{\text {iMA }}$ is the activity of the salt $M_{A}, \Gamma_{A}{ }^{-}$is the adsorption density of $A^{-}, k$ is the Boltzman constant, $T$ the temperature, $E$ the electric field strength, and $\varepsilon$ the firm dielectric constant.

He was able to calculate from [3] using the results of Leckie and Uhiig (15) for co-existing anions that the density of adsorption of the aggressive $\mathrm{Cl}$ ion on passive stainless steel is of the same order as that for the inhibitive $\mathrm{OH}^{-}, \mathrm{NO}_{3}^{-}$, and $\mathrm{SO}_{4}{ }^{-}$ions. One problem with the relation of $\mathrm{E}_{\mathrm{f}}$ to $\mathrm{film}$ pressure is that the special role of aggressive anions such as $\varepsilon_{7}$ is uncertain because they have about the same polarizability as oxygen ions and only slight changes in dielectric strength (a few percent) might occur if they were to replace the oxygen ions. This would be particularly true at the low concentrations of $\mathrm{Cl}^{-}$to be expected in passive films undergoing breakdown (48).

c) $E_{c}$ is determined by repassivation kinetics - This concept of $E$ is based on kinetic considerations. Some studies $(28,29,34,38)$ have found that a competition between repassivation and breakdown of films on $A 7$ is important in determining initiation of final breakdown. Videm (28) proposed that the value of $E$ is determined by the relative rates of these two processes. He based this ${ }^{C}$ on his experiments that showed a narrow potential region where repair and breakdown were competitive. Below this region, repair predominated and above $i t$, breakdown was the major process. Because potential can affect repassivation kinetics $(31,32$ ) (see Fig. 3) and because, as Videm and others $(47,34,38,29,49)$ suggest, initiation of localized attack depends on a dynamic balance between breakdown and repair, the kinetic control of $E$ must definitely be considered. More quantitative details are still ${ }^{\mathrm{c}}$ lacking, hovever, and the problem remains of finding a way to concentrate damaging anions before final breakdown occurs when no crevice or "occluded ce11" situation exists.

d) $E_{c}$ is determined by the potential of formation of an unprotective

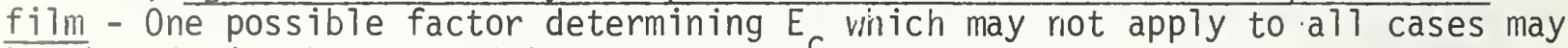
be that it is the potential above which an unprotective film may form or deposit. Ambrose and Kruger (17) suggest that this may be the case for iron. They found that the $\mathrm{E}$ they measured in $\mathrm{pH} 8.4$ borate solutions containing $\mathrm{Cl}^{-}$ was botin equal to tine ${ }^{C}$ pzc for iron found by Lorenz and Fischer (50) and the equilibrium potential for the reaction that produces in a series of steps the non-protective $\gamma$-FeOOH (57). It was proposed that $\gamma$-FeOOH was formed after penetration by $\mathrm{Cl}^{-}$had produced an ion conductive path for $\mathrm{Fe}^{2+}$ which would produce the non-protective $\gamma-\mathrm{FeOOH}$ above $\mathrm{E}_{\text {. The }}$. The played by $\mathrm{E}_{\text {in }}$ in producing a non-protective film in the presence of $\mathrm{Cl}^{-}$is shown dramatically in Fig. 4. Whether this sort of explanation of $E_{C}$ can apply to a large variety of situations remains to be shown. 
It is not possible within a limited space to discuss the many complex and contradictory results concerned with the effect of alloy composition and structure and environmental factors that influence breakdown initiation processes. Two excellent reviews have been given by Smialowska $(1,2)$. Instead, I will describe briefly how some of these factors relate to the theoretical models for breakdown.

\section{1) Alloy composition}

Kolotyrkin (3) points out in his review of pitting that the tendency to breakdown decreases with an increase in the content of $\mathrm{N}, \mathrm{Ni}, \mathrm{Cr}$, and Mo, especially for the latter two. The main effect of these beneficial alloying elements is to shift $E_{\text {in }}$ in noble direction. This explains phenomenologically why they are beneficial but does not actually tell us how they work. One way in which they can retard initiation processes is by producing a passive film that is more difficult to penetrate because it provides fewer diffusion paths. Hoar (51) has suggested that some of these beneficial alloying elements can do this by producing amorphous (glassy) films. McBee and Kruger (39) have found experimental evidence for this when $\mathrm{Cr}$ is added to $\mathrm{Fe}$ and also have found reduced rates of penetration (52). Another way, however, in which these alloying elements can affect breakdown is by affecting repassivation kinetics. Thus, Mo which has not been found in the films on alloys containing it (53), is known to be beneficial in retarding breakdown. Heasurements by Ambrose and Kruger (29) indicate that its addition to an alloy does, however, increase the rate of repassivation, perhaps by its entrance into the environment.

\section{2) Alloy structure}

Only the surface structure of alloys will be considered here. Three kinds of possible variations in surface structure have been studied. First, Kruger has looked at the role of crystallographic orientation on breakdown tendency for iron (54.) As Fig. 5 show's, the tendency to pit goes up as the surface approaches the $\{110\}$ orientation. He also found that pitting density varied with crystallographic orientation (55). Another example is the single crystal work by Smialowska and colleagues $(56,57)$ on $\mathrm{Fe}-16 \mathrm{Cr}$. They found that nucleation occurred at crystal subboundaries as well as at other sites where there were not necessarily any metal inhomogenieties.

The second surface variation can occur by the introduction of defects by abrasion, cold work or other deformation processes. Contradictory results have been found. Thus, Rozenfeld (58) found that removing cold work by annealing an $18 \mathrm{Cr}-9 \mathrm{Ni}-\mathrm{Ti}$ steel increased the number of pits while Randak and Trautes (59) found that cold work increased the number of breakdown sites for an $18 \mathrm{Cr}-8 \mathrm{Ni}$ steel.

Finally, surface heterogenieties play a big role in initiating breakdown. Smialowska and co-workers $(57,60,61)$ have found extensive evidence for the nucleation of pits at inclusions such as sulfides or 
chromium oxide for a number of alloys. Bond and co-workers (62) showed that very small amounts of segregated metallic impurities in quite pure aluminum single crystals could produce breakdown nucleation sites.

The obvious, but sometimes contradictory, effect of surface structure or breakdown can be explained by all the theoretical models discussed because it is reasonable to expect adsorption, penetration, complex formation, or repassivation kinetics to be affected by surface heterogenieties.

\section{3) Environmental factors}

These factors can include solution composition (including $\mathrm{pH}$ ) and temperature. There are large numbers of experiments in the literature (see 1,3) and the results are contradictory. Generally, however, breakdown tendency increases with temperature and concentration of damaging anions while it is not strongly dependent on ph (63). The nature of the anions in solution play a large role (15) especially if competitive anion adsorption situations are possible. There is some controversy as to what consitutes a damaging anion. Thus, Hoar (7) considers the $\mathrm{C} 10^{-}$ion as damaging as $\mathrm{Cl}^{-}$whereas $\mathrm{Uhl}$ ig has found it to be inhibitory $(15,48)$. With regard to models, again all models will depend on environmental considerations. A detailed examination of how all the various and contradictory results in the literature best fit the various models is outside the scope of this discussion.

\section{CRITICAL QUESTIONS}

Based on the foregoing discussion the following non-inclusive list of critical questions can be posed:

1) What makes a damaging anion damaging?

2) What happens when a damaging anion reaches an expoded metal surface?

3) Are the values obtained for induction times consistent with any of the penetration models?

4) How does the damaging anion concentration build up during the breakdown of uncovered (non-creviced) surfaces before corrosion products form?

5) Is the pzc always related to $E_{c}$ ?

6) Does the effect of alloying on breakdown show itself by altering the nature of the film, the environment, or the exposed metal surface?

7) What is the role of repassivation in breakdown?

8) Are significant changes in film pressure affected by damaging anions? 
9) Are the pulses observed for some passive surfaces related to breakdown and repassivation events?

\section{ACKNOWLEDGEMENT}

I am grateful to the Office of Naval Research, which supported this work under contract NAONR 18-89 NRO 36-082. I a7so wish to acknowledge many stimulating and helpful discussions with Dr. John R. Ambrose, whose work has served as a basis for many of the ideas presented here. 


\section{REFERENCES}

1) Z. Szk1arska-Smialowska, Corrosion, 27, 223 (1971).

2) Z. Sklarska-Smialowska, "Localized Corrosion," Staehle, Brown, Kruger, and Agrawal, Editors, National Ass. Corr. Eng., Houston, p. $312(1974)$.

3) Ya.M. Kolotyrkin, Corrosion, 19, 261 (1963).

4) P. Forchhammer and H. J. Enge11, Waksoff U. Korr., 20, 1 (1969).

5) W. Schwenk, Corrosion, 20, 1291 (1964).

6) R. W. Staehle - Paper on mechanical breakdown presented at JapaneseAmerican Conference on Passivity, Honolulu (1975).

7) T. P. Hoar, Corrosion Science, $\underline{7}, 355$ (1967).

8) T. P. Hoar and W. R. Jacob, Nature, 216, 1299 (1967).

9) M. Pourbaix, L. Kleinzack-Mathieu Cl. Mertens, J. Meunier, Cl. Vanlengenhaghe, L. de Munck, L. Laureys, L. N. Nellmans, and M. Warzu, Corrosion Science, $\underline{3}, 239$ (1963).

10) H. Kaesche, Z. physik Chem., N.F., 34, 87 (1962).

11) M. Pourbaix, Ref. 2, p. 12.

12) N. Pessal1 and C. Liu, Electrochemica Acta, 16, 1987 (1971).

13) Ya.M. Kolotyrkin, J. Electrocliem. Soc., 108, 209 (1961).

14) H. Bohni and H. H. Uhiig, J. Electrochem. Soc., 116, 906 (1969).

15) H. P.'Leckie and H. H. Uhlig, J. Electrochem. Soc., 113, 1262 (1966).

16) C. L. McBee and J. Kruger, Ref. 2, p. 252.

17) J. R. Ambrose and J. Kruger, Proc. 4th Int. Cong. on Metallic Corrosion, NACE, Houston, p. 698 (1972).

18) I. L. Rozenfeld and V. K. Maksimchuk, Z. Physik Chem., 215, 25 (1960).

19) T. P. Hoar and D. J. Foster, quoted in Ref. 2, p. 114.

20) V. R. Evans, L. C. Bannister and S. C. Britton, Proc. Roy. Soc., A131, 367 (1931).

21) J. A. Richardson and G. C. Wood, J. Electrochem. Soc., 120, 193 (1973). 
22) J. A. Richardson and G. C. Wood, Corrosion Science, 10, 313 (1970).

23) T. P. Hoar, D. C. Mears, and G. P. Rothwe11, Corrosion Science, 5, 279 (1965).

24) M. A. Heine, D. S. Keir, and M. S. Pryor, J. Electrochem. Soc., 112, 29 (1965).

25) M. J. Pryor, Ref. 2, p. 2.

26) N. Sato, Electrochemica Acta, 19, 1683 (1971).

27) P. Delahay, "Double Layer and Electrode Kinetics," Interscience, New York, p. 23 (1965).

28) K. Videm, Kjeller Report KR-149, Institutt for Atomenergi, Kjeller Norway (1974).

29) J. Kruger and J. R. Ambrose, NBS Report NESIR 74-583, September (1974).

30) C. L. Foley, J. Kruger, and C. J. Bechtoldt, J. Electrochem. Soc., 114, $994(1967)$.

31) J. R. Ambrose and J. Kruger, Proc. 5th Int. Cong. on Metal1ic Corr., NACE, Houston, p. 406.

32) J. R. Ambrose and J. Kruger, J. Electrochem. Soc., 121, 599 (1974).

33) F. D. Bogar and R. T. Foley, J. Electrochem. Soc., 119, 462 (1962).

34) J. Zahavi and M. Metzger, Ref. 2 p. 547.

35) B. E. Wi 1 de, Ref. 2, p. 342.

36) H. Engell and N. Stolica, Z. Physik Chem., N.F., 20, 113 (1959).

37) D. A. Vermilyea, J. Electrochem. Soc., 104, 485 (1957).

38) G. Okamoto, Corrosion Science, 13, 471 (1973).

39) C. L. Mckee and J. Kruger, Electrochemica Acta, 17, 1337 (1972).

40) W. P. Iverson, J. Electrochem. Soc., 115, 617 (1968).

41) M. J. Pryor, Corrosion Science, 10, 313 (1970).

42) B. Verkerk, Proc. UNESCO Int. Conf. on Radioisotopes in Scientific Research UNESCO/BS/RIC44.

43) G. C. Wood, Ref. 2, p.10.

44) S. Smialowska and M. Czachor, Ref. 2, p. 353.

45) J. O'M. Bockris and A. K. N. Reddy, "Modern Electrochemistry," Vo1.2, P1 enum Press, New York, p. 706 (1970). 
46) S. D. Argade and E. Gileadi in "Electrosorption," E. Gileadi, Ed., Plenum Press, New York, p. 87 (1967).

47) J. R. Galvele, S. M. de Micheli, I. L. Muller, S. B. de Wexler, and I. L. Alanis, Ref. 2, p. 580.

48) H. S. Parker and C. A. Harding, J. American Ceramic Soc., 53, 583 (1970).

49) K. J. Vetter and H. H. Strehlow, Ref. 2, p. 240.

50) W. J. Lorenz and H. Fischer, Electrochemica Acta, 11, 1597 (1966).

51) T. P. Hoar, J. Electrochem. Soc., 117, 17C (1970).

52) C. L. McBee and J. Kruger, work presented at Japanese-American Conf. on Passivity, Honolulu (1971).

53) J. B. Lumsden and R. W. Staehle, Scripta. Meta11., $\underline{6}, 1205$ (1972).

54) J. Kruger, J. Electrochem. Soc., 106, 736 (1959).

55) J. Kruger, J. Electrochem. Soc., 110, 654 (1963).

56) M. Janik-Czachor and Z. Szklarska-Smialowska, Corrosion Science, $\underline{8}, 215$ (1968).

57) A. Szummer, Z. Szklarska-Smialowska, and M. Janik-Czachor, Corrosion Science, $\underline{8}, 827(1968)$.

58) I. L. Rozenfeld, Korrzija i Zachita Metallov, Lokanyje konosionnyje, Izd. Metallurgia (1970).

59) A. Randak and F. W. Trautes Werkstoff word. Korr., 21, 97 (1970).

60) Z. Szlarska-Smialowska, A. Szummer, and M. Janik-Czachor, But. Corr. J., $\underline{5}, 159(1970)$.

61) M. Smialowski, Z. Szklorska-Smialowska, M. Rydicik, and A. Szummer, Corrosion Science, $\underline{9}, 123$ (1969).

62) A. P. Bond, G. F. Bolling, and H. A. Domian, J. Electrochem. Soc., 113, 773 (1966).

63) W. Schwenk, Werstoff U. Korr., 19, 791 (1968). 


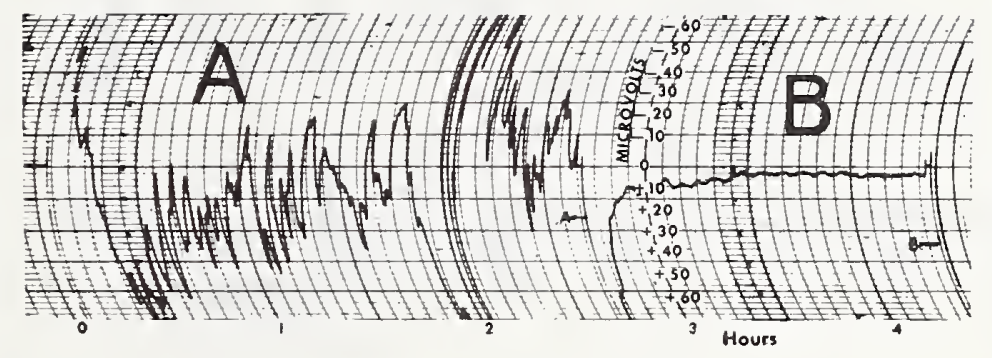

Fig. 1. Periodic potential fluctuations on A--a mild steel surface in $0.1 \% \mathrm{NaCl}$ solution and $\mathrm{B}--$ after $1 \% \mathrm{NaNO}_{2}$ has been added to the $\mathrm{NaCl}$ solution. Note how the inhibitor $\mathrm{NaNO}_{2}$ reduces the pulse intensity. From Iverson (40). 


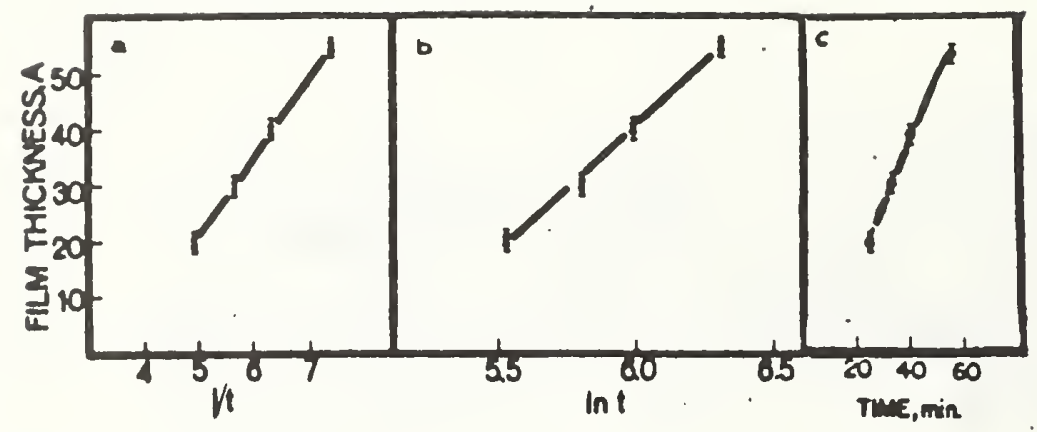

Fig. 2. Plots of time to breakdown as a function of film thickness for iron in decreated 8.4 buffered borate solution containing

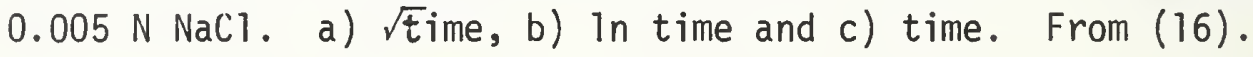




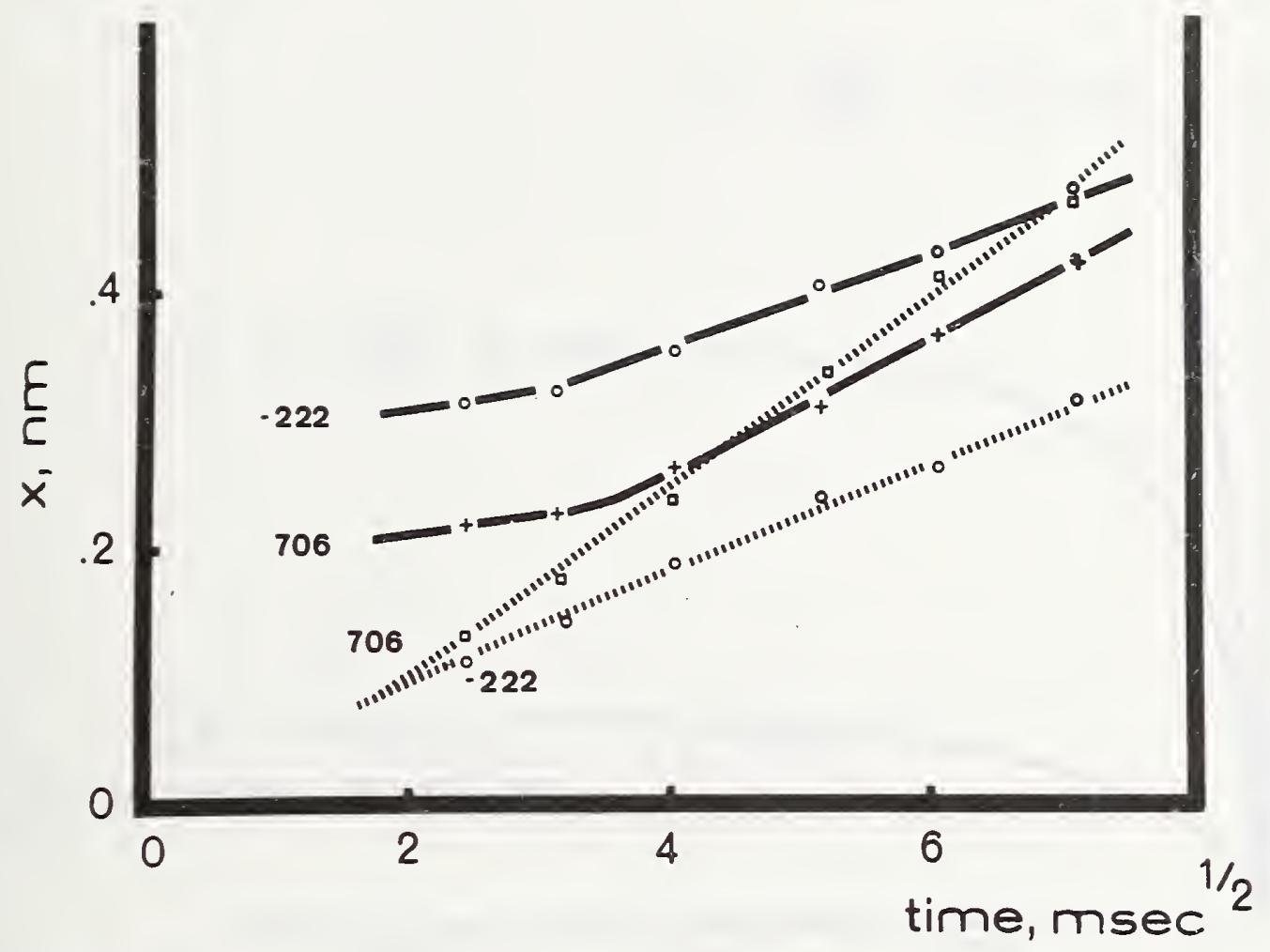

Fig. 3. Effect of potential repassivation rate as shown by changes in film thickness, $x$, for $\mathrm{Ti}^{2}$ alloy in $1 \mathrm{~N} \mathrm{NaNO}$ (dashed line) and in $1 \mathrm{~N} \mathrm{NaCl}$ (dotted line) at -222 and $+706 \mathrm{mV}$ (SHE) at $25^{\circ} \mathrm{C}$. From (32). 


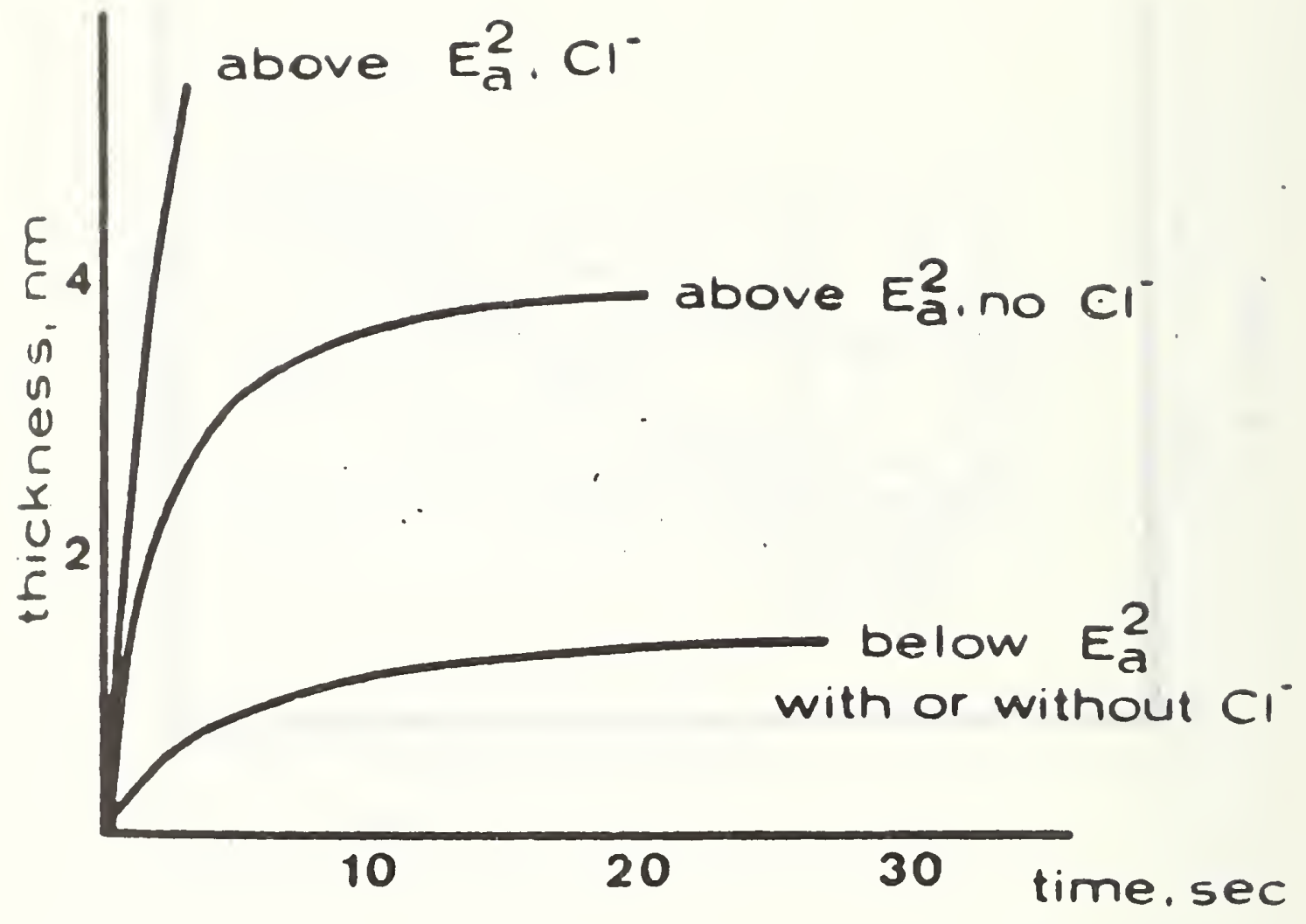

Fig. 4. The effect of potential on film growth in the absence and presence of chloride ion $\left(10^{-2} \mathrm{M}\right)$ in boric acid-sodium tetraborate buffer solution $(\mathrm{pH}=8.4)$. Potentials were above $E_{a}^{2}(a t-0.11 \mathrm{~V})$. Film thickness was measured by ellipsometry. $E_{a}^{2}$ is as defined as $E_{c}$ in the text. From (17). 


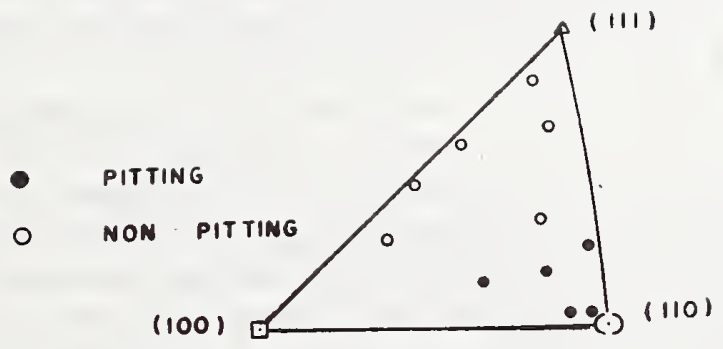

Fig. 5. Stereographic triangle showing the effect of orientation of iron grains on tendency of pit. From (54). 
(To be published by Surface Science as proceedings of the 3rd International Conference on E1lipsometry)

\author{
Qualitative Use of Ellipsometry \\ to Study Localized Corrosion Processes \\ J. Kruger and J. R. Ambrose \\ Institute for Materials Research \\ National Bureau of Standards \\ Washington, D. C. 20234
}

Localized corrosion processes (see [1] for a detailed description) such as pitting, intergranular corrosion, crevice corrosion, and stress corrosion involve many aspects that are not amenable to a quantitative study by ellipsometry. For example, a protective film undergoing the breakdown that leads to pitting probably involves such complications as a continually varying refractive index, the possibility of a changing medium, and the formation of other films on top of the original film present at the inception of pitting. Quantitative characterization of the thicknesses and complex refractive indices of all the films involved is questionable under the best of circumstances, but within the current state of the art is out of the question for localized corrosion processes. This paper will describe certain qualitative uses of ellipsometry that can, however, provide valuable insights into localized corrosion processes.

By qualitative ellipsometry we mean the use of the ellipsometer in such a way that we do not determine the optical constants of the film on the surfaces studied nor do we attempt to determine film thickness with any accuracy, but we do use rough estimates of film thickness. Instead, changes in $\Delta$ and $\psi$ can be used in the following ways:

1) To measure the time during the course of a process when significant changes occur as indicated by abrupt changes in $\Delta$ and $\psi$ and to correlate the $\Delta, \psi$ changes with others, e.g., electrochemical ones.

2) To observe variations of $\Delta$ and $\psi$ as a function of wavelength under different environmental conditions in order to detect regions of the spectrum where special effects are observed.

3) To determine what rate laws are operative by measuring variations of thickness (for thin $(<5 \mathrm{~nm})$ films, as sumed proportional to $\Delta$ ) with time.

We will describe the application of some of these "qualitative" uses of ellipsometry to the study of a) the initiation of pitting, b) the initiation of crevice corrosion, and c) repassivation kinetics as applied to stress corrosion. 
The process of pit initiation involves a change in the protective ability of a passive film on a metal surface at discrete sites so that extensive metal dissolution occurs. Such a description does not assume any of the many proposed mechanisms for pit initiation [2] at these sites. Once metal dissolution begins the initiation process is over and the pit propagation stage is underway with its usually accompanying deposition of non-protective corrosion products on top of the growing pit. Ellipsometry is especially applicable to the initiation stage where subtle changes in the protective film can be observed upon introduction of the damaging species (usually chloride ions) that cause $f i l m$ breakdown. During pit propagation, the usually accompanying surface roughening and corrosion product deposition makes the application of ellipsometry more difficult.

We will describe three ways in which ellipsometry can be applied qualitatively to pit initiation, 1) to make induction time measurements, 2) to observe changes in the passive film during the induction time, and 3) to study the effects of potential. All of these studies used to illustrate the application of qualitative ellipsometry to pitting are concerned with the pitting of passivated iron surfaces by chloride ions.

Induction time measurements

These studies were originaliy described in a paper by Ambrose and Kruger [3] where more complete experimental details are given. In brief, the experimental procedure involved potentiostatically polarizing pure iron surfaces in sodium borate-boric acid solutions at potentials that promoted the formation of a passive film. When the thickness of the passive film was no longer changing (for all practical purposes), measured amounts of solutions of chloride ions were added to the solution already in the experimental cell. The onset of pitting was then observed both by ellipsometric and current density measurements. Fig. 1 shows the effect of chloride ion concentration on induction time, defined as the time required before pitting is initiated by passive film breakdown at discrete sites. The initiation of pitting is signalled both optically and electrochemically but at two different times $t$ and $t_{2}$. The first indication of breakdown at $t_{1}$ is signalled by an increase in current which corresponds to a rapid increase in the rate of metal dissolution. The second indication at $t_{2}$ involves a rapid change in $\Delta$ (a decrease) and probably corresponds to the formation of a corrosion product film at the breakdown site. This is suggested by the fact that if sufficient time is allowed one can observe the deposited corrosion products visually without the aid of the ellipsometer. The electrochemically measured induction time $t_{1}$ is dependent on a number of factors such as concentration (see Fig. 1), temperature of initial passive film formation, time allowed for passive film growth prior to $\mathrm{Cl}^{-}$introduction and others, but $t_{2}-t_{1}$ was found to be approximately constant (around $1 \mathrm{~min}$.) It indicates that such deposition is not coincidental with breakdown.

These qualitative ellipsometric studies carried out at one wavelength, $546.1 \mathrm{~nm}$, provided the following data that are useful in developing an understanding of the localized corrosion processes of pitting: 
a) No detectible optical changes due to thinning or refractive index variations (when using $\lambda=546.1 \mathrm{~nm}$ ) occur in the passive film prior to the initiation of pitting.

b) Pit initiation is not simultaneous with corrosion product deposition but requires its own induction period of around $1 \mathrm{~min}$.

The implications of these useful results revealed by qualitative ellipsometry on the mechanism of pitting are given elsewhere [4].

Changes in the passive film leading to pitting

Probing more deeply into the just described work by Ambrose and Kruger, McBee and Kruger [5] sought to determine whether optical changes could be detected during the time before breakdown (the induction time) if el1ipsometric measurements were made using a light source that permitted measurements at a number of wavelengths in the visible region of the spectrum. They found for the same system as that of Ambrose and Kruger that for a few wavelengths, changes in $\Delta$ and $\psi$ (more markedly in $\Delta$ ) could be detected during the induction period. Fig. 2 shows that some of these changes in $\Delta$ were significantly outside the range of experimental errors.

Since changes in $\Delta$ and $\psi$ occur during the induction period at a few wavelengths, it is possible to follow these changes as a function of time by working at any one of these wavelengths. Fig. 3 shows that, indeed, continuous variations in $\Delta$ and $\psi$ occur during the induction period until pitting is initiated (at the cross hatched area in Fig. 3). Unambiguous determination of the optical constants for the passive film, and the changes in these constants with the addition of the chloride, were not made for reasons given elsewhere [6]. However, calculations were made which show that the changes in the film brought about by the chloride addition can alter the refractive index, $n$, and the absorption coefficient, $k$, at the affected wavelengths, while producing no changes at the other wavelengths studied.

Fig. 3 also shows other valuable details about the events occurring in connection with the induction period. First, it shows that if chloride is removed from the environment the passive film will eventually recover its original $\Delta$ and $\psi$ values. Second, the time to breakdown and the time to recover depend strongly on the thickness of the passive film originally exposed to the chloride. Finally, the extent of the optical change,

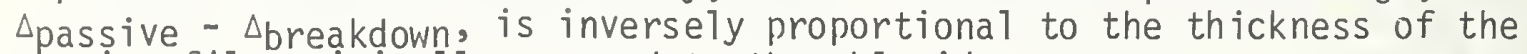
passive film originally exposed to the chloride.

Thus, these results illustrate how, by just following $\Delta$ and $\psi$ changes without attempting to calculate optical constants or thicknesses, one can learn valuable insight into the subtle processes leading to pitting. The bearing that these results have on the mechanism of $f i 1 \mathrm{~m}$ breakdown is beyond the scope of this paper but is given by McBee and Kruger [5]. 
Thus far, we have described studies where the surface observed was held at a potential above that necessary to initiate pitting, the critical pitting potential, $E_{C}$. Many workers [7] believe that pits will not initiate at potentials below $E_{C}$. Others [8] believe that if one waits long enough pitting will initiate below $E_{C}$. This disagreement may arise because of the use of different techniques for measuring $E_{C}$. Ellipsometry, however, does reveal that one can distinguish entirely different optical behavior between passivated surfaces exposed to chloride well below and well above most commonly accepted values of $E_{C}$.

First, it can be shown (Fig. 4) that passive film growth starting with a bare iron surface proceeds in an identical fashion in solutions containing chloride to that observed for solutions without damaging ions when the potential at which the film is grown is below $E_{C}$. When, however, the potential is above $E_{C}$, chloride in the aqueous solution promotes rapid limiting thickness). This type of growth is similar to that observed at time $t_{2}$ and attributed to the deposition of a nonprotective corrosion product $f i 1 \mathrm{~m}$ as described earlier. Therefore, ellipsometry shows that potential has a profound effect on events occurring after pit initiation occurs.

Secondly, potential can also affect the processes occurring prior to breakdown when chloride in introduced. Above $E_{C}$, as described earlier, the introduction of chloride produces changes in the ellipsometric parameters, especially $\Delta$, at only a few wavelengths. Below $E_{C}$, however, Fig. 5 shows that approximately equal changes in $\Delta$ occur at every wavelength when chloride ions are introduced. This essentially uniform decrease in the overal1 $\Delta$ values, except perhaps at $590 \mathrm{~nm}$, accompanied by mainly insignificant changes in the $\psi$ spectrum indicates an increase in film thickness. An increase in film thickness can be caused by either the adsorption of chloride on top of the film or further growth of the passive film. It is also possible that both of the above mentioned processes take place concurrently. Calculations show that the magnitude of the changes in $\Delta$ and $\psi$ require a change in film thickness of at least $1.5 \mathrm{~nm}$. This is too large to be accounted for by only chloride adsorption. At any rate, for surfaces at potentials below $E_{C}$, calculations show that the ellipsometric spectra indicate changes in film thickness (usually by a downward shift in $\Delta$ and insignificant changes in $\psi$ ) rather than changes in the $f i 1 \mathrm{~m}$ properties, as would be indicated by irregular movements in the $\Delta$ and $\psi$ values at discrete wavelengths.

These ellipsometric studies thus reveal that potential may affect much more than the kinetics of pit initiation. They reveal that subtle changes in the passive film itself are affected by the potential at which it is exposed to chloride, and these changes must be related to the tendency for the film to break down when the potential is above $E_{C}$. 
Once it starts, crevice corrosion bears some similarities to pitting corrosion, in that both forms of localized corrosion propagate because of restricted mass transport of reactants or reaction products. In the case of pitting, mass transport is restricted because of corrosion products deposited on top of the pit and, in the case of the crevice, because of the existence of some material that restricts mass transport, e.g. gaskets, another piece of metal, a deposit of dirt, etc. Ambrose [9] has described how one can apply ellipsometry to the study of processes occurring inside a crevice by creating a crevice with a glass plate on top of the metal surface to be studied (Fig. 6). Use of such transparent windows for visual observation of a crevice is not new $[10,11]$, but the results from such studies have been limited to detection of crevice corrosion in its advanced stages. The optical technique of ellipsometry, however, not only permits measurement of small changes in thickness and optical properties of surface films on metal substrates, but can perhaps be used to detect changes in composition of aqueous media as well. One can only hope to gain qualitative indications of the changes because the system is extremely complicated from an ellipsometric point of view. Besides the complications of the bottom surface of the glass plate which can be a surface for the adsorption of films and the changing index of retraction of the solution in the crevice, there exist the possibilities of passive film growth or dissolution, the deposition of corrosion products on the glass or metal and the effects of metal roughening once crevice corrosion has commenced. We will show, however, that this application of ellipsometry can provide additional information that helps in the interpretation of electrochemical results by being able to detect small changes occurring early in the chain of events leading to crevice corrosion and being able to determine at what time these changes occur.

The device used to simulate a crevice in these studies is shown in Fig. 7 and consists of a Teflon adapter which serves to position a circular pyrex glass plate against the surface of a polished metal specimen. The thickness of the pyrex disc was such that interference between the beams reflected from the metal surface and those reflected from the top of the plate did not occur (Fig。6). The sides of the Teflon adapter were cut away in order to allow access of a bulk solution to the crevice. The lateral surfaces of the specimen were isolated from the environment by a tightly wound layer of Teflon tape in order to prevent crevice attack where it could not be observed optically. The rear surface of the specimen was similarly protected during those experiments where potentiostatic control was applied. Using this device, as well as looking at surfaces without a crevice where solution conditions are changed to simulate the conditions existing in the solution within a crevice, useful insights can be gained into the processes leading to crevice corrosion in two areas,
a) the effect of deoxygenation and
b) the effect of the crevice. 
There appears to be general agreement with the fact that oxygen depletion within the crevice constitutes the initial phase of crevice corrosion attack [12]. Therefore, ellipsometric measurements can examine the effect of oxygen depletion on the protective film on the metal in the absence of a crevice. For a metal with absorbing films such as stainless steel, $\Delta$ is more sensitive than $\psi$ to changes in film thickness [13]. Both parameters are affected by film optical property changes. Results for 304 stainless steel exposed to $1.0 \mathrm{~N} \mathrm{NaCl}$ without a crevice, in the open circuit mode, are shown in Fig. 8. Oxygen depletion results in the expected shift in corrosion potential toward more negative values with the $\Delta$-values remaing virtually unchanged throughout the exposure period, increasing by only $0.08^{\circ}$ after 1350 minutes. The value of $\psi$ similarly is constant during the first 100 minutes or so of exposure, but then increases during a period where the rate of potential change appears to increase. Overal1, $\psi$ is increased by $0.260^{\circ}$ over the exposure period.

These data indicate that in a deoxygenated solution where the potential is changing slowly $(9.4 \mathrm{mV} /$ minute), the ellipsometric parameters $\Delta$ and $\psi$ are rather constant with only very slight thinning or change in the nature of the film on the stainless steel substrate having occurred. Based on the reaction:

$$
\mathrm{O}_{2}+2 \mathrm{H}_{2} \mathrm{O}+4 \mathrm{e}^{-} \stackrel{\leftarrow}{\rightarrow} 4 \mathrm{OH}^{-}
$$

the overall potential change of $-94 \mathrm{mV}$ would correspond to a 6 orders of magnitude decrease in oxygen concentration. However, after about 100 minutes there is an increase in the rate of potential change accompanied by a significant increase in the values of $\psi$ while $\Delta$ remains essentially constant. This would appear to indicate that a change in the nature of the film has occurred, but because $\Delta$ does not change there appears to be no significant thinning. Since micropits were observed at this stage, such behavior indicates a localized breakdown in passivity.

These ellipsometric studies suggest that, contrary to what has been proposed in the literature [13], depletion of oxygen alone does not lead to a uniform film thinning and loss of passivity over the whole surface, a behavior characteristic of crevice corrosion attack. Instead oxygen depletion results in a discrete change in the nature of the film followed by a localized loss of passivity that is more characteristic of pitting.

Effect of the crevice

When a crevice is present not only is there oxygen depletion but also a change in the concentration of other species in the aqueous solution in the crevice. Using the apparatus shown in Fig. 6, ellipsometric observations of the metal surface in a crevice produced results of the sort shown in Fig. 9. With the surface held at the initial immersion corrosion potential $(+42 \mathrm{mV}), \Delta$ values decreased markedly during the first 20 minutes of exposure ( $\delta \Delta=\sim$ $\left.-0.12^{\circ}\right)$ before increasing to a maximum value $\left(\delta \Delta=+.60^{\circ}\right)$, after about 1450 minutes. The $\psi$ values fluctuated a great deal but, in general they decreased 
during the first 200 minutes $\left(\delta \Delta=0.65^{\circ}\right)$ then increased for the remainder of the exposure period. Current values slowly increased from $+0.66 \mu \mathrm{A}$ to a final value of $300 \mu \mathrm{A}$ at the end of the run. The major increase in the current, which indicates an increase in corrosion rate, occurred at about the same time that the $\Delta$ values started to decrease sharply. It is worth noting that, while large optical changes occur, virtually no electrochemical changes are observed until the current increase signals the onset of crevice attack. The optical changes are those that presumably lead to the initiation of this attack.

It is obvious from Fig. 9 that optical results completely different from those obtained without a crevice (Fig. 8) are obtained when a crevice is introduced. Although the process of oxygen depletion is probably accelerated within the low volume crevice, the initial direction of change of both $\Delta$ and $\psi$ is opposite to that observed in oxygen depletion where a crevice was not present, and apparently processes other than oxygen depletion are playing a predominant role. Other studies [12] indicate that these processes are leading to a marked change in the concentration of hydrogen ions, chloride ions and metal ions in the crevice solution.

Before attempting to interpret the ellipsometric observations, it is necessary to discuss the effect of the glass plate on the ellipsometric observations. Since the glass plate is a dielectric there will be no phase change with transmission through the glass plate assuming no adsorption takes place on theplate and the $\Delta$ measured will not differ from that resulting from optical conditions at the metal surface. The value of $\psi$ measured, however, will be changed due to the transmission coefficients at the surfaces of the glass plate. These transmission coefficients will in turn depend upon the refractive index of the solution in the crevice. This latter is generally unknown and changing during the course of such an experiment.

- In order to determine empirically the effect of increase of the solution refractive index on $\Delta$ and $\psi$ outside of a crevice, ellipsometric measurements were made on a stainless steel surface, with a crevice, in both $1 \mathrm{~N} \mathrm{NaCl}$ and 2.5N NaCl solutions, the latter having a higher refractive index. As Table 1 shows, the measured value of $\Delta$ with the crevice in place decreased markedly in value in the more concentrated solution. The value of $\psi$ increased slightly. Thus, based on the changes in $\Delta$ shown in Fig. 9, the initial stages of crevice corrosion are consistent with an increase in crevice solution index of refraction, i.e., an increase in the concentration of Cl- and metallic ions. Because $\psi$ is difficult to interpret in the presence of a crevice for the reasons given above and because of the greater fluctuations in the values measured, we cannot judge whether the $\psi$ measurements are indicative of crevice solution concentration during the first part of the chain of events leading to crevice corrosion.

The substantial increase in $\Delta$ and continued decrease in $\psi$ following the first phase is consistent with an overall decrease in thickness of the protective surface film. Since oxygen depletion alone has been shown not to produce such an effect, we can assume that such thinning results from whatever happened during the first phase of the process, where $\Delta$ was observed to decrease. Finally, the marked decrease in $\Delta$ is in the same direction as was previously noted for the non- crevice oxygen depletion studies, and is characteristic of surface roughening and/or film growth. Notably, this 
decrease comes at the same time that the current measurements indicate an increased rate of corrosion where presumably metal roughening and/or corrosion product deposition occurs.

The effect of a crevice on the corrosion rate and ellipsometric parameters of a Ti 8A1-1Mo-1V alloy was also studied. This alloy, which is not susceptible to crevice corrosion in a similar environment at room temperature, exhibited none of the ellipsometric variations associated with the onset of crevice corrosion attack on 304 stainless steel when its surface was held at the open circuit corrosion potential while exposed to the crevice created by the glass plate. In fact, $\Delta, \psi$, and $i$ were relatively constant over the entire period of exposure.

Although these mechanistic inferences are consistent with the observed ellipsometric variation, they are by no means the only possible interpretation. This is so because the ellipsometric measurements reflect average overall changes occurring under the glass plate. In other words, one process - i.e., solution concentration - could easily mask out small changes in the $f i 1 \mathrm{~m} / \mathrm{metal}$ substrate. Much further work is necessary to make ellipsometric observations of crevices more definitive and quantitative. However, the results just described are important qualitatively because they indicate the times at which changes occur in the crevice in the processes leading to crevice attack. Moreover, a reasonable picture, consistent with the optical measurements of events initiated during these changes can be developed using measurements in special environments without a crevice. The sequence of events for the susceptible stainless steel exposed to a crevice in a chloride solution can be described as follows:

1) The initial decrease in $\Delta$ may correspond to the concentration of metal and chloride ions leading to an increase in the refractive index of the solution in the crevice.

2) The subsequent increase in $\Delta$ may correspond to film thinning.

3) The final decrease in $\Delta$ may correspond to both metal roughening and corrosion product deposition.

In contrast, for the non-susceptible Ti alloy, a constancy of ellipsometric and current measurements over the entire exposure period indicates that none of the crevice solution concentration effects which were detected for the susceptible 304 stainless steel had occurred.

\section{Repassivation Kinetics}

This last to be described application of ellipsometry seeks to measure the rate at which a protective film grows on a surface once the previous film is removed. This phenomenon is of great importance to stress corrosion cracking (SCC) where films are ruptured when a metal is stressed, and the rate at which the surface is repassivated determines the length of time the unprotected metal can be attacked by an environment. To measure this repassivation process, Ambrose and Kruger [14] developed a technique called "triboellipsometry". The technique uses a small abrasive polishing wheel in 
the environment to be studied to remove the protective film on a metal surface. This abrasion step leaves the metal surface in a coldworked state, but, since the tip of a growing stress corrosion crack is continually undergoing plastic strain, the growth rate of a film on the abraded surface is probably closer to that which occurs at the crack tip than the rate for a strain free surface. The polishing wheel is then quickly withdrawn, and ellipsometric and electrochemical current transients are recorded on an oscilloscope. The current is a measure of both the film growth and the metal dissolution that occur during repassivation. The ellipsometer measures mainly film regrowth.

While there are other electrochemical techniques [15, 16] for measuring repassivation kinetics by using current decay measurements, the triboellipsometric technique allows one to determine how much of the current is involved in film repair and how much is involved in metal dissolution. It cannot do this quantitatively because it is difficult to measure the amount of bare surface produced by abrasion so that the current density is difficult to determine. Moreover, exact measurements of film thickness by ellipsometry on the abraded surface are difficult. (One can, however, measure changes in $\Delta$ and $\psi$ and relate these changes to thickness changes that are reasonable estimates even when the optical constants of the film are not well known [17]). To overcome the difficulties of inexact current density and film thickness measurements, a parameter has been defined $[18,19]$ that allows one to compare the repassivation behaviors of a given metal in different environments and thus use it as a diagnostic tool for estimating which environment would have the greater likelihood. to promote stress corrosion. This parameter, $R_{p}$, has been defined in a manner that is convenient for triboellipsometric measurements as the ratio

$$
R_{p}=\frac{\int^{t} t^{d t}}{x_{t}}
$$

where $i_{t}$ is the total anodic current which flows for a given time interval, $t$, to a surface made bare by film removal (through rupture or by other means) and $x_{t}$ is the thickness of the film at time $t$. $R_{p}$ can also be expressed as

$$
R_{p}=\frac{Q_{T}}{Q_{f}}=k \frac{Q_{d}+Q_{f}}{Q_{f}}
$$

where $\Omega_{T}$ is the total charge involved in the anodic process, $Q_{d}$ is the charge involved in metal dissolution, $Q_{f}$ is the charge involved in the film formation, and $K$ is a constant which depends on the surface area, and the nature of the film. 
The value of $R_{p}$ is a measure of the effectiveness of the repassivation process after film removal. If repassivation is ineffective at first, ?T increases rapidly, resulting in a large value of $R_{p}$. On the other hand, effective repassivation, where $Q_{f}$ does not differ greatly from $Q_{T}$, yields a small value $R_{p}$. Since $R_{p}$ is measured as a function of time, Ambrose and Kruger examined [18] what happens to $\mathrm{dR}_{\mathrm{p}} / \mathrm{dt}$ under different hypothetical situations which could exist at a crack tip. A more detailed and rigorous analys is is given else-where [19].

Case $1 d R_{p} / d t=0$. This occurs when $Q_{f}=Q_{d}$. Here $S C C$ susceptibility is highly unlikely. From Equation (3), it can be seen that $R_{p}=K$ and $d R_{p} / d t$ $=0$.

Case $2 d R_{p} / d t>0$. This reflects the situation when $Q_{d}>Q_{f}$ and $R \sim K Q_{d} / Q_{f}$ so that $\mathrm{dR} / \mathrm{dt}$ is positive. If $\eta_{\mathrm{d}} \gg \eta_{f}, \mathrm{dR} / \mathrm{dt}$ can become a large positive number and SCC may be unlikely because the extensive dissolution involved may result in considerable blunting of the crack tip.

Case $3 d R_{p} d t<0$. This can happen where $d x / d t>d \Omega_{T} / d t$. By differentiating the expression for $R_{p}$ in Equation 2.

$$
\frac{d R_{p}}{d t}=\frac{d Q_{T} / d t}{x}-\frac{Q_{T} d x / d t}{x^{2}}
$$

it can be seen that, since $Q_{T}$ is always greater than $Q_{f}$, when $d x / d t>d Q_{T} / d t$, $\mathrm{dR}_{\mathrm{p}} / \mathrm{dt}$ will have a negative value. The significance of $d R_{\mathrm{p}} / \mathrm{dt}<0$ can not be explained until two other important parameters determined by triboellipsometry are examined; $d x / d t$, the rate of $f i l m$ growth, and $t_{p}$, the time when $d x / d t$ becomes small (arbitrarily defined as the point in time where $d x / d t<0.001$ $\mathrm{nm} / \mathrm{msec})$. Using these two parameters, in addition to $R_{p}$ and $d R_{p} / d t$, their possible values in various environments for a given metal known to meet mechanical and metallurgical requirements for SCC can be compared as shown in Table II.

Using the analysis shown in Table II, a highly qualitative but useful guide for comparing SCC behavior of a metal in an environment where susceptibility is known with its behavior in an unknown environment can be developed. Table II also provides insights into the process occurring at a crack tip or during crack initiation. It allows, for example, an estimation of the effectiveness of a protective film from the value of $\mathrm{dR}_{\mathrm{p}} / \mathrm{dt}$. It also points out that a high rate of film formation is not a sufficient condition for nonsusceptibility because the ability of the film to prevent dissolution (its protective quality) is equally important (Condition A). Table II further indicates that the formation of a good protective $f i l m$ is not sufficient to prevent SCC if $\mathrm{dx} / \mathrm{dt}$ is small (Condition B). 
Fig. 10 shows the application of the techniques and analysis just described to the study of the repassivation behavior of a low carbon steel in three environments: a) $4 \mathrm{~N} \mathrm{NaNO}_{3}$ solution at $90^{\circ} \mathrm{C}$ where this steel is susceptible to $\mathrm{SCC}$, b) $1 \mathrm{~N} \mathrm{NaNO} 2$ at $25^{\circ} \mathrm{C}$ where it is not susceptible to SCC, and c) $1 \mathrm{~N} \mathrm{NaCl}$ at $25^{\circ} \mathrm{C}$ where it is not susceptible to SCC but where extensive corrosion takes place. Table III gives the various repassivation parameters for the low carbon steel in the above environments.

The three different kinds of behaviors shown in Fig. 10 and in Table III provide examples of three of the conditions described in Table II. These examples were described a number of years ago by Evans quoted in [20] before techniques existed that could clearly distinguish them. He proposed that "chemical factors in the liquid mainly decide whether attack at any point will (a) heal up [condition $\mathrm{C}$ existing in $\mathrm{NaNO}_{2}$ ], (b) remain localized developing into a crack [Condition D existing in $\mathrm{NaCT}$ ], or (c) spread out [condition $\mathrm{A}$ existing in $\mathrm{NaNO}_{3}$ ], leading to general attack." The fact that triboellipsometry can distinguish these three kinds of behavior during the first few tens of milliseconds of a repassivation event points to its great usefulness in gaining an understanding of phenomena that involve repassivation. 
[1] M. G. Fontana and N. D. Green, "Corrosion Engineering", McGraw-Hill Book Co., New York (1967).

[2] T.P. Hoar, Corrosion Sci., 7, (1967), 341.

[3] J.R. Ambrose and J. Kruger, Proc. 4th International Congress on Metallic Corrosion, 1969, Nat' 1 . Assn. of Corrosion Eng., Houston, Texas (1972), p. 698.

[4] J. Kruger, Proceedings of Japanese American Conference on the Passivity and Breakdown of Passivity of Iron Base Alloys, to be published by Nat'1. Assn. Corrosion Eng., Houston.

[5] C.L. McBee and J. Kruger, "Localized Corrosion", N.A.C.E.-3, Staehle, Brown, Kruger, Agarwal, Editors, Nat. Ass. Corrosion Eng., Houston, (1974), p. 252.

[6] C.L. McBee and J. Kruger, Sur. Sci., 16, (1969), 340.

[7] H. Bohni and H.H. Uhlig, J. Electrochemical Soc., 116, (1969), 906.

[8] M.J. Pryor, "Local ized Corrosion", N.A.C.E.-3, Staehle, Brown, Kruger, Agarwal, Editors, Nat. Ass. Corrosion Eng., Houston, (1974), p. 2.

[9] J.R. Ambrose - to be submitted to the Electrochem. Soc.

[10] R.B. Mears and U.R. Evans, Trans. Faraday Soc. 30 (1934), 417.

[11] U.R. Evans, J. Inst. Metals 30, (1923), 239.

[12] I.L. Rosenfeld and I.K. Marshakov, Corrosion 20 (1964), $115 t$.

[13] J.F. Bates, Corrosion 29 (1973), 28.

[14] J.R. Ambrose and J. Kruger, Corrosion, 28 (197.2), 30.

[15] J.C. Scully and T.P. Hoar, 2nd Int. Congress of Metallic Corrosion, New York 1963, Nat. Ass. Corrosion Eng., Houston (1966), p. 184.

[16] N.D. Tomashov and L.P. Vershinina, Electrochimica Acta, 15, (1970), 501 .

[17] J. Kruger, "Advances in Electrochemistry and Electrochemical Engineering", Vo1: 9, R.ll. Muller, E., John Wiley and Sons, New York (1973), pp. 249250 . 
[18] J.R. Ambrose and J. Kruger, Proc. 5th International Congress on Metallic Corrosion, 1972, Nat'l. Assoc. of Corrosion Eng., Houston, Texas, (1974), p. 406.

[19] J.R. Ambrose and J. Kruger, J. Electrochem. Soc. 12] (1974), 599.

[20] R.N. Parkins and R. User, Ist Int. Congress on Metallic Corrosion, Butterworths London (1962), p. 289. 
Table I - The Variation of $\Delta$ and $\psi$ as a Function of Solution Concentration $\mathrm{NaCl}$ Solution Refractive Concentration $\Delta$ Index $\psi \quad \delta \Delta$ $1.0 \rightarrow 2.5 \quad \delta \psi 1.0 \rightarrow 2.5$

$1 . \mathrm{ON}$

1.3432

113.86

29.38

2.5

1.3567

111.70

29.41

$-2.16$

$+.03^{\circ}$ 


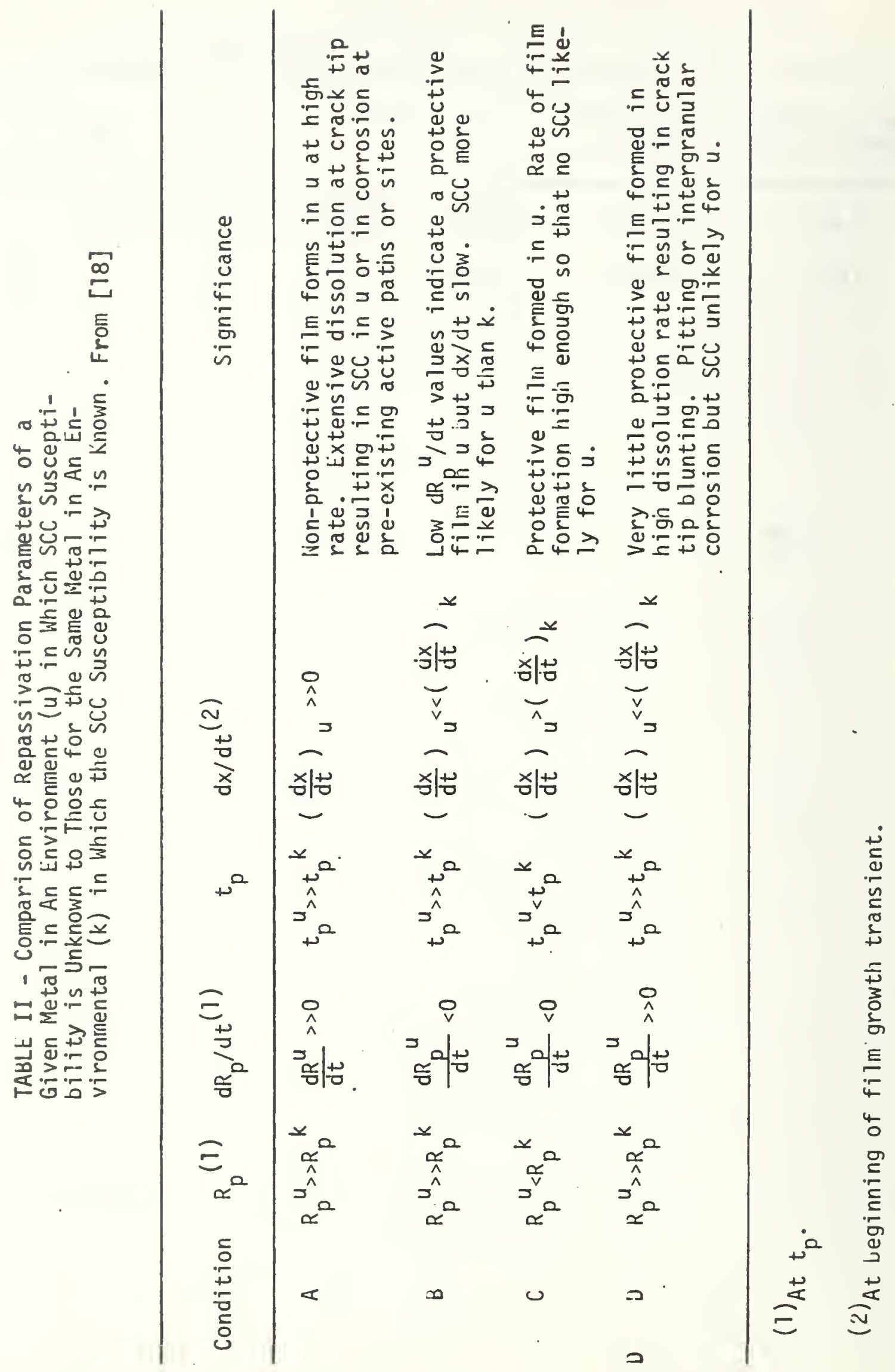


TABLE III - Repassivation Parameters for Low Carbon Steel for Nitrate, Nitrite, and Chioride Solutions. From [18]

\begin{tabular}{lcccc}
\hline & $\begin{array}{c}\mathrm{R}_{\mathrm{p}} \\
\left(\frac{\mathrm{mcoul} / \mathrm{cm}^{2}}{n m}\right)\end{array}$ & $\mathrm{dR}_{\mathrm{p}} / \mathrm{dt}$ & $\begin{array}{c}t_{\mathrm{p}} \\
(\mathrm{msec})\end{array}$ & $\begin{array}{c}\mathrm{dx} / \mathrm{dt} \\
(\mathrm{nm} / \mathrm{msec})\end{array}$ \\
\hline 4iv $\mathrm{NaNO}_{3}$ at $90 \mathrm{C}$ & $>2.75$ & + & 750 & 0.00425 \\
IN $\mathrm{NaNO}_{2}$ at 25C & 0.25 & -0 & 100 & 0.012 \\
IN $\mathrm{NaCl}$ at 25 C & $>8.0$ & + & $>500$ & -0
\end{tabular}




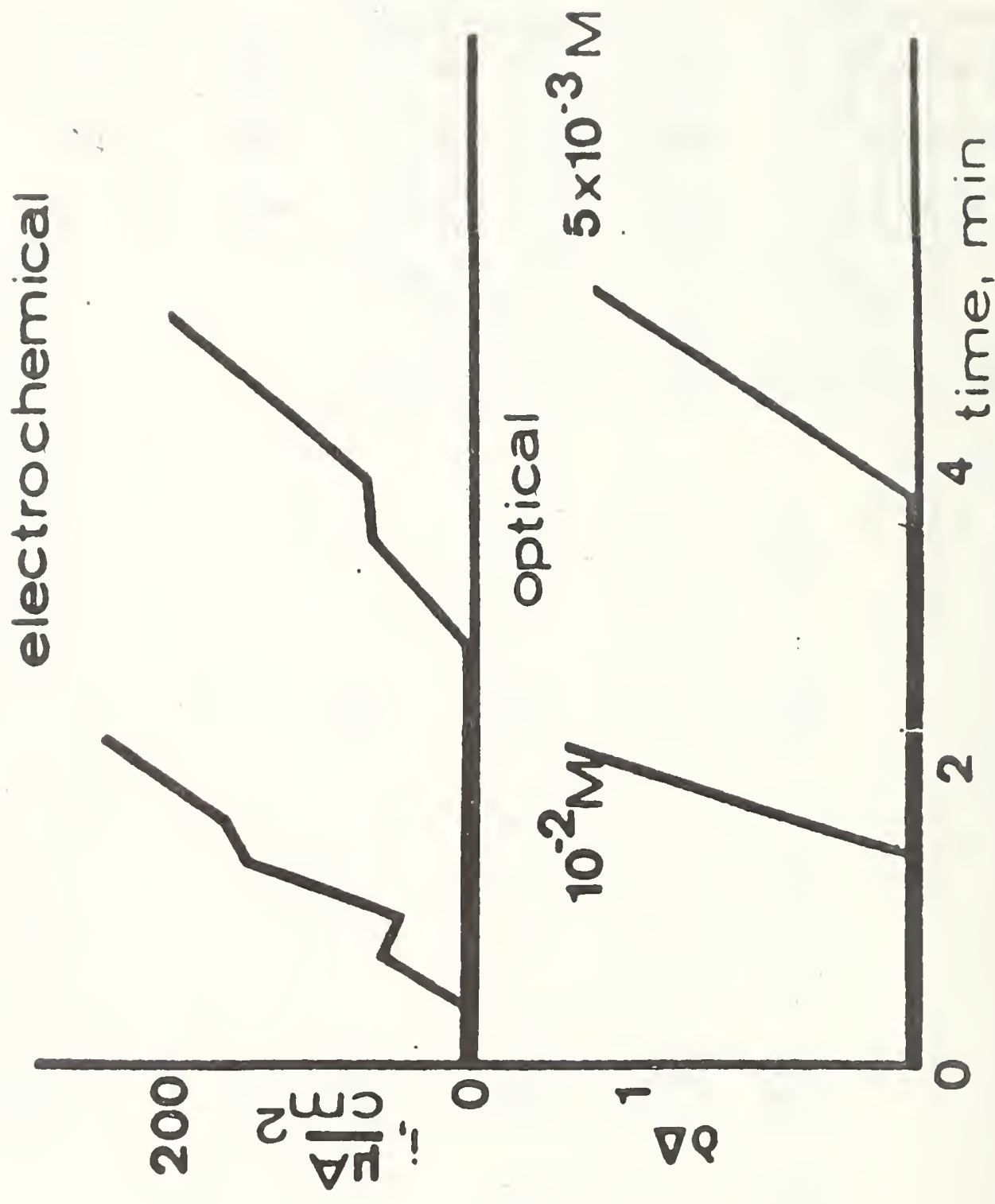

(1) Ф. ฏ

〔

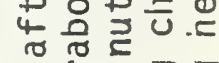

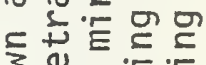
30 응잉ㅇㅇㅇ 홍 \&. 웅 ᄂ. 品> 동 1 등정

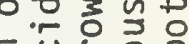

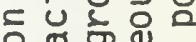

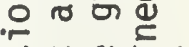

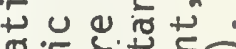
ช. \&

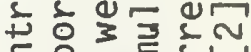
क्षे थ. E Uू ㅇㅇㅇ중

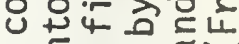
등.ㅎํㅇ 幽文。 ๑の os '도은등 둥

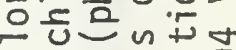
눈 $=$ 尔 응

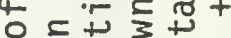

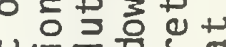

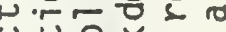

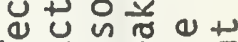

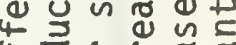
4 ㅎำ 4 0

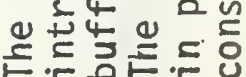




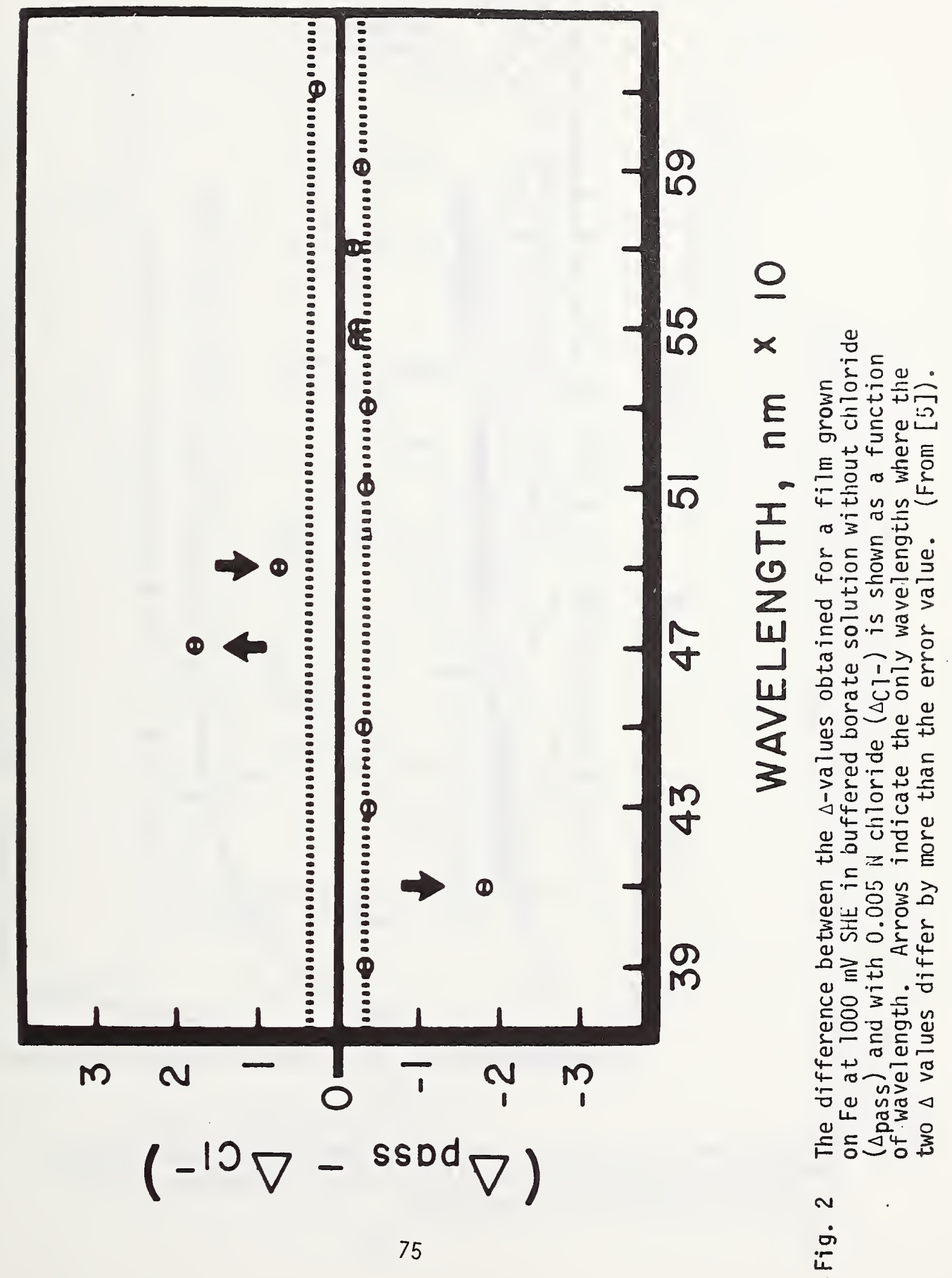




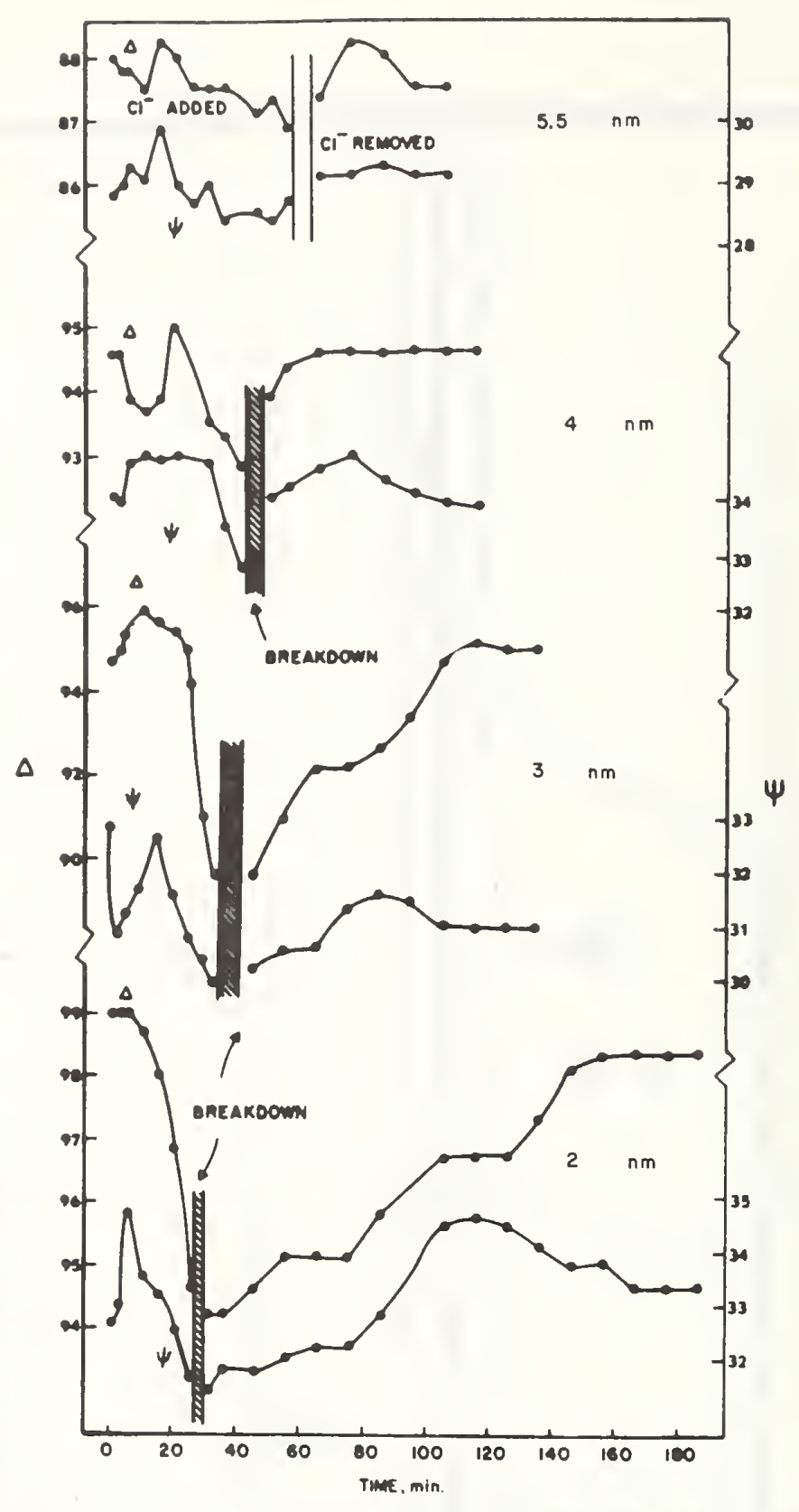

Fig. 3 Modulations in $\Delta$ and $\psi$ at $410 \mathrm{~nm}$ for prebreakdown and recovery processes are indicated for films of four thicknesses, 5.5, $4.0,3.0$, and $2.0 \mathrm{~nm}$. (From [5]). 


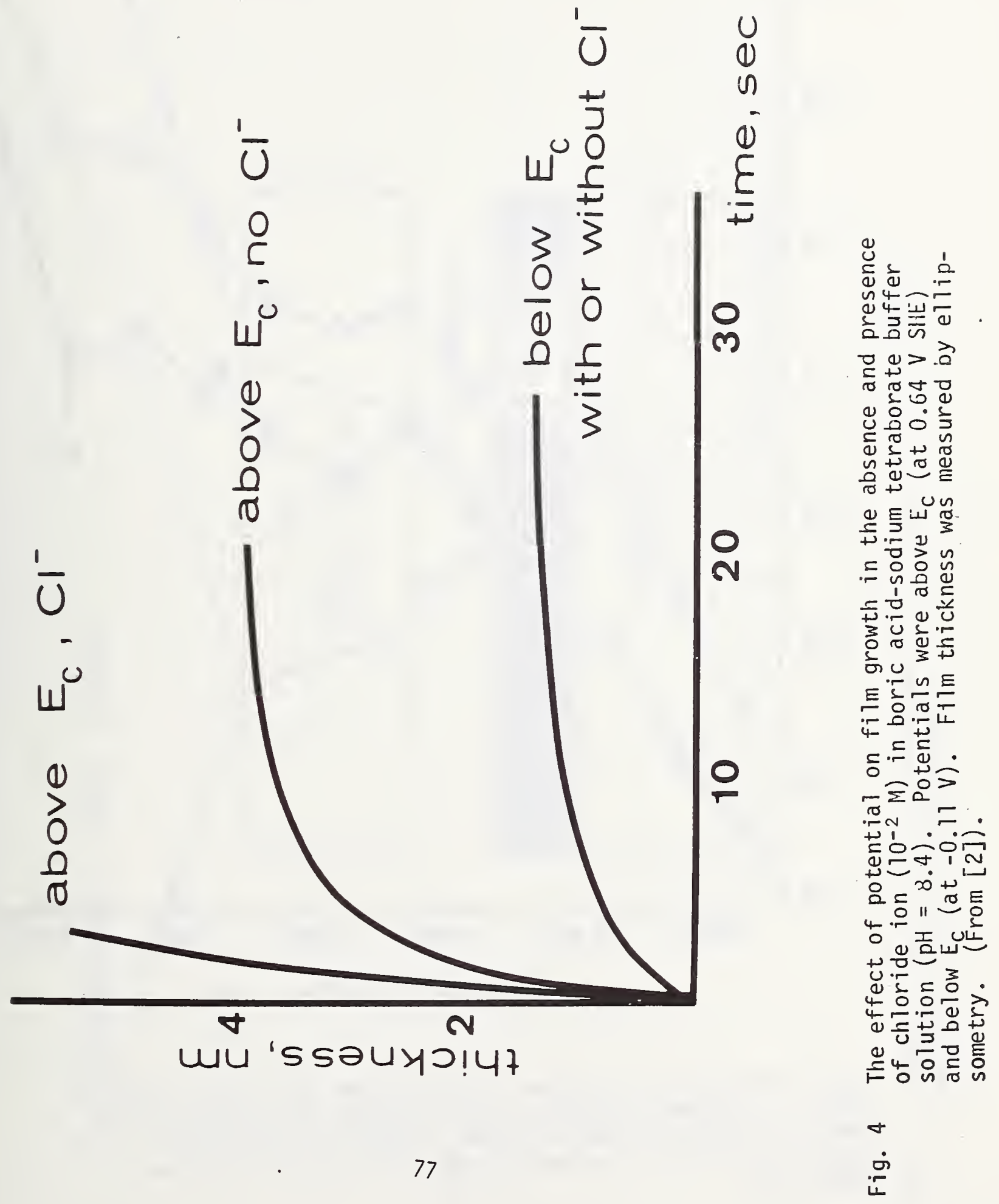




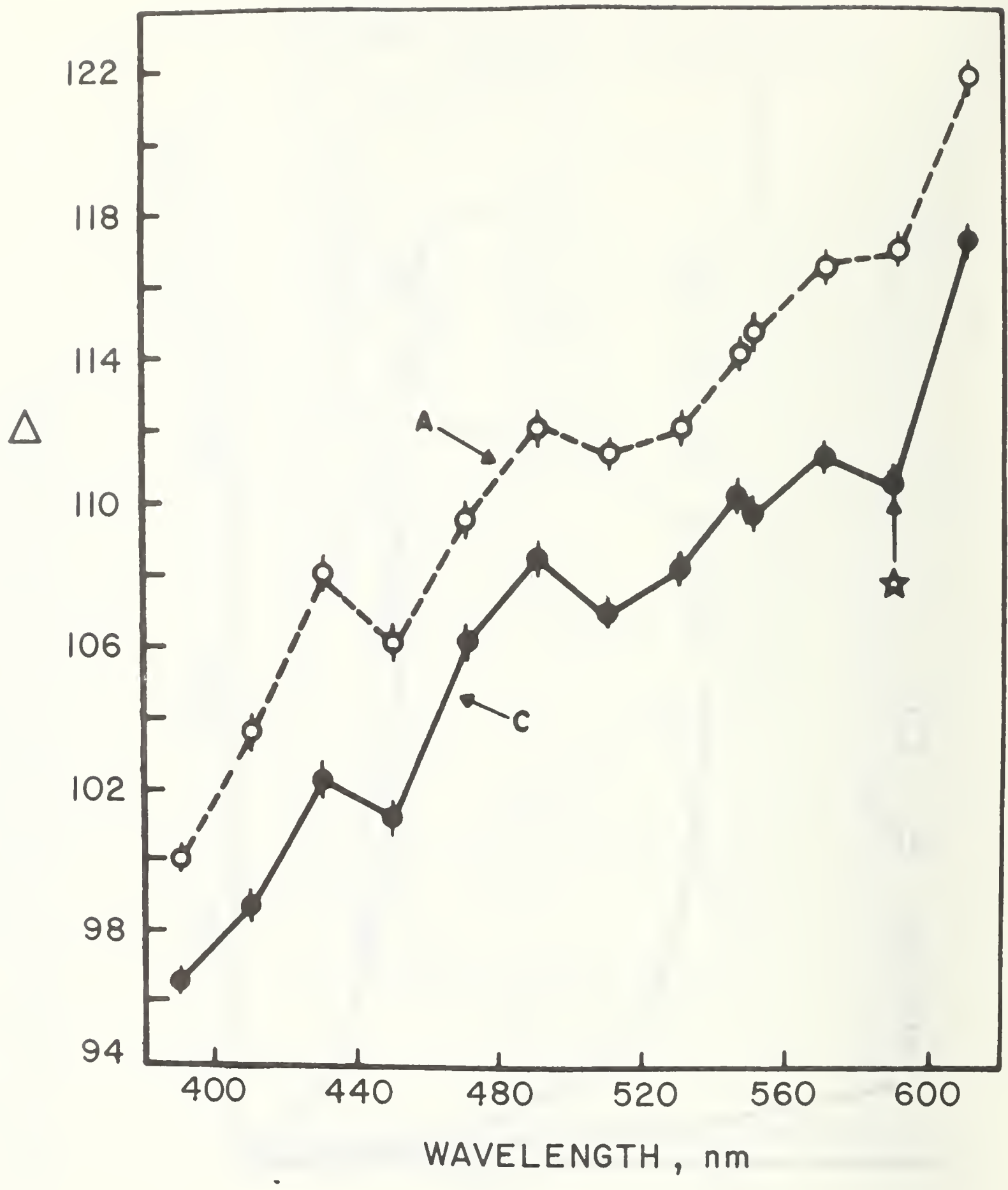

Fig. 5 Curve A represents the values of $\triangle$ obtained at $-100 \mathrm{mV}$ (SHE) for $\{221\} \mathrm{Fe}$ in borate solution. Curve $\mathrm{C}$ shows the changes in the spectrum that occur when chioride is added to the solution. The star indicates that the spectra are not similar at $590 \mathrm{~nm}$. (From [5]). 


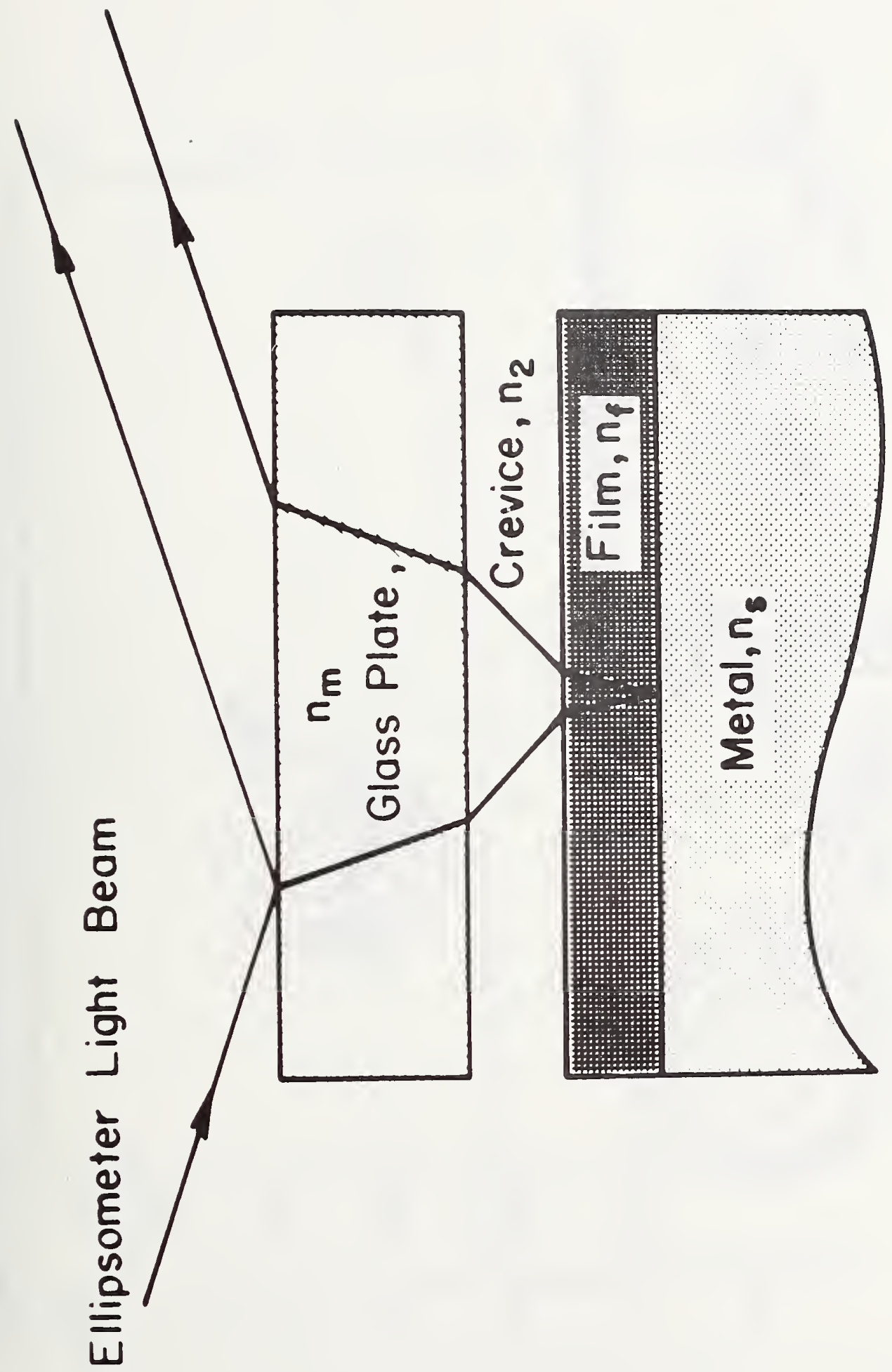

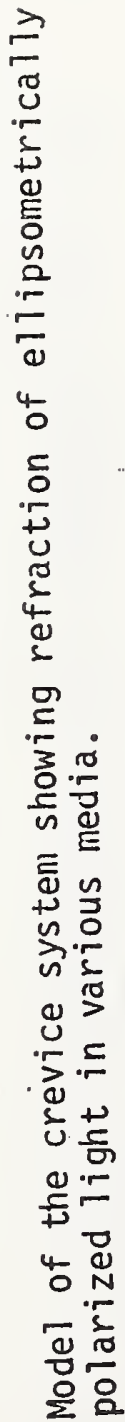



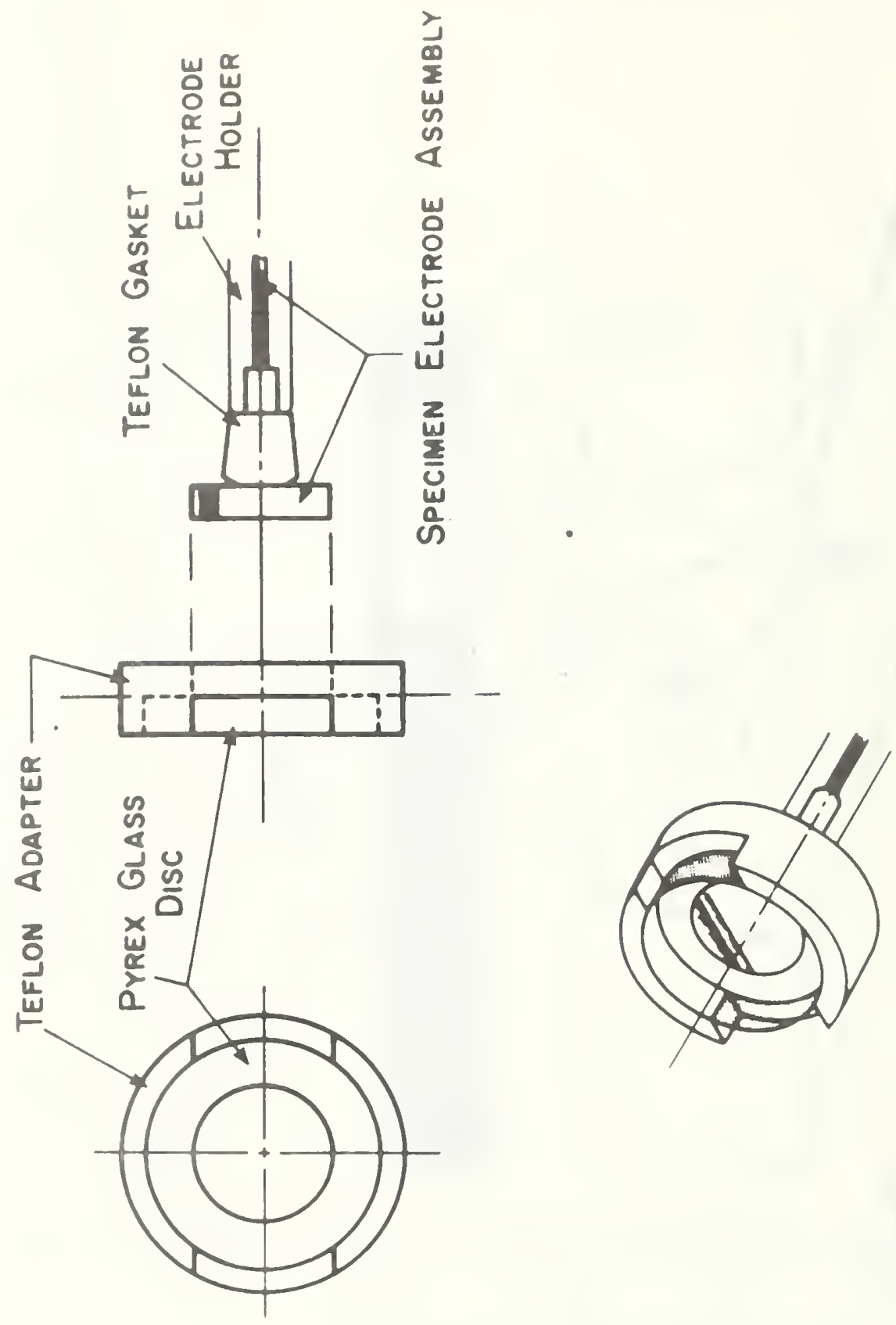


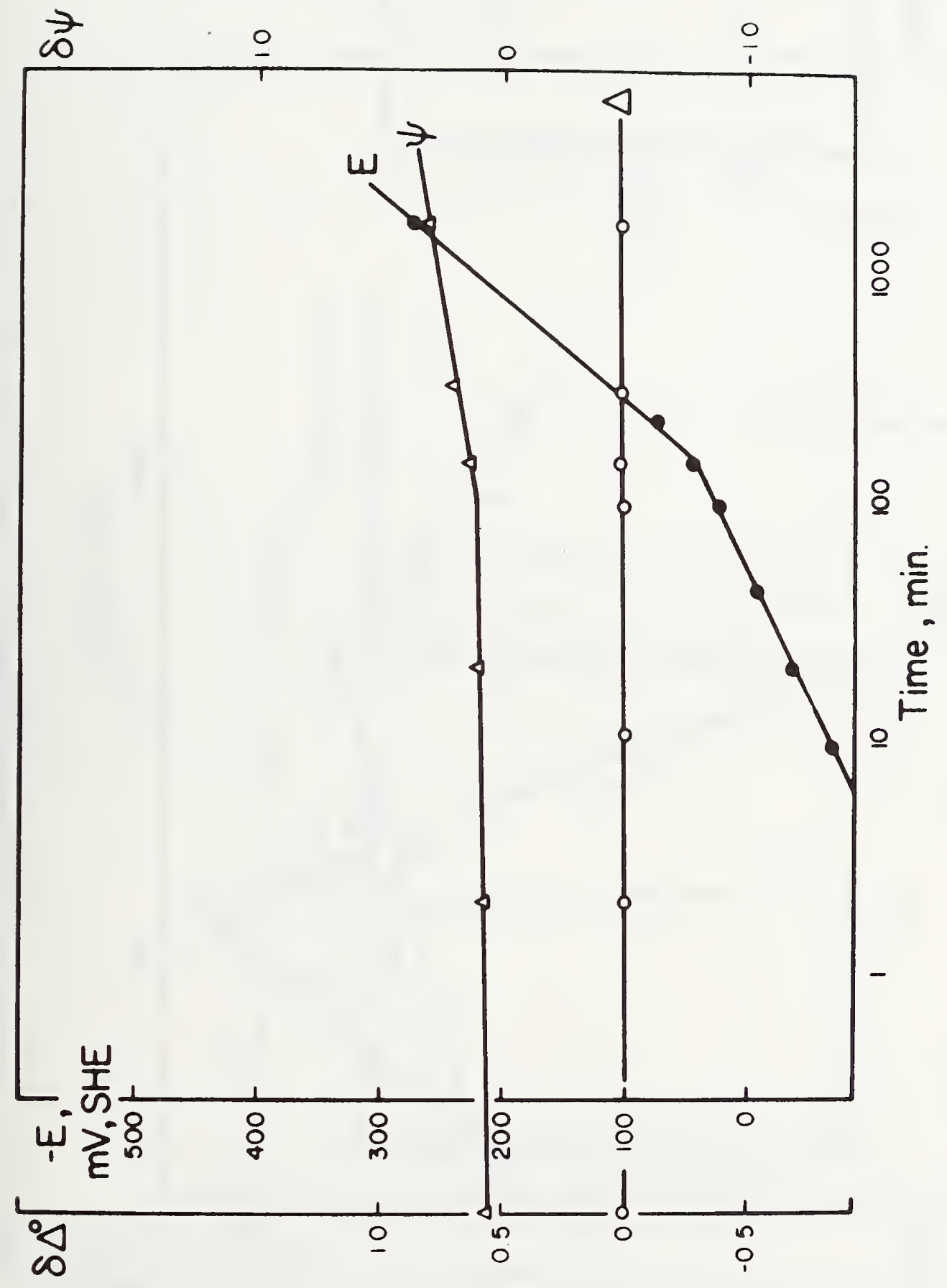

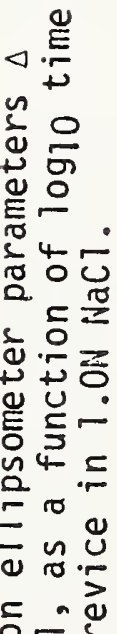

ᄃ

드ㅇㅛㅛ

অ

동하

o 2

주음

용 告

ᄂ

등 엉

$\mp$

寻是至

ง.

4 近 新

蕉

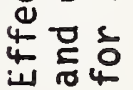




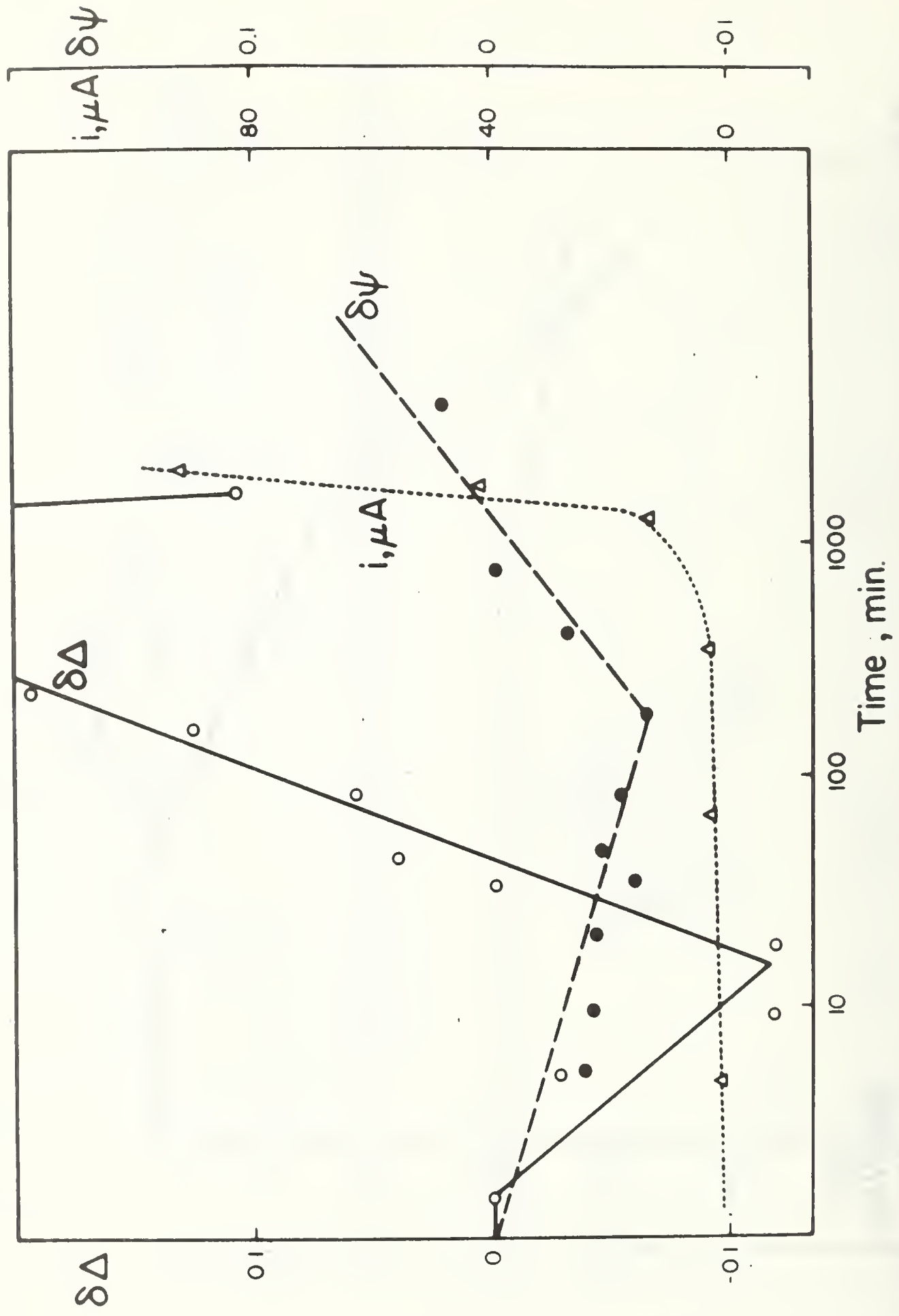

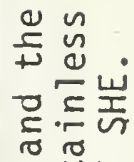
出 ช オ 믕 s $\checkmark$ ○ 乞 \& व ब +口. थ त 00 万人干 20 든 ธ4 +4 통․․ ㅇ․․ 告 - 넝 - 5. व 4 U ᄃ ब $\tilde{0}$. U ¿ $\frac{c}{0}$ 는

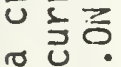
45 음도 + in

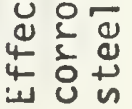



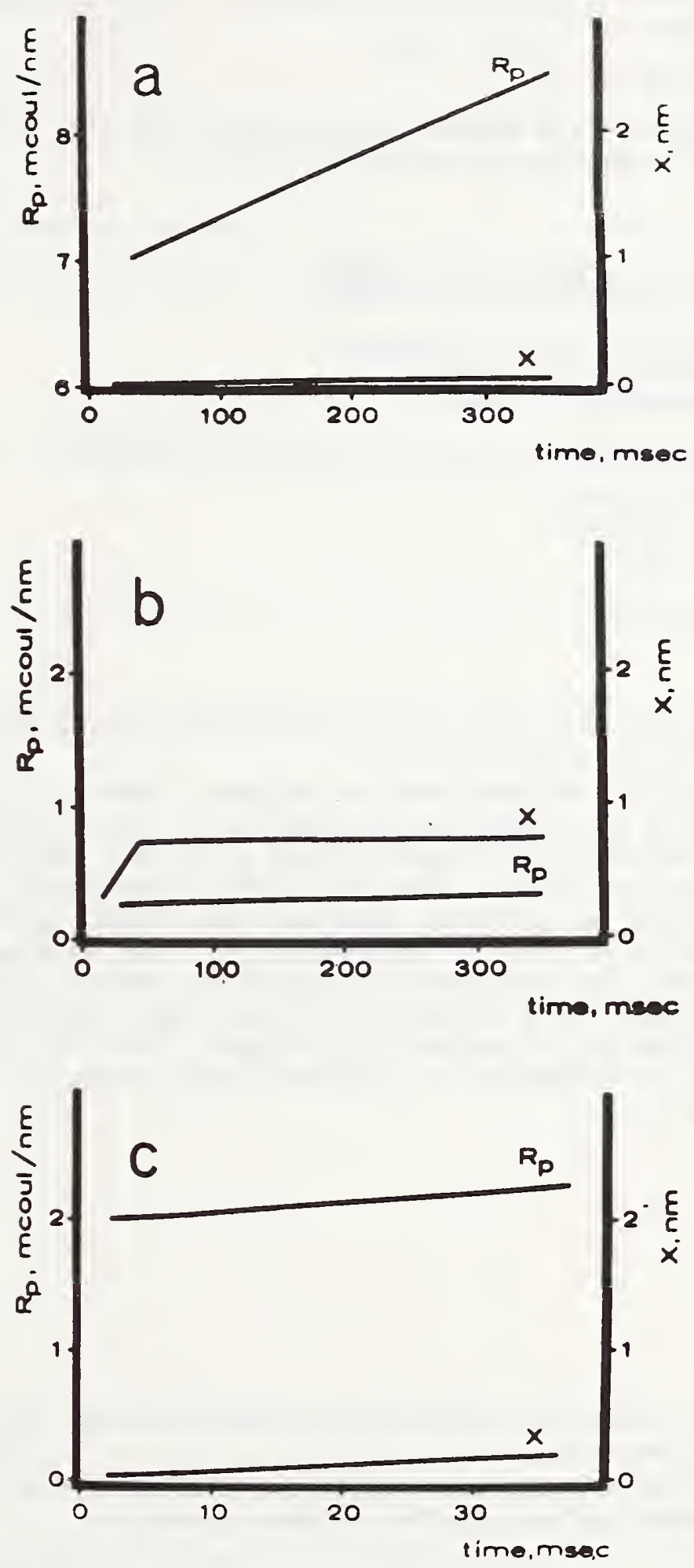

Fig. 10 Change in thickness, $x$, and repassivation ratio, $R_{n}$, after removal of abrasion wheel of triboellipsometric apparatus for low carbon steel in (a) 4 i $\mathrm{NaNO}_{3}$ at $90 \mathrm{C}$ at open circuit potential $-288 \mathrm{mV}$, in (b) IN $\mathrm{NaiNO}_{2}$ at $25 \mathrm{C}$ at open circuit potential $-180 \mathrm{mV}$, and in (c) iN $\mathrm{NaCl}$ at $25 \mathrm{C}$ at open circuit potential $-298 \mathrm{mV}$. (From [14]). 


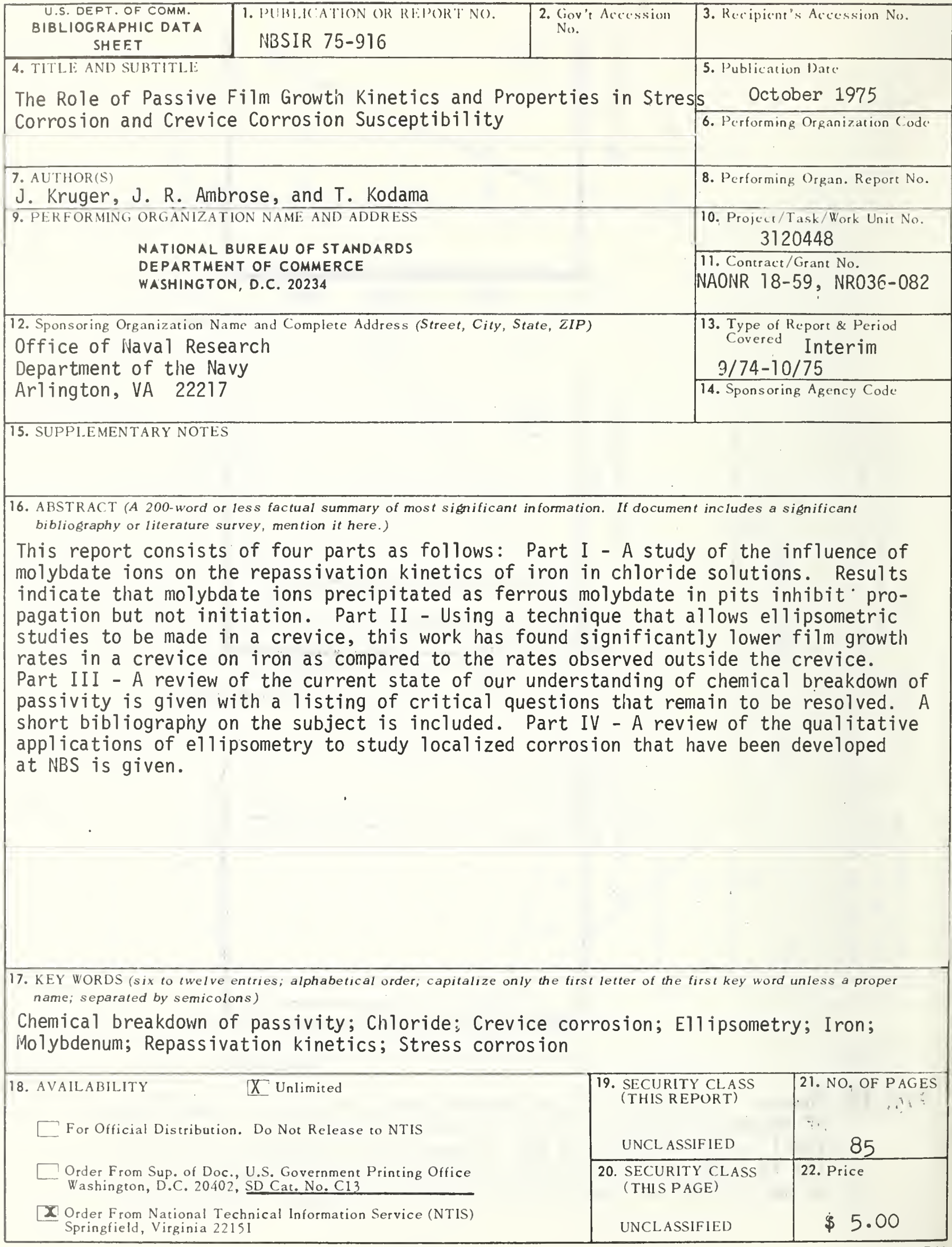




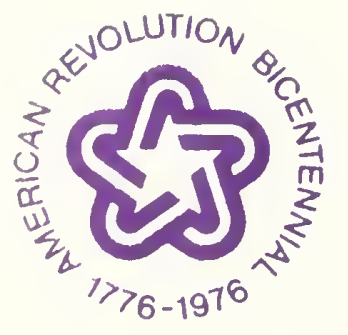

